Portland State University

PDXScholar

1990

\title{
Job Satisfaction of Classified Employees in a Public Suburban School District
}

Jeradean Emma Rehm Masciocchi

Portland State University

Follow this and additional works at: https://pdxscholar.library.pdx.edu/open_access_etds Let us know how access to this document benefits you.

\section{Recommended Citation}

Masciocchi, Jeradean Emma Rehm, "Job Satisfaction of Classified Employees in a Public Suburban School District" (1990). Dissertations and Theses. Paper 1272.

https://doi.org/10.15760/etd.1271

This Dissertation is brought to you for free and open access. It has been accepted for inclusion in Dissertations and Theses by an authorized administrator of PDXScholar. Please contact us if we can make this document more accessible: pdxscholar@pdx.edu. 


\title{
JOB SATISFACTION OF CLASSIFIED EMPLOYEES IN A PUBLIC SUBURBAN SCHOOL DISTRICT
}

\author{
by
}

JERADEAN EMMA REHM MASCIOCCHI

A dissertation submitted in partial fulfillment of the requirements for the degree of

\author{
DOCTOR OF EDUCATION \\ in \\ EDUCATIONAL ADMINISTRATION AND SUPERVISION
}

Portland State University

(C) 1990 
TO THE OFFICE OF GRADUATE STUDIES:

The members of the Committee approve the dissertation of Jeradean Emma Rehm Masciocchi presented April 4, 1990.

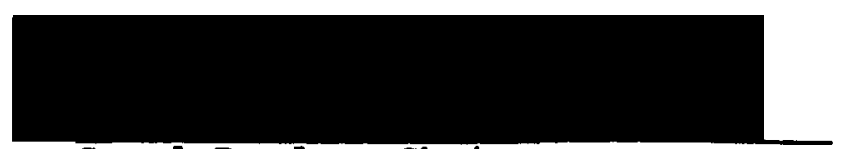

Carol Burden, Chair
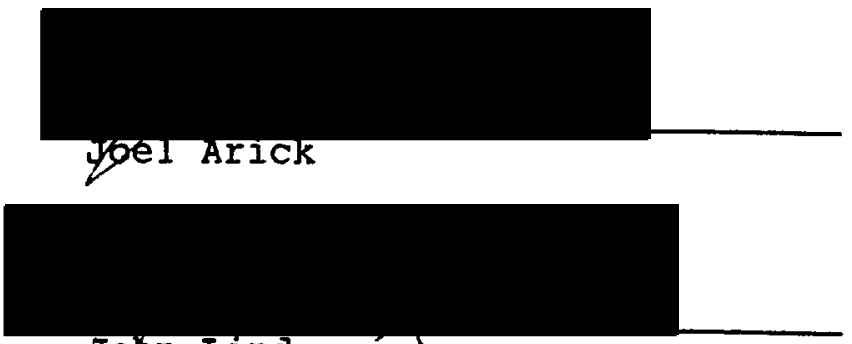

John Lind

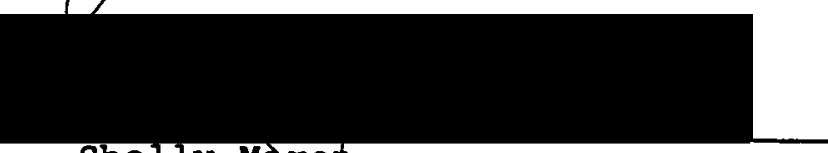

Shelly Maroh

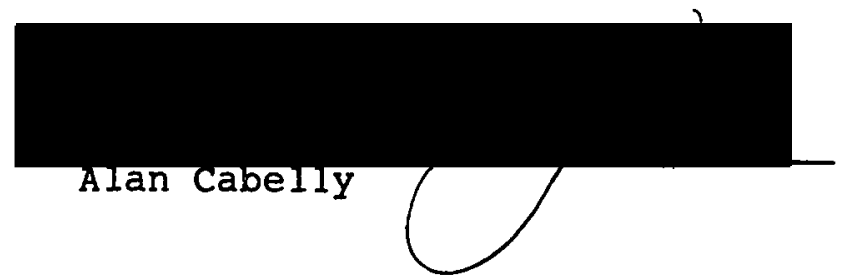

APPROVED :

Robert B. Everhart, Dean, school of Education

C. William Savery, Interin Vice Provost for Graduate Studies and Research 
This work is fondly dedicated to Mama, Daddy, Susie, and John 


\section{ACKNOWLEDGEMENTS}

First, I respectfully thank my dissertation committee (Carol Burden, Joel Arick, Alan Cabelly, John Lind, Shelly Maron, and Jim Carlile, Consultant) for their assistance throughout this process. Special regards go to Carol Burden, as my friend, mentor, and committee chairperson, and to Joel Arick, who patiently guided me through the jungle of statistical analysis.

I thank Beaverton School District for permitting me to conduct this study. In particular, I appreciate the many classified employees whose hard work attracted my interest and whose opinions formed the basis of my research.

I gratefully acknowledge the love and support of my family, Dolly Field Rehm, Gil Rehm, and Susie Rehm. My mother, an endless source of sweetness and sunshine, has always gently nurtured me to reach my potential. Mama, I finally finished "you-know-what!" My father kindly taught me self-discipline and has generously supported my long academic career. Daddy, this one's for you! My dear sister has been my best friend, sounding board, collaborator, proofreader, and, above al1, my inspiration. How fortunate I am to be your sister, Susie! 
With admiration, I thank my husband, John

Masciocchi, for selflessly and patiently supporting my professional and personal goals. Your love opens my heart and helps me to grow.

I thank stuart Perrin for enriching my life with his spiritual teachings.

In good conscience, I thank Dave Gettling who, without complaint, typed and retyped the tables and figures presented here.

To others who touch my life--Tony and Betty Masciocchi, Pat Fay, Kris Carlson--thank you. 
TABLE OF CONTENTS

PAGE

ACKNOWLEDGEMENTS. • • • • . . . . . . . . . . . i ii

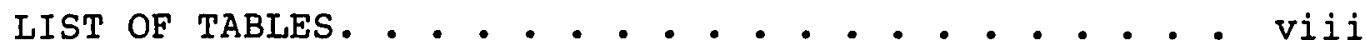

LIST OF FIGURES. . . . . . . . . . . . . . . . . xi

CHAPTER

I INTRODUCTION. . . . . . . . . . . . 1

Purpose. . . . . . . . . . . . 3

Statement of the Problem. . . . . . 4

Significance of the Problem. . . . . 4

Significance of the study. . . . . . 5

Rationale.......... . . . 6

School Effectiveness

Labor Market

Assumptions. . . . . . . . . . 17

Limitations. . . . . . . . . 19

Definition of Terms. . . . . . . 22

Organization of the Study. . . . . . . 24

I I REVIEW OF THE LITERATURE. . . . . . . . . 25

Introduction. . . . . . . . . . 25

A Framework. . . . . . . . . . 26

Physical-Economic School

Human Relations Movement

Work Itself Theme

Equity Theory

Expectancy Theory 
Organizational Management Theories. . . 45

Education. . . . . . . . . . . 49

Job Satisfaction and Demographic/ Personal Variables. .. . . . 52

Hypotheses. . . . . . . . . 56

Summary. . . . . . . . . . 57

III METHODOLOGY. . . . . . . . . . . . 59

Introduction. . . . . . . . . 59

Focus Groups. . . . . . . . . . 60

Theory

Application

Questionnaire........ . . 67

Design

Administration

Validity and Reliability

Approvals. . . . . . . . . 75

Data Analysis. . . . . . . . 76

Summary. • . . . . • . . . . 78

IV RESULTS. . . . . . . . . . . . 80

Focus Groups. . . . . . . . . . 81

Description of Focus Group

Participants

Presentation of Focus Group

Responses

Summary of Focus Group Results

Questionnaire. . . . . . . . . 123

Description of Questionnaire Respondents

Analysis of Quantitative Data

Results of Open-Ended Questions

Overview of Results. . . . . . . 178 
vii

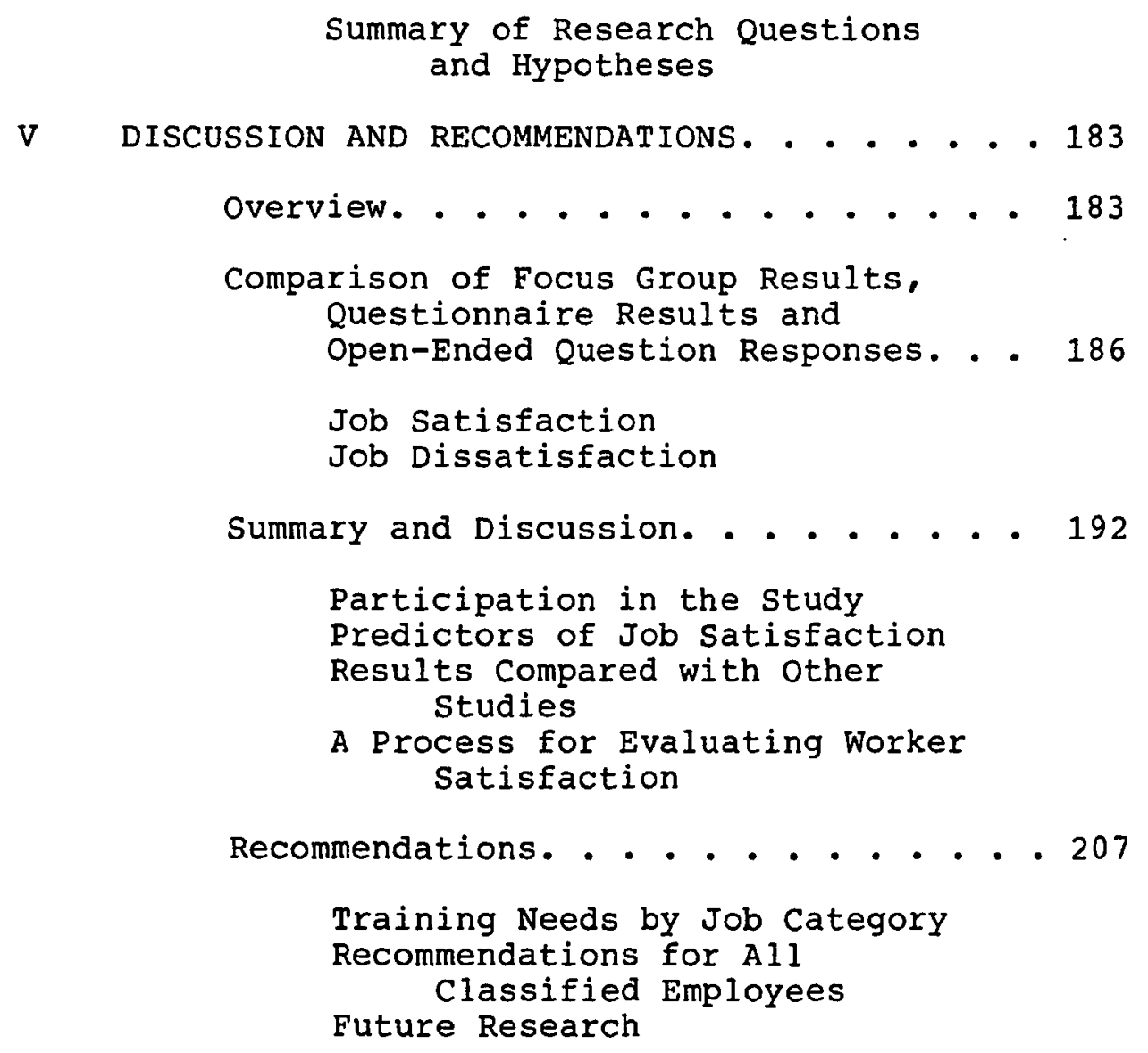

REFERENCES CONSULTED. • . . . . . . . . . . . 216

APPENDICES

A LETTER TO DEPARTMENT COORDINATORS. . . . . 226

B LetTer to employees. . . . . . . . . . . 228

C FOCUS GROUP QUESTIONS. . . . . . . . . 230

D FOCUS GROUP SURVEY. . . . . . . . . . . 233

E JOB SATISFACTION QUESTIONNAIRE. . . . . . 236

F COVER LETTER FOR QUESTIONNAIRE. . . . . . . 242

G COVER LETTER FOR FOLLOW-UP QUESTIONNAIRE. • . 244

H QUESTIONNAIRE ITEM SPLIT-HALF RELIABILITY

CORRELATION STATISTICS. . . . . . . 246 


\section{LIST OF TABLES}

TABLE

PAGE

I Demographic Characteristics of Focus Group

Participants. . . . . . . . 82

II Job Satisfiers of Classified Employees as

Presented in Focus Groups. . . . . 85

II Job Dissatisfiers of Classified Employees as

Presented in Focus Groups. . . . . . 86

IV Self-reported Level of Job Prestige of

Classified Employees in Focus Groups. . 116

$\mathrm{V}$ Self-reported Level of Job Satisfaction of

Classified Employees in Focus Groups. . 122

VI Profile of Questionnaire Respondents by

Job Category. . . . . . . . . . 124

VII Education Completed: Summary of Number and

Percent of Questionnaire Respondents. . 126

VIII Hours Worked Each Week for School District:

Summary of Number and Percent of

Questionnaire Respondents. . . . . 126

IX Years Worked for School District: Summary

of Number and Percent of Questionnaire

Respondents. . . . . . . . . 128 
$\mathrm{X}$ Years in Present Position: Summary of

Number and Percent of Questionnaire

Respondents. . . . . . . . . 128

XI Primary Work Setting: Summary of Number and

Percent of Questionnaire Respondents. . 129

XII Gender: Summary of Number and Percent of

Questionnaire Respondents. . . . . . 129

XIII Personal Status: Summary of Number and

Percent of Questionnaire Respondents. . . 131

XIV Paid Position Outside of District: Summary

of Number and Percent of Questionnaire

Respondents. . . . . . . . . . 131

XV Primary Wage Earner: Summary of Number and

Percent of Questionnaire Respondents. . 132

XVI Benefit Use: Summary of Number and Percent

of Questionnaire Respondents. . . . . 132

XVII Spouse Employed: Summary of Number and

Percent of Questionnaire Respondents. . 134

XVIII Response Means for Questionnaire Items. . . 135

XIX Questionnaire Items of Highest Satisfaction. - 137

XX Questionnaire Items of Lowest Satisfaction. . 138

XXI Rotated Factor Loadings and Questionnaire

Items by Factor. . . . . . . . . 140

XXII Means and Standard Deviations for Factors. . 146

XXIII Means and Standard Deviations for

Questionnaire Items 92-99. . . . . 147 
XXIV Contribution of Factors to overall Job

Satisfaction for All Classified

Employees. . . . . . . . . . 149

XXV Relative Percentage Contribution of

Factors to Overall Job Satisfaction

by Job Category. . . . . . . . 151

XXVI Factor Means by Job Category. . . . . . . 152

XXVII Planned Comparisons of Job Categories for

Job Factor and Level of Significance. . 160

XXVIII Analysis of Covariance for Job

Satisfaction and Demographic/Personal

Variables with Job Category as

Covariate. . . . . . . . . 163

XXIX Analysis of Covariance for Job

Satisfaction and Job Category with

Demographic/Personal Variable as

Covariate. . . . . . . . . 163

XXX Job Satisfiers of Classified Employees

Compiled from Write-in Responses on Questionnaires. . . . . . . . 170

XXXI Job Dissatisfiers of Classified Employees

Compiled from Write-in Responses on Questionnaires. . . . . . . . 171 


\section{LIST OF FIGURES}

FIGURE

PAGE

1. Adaptation of Maslow's Hierarchy of Needs (1943). . . . . . . . . . . 34

2. Herzberg's Motivator and Hygiene Factors

Presented in order of Magnitude (adapted from Herzberg, 1968). . . . . . . 38

3. Herzberg's Principles of Vertical Job

Loading (adapted from Herzberg, 1968). • 39

4. Needs of School District Employees (adapted

from Myers, 1964). . . . . . . . . 4 41

5. Distribution of Responses: Supervisor. . . 143

6. Distribution of Responses: Facilities and

Equipment. . . . . . . . . . . 144

7. Distribution of Responses: District

policies. . . . . . . . . . . 145

8. Job Satisfaction Means by Job Category:

Facilities and Equipment. . . . . . 154

9. Job Satisfaction Means by Job Category:

Co-Workers. . . . . . . . . . 154

10. Job Satisfaction Means by Job Category:

District Policies. . . . . . . . 155

11. Job Satisfaction Means by Job Category:

Supervisor. . . . . . . . . . 155 
12. Job Satisfaction Means by Job Category: Benefits and Salary. . . . . . . . 156

13. Job Satisfaction Means by Job Category:

Schedule. . . . . . . . . . 156

14. Job Satisfaction Means by Job Category:

Work Itself. . . . . . . . . . 157

15. Job Satisfaction Means by Job Category:

Work Quantity. . . . . . . . . . 157

16. Overall Job Satisfaction Rating by Job

Category. . . . . . . . . . 158

17. Job Satisfaction of Classified Employees by

Hours Worked per Week. . . . . . . 164

18. Job Satisfaction of Classified Employees by

Gender. . . . . . . . . . 165

19. Job Satisfaction of Classified Employees by Work Setting. . . . . . . . . . 166 
AN ABSTRACT OF THE DISSERTATION OF Jeradean Emma Rehm Masciocchi for the Doctor of Education in Educational Administration and Supervision presented April 4, 1990. Title: Job Satisfaction of Classified Employees in a Public Suburban School District. APPROVED BY THE MEMBERS OF THE DISSERTATION COMMITTEE:

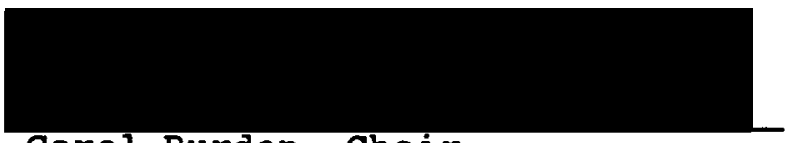
Carol Burden, Chair
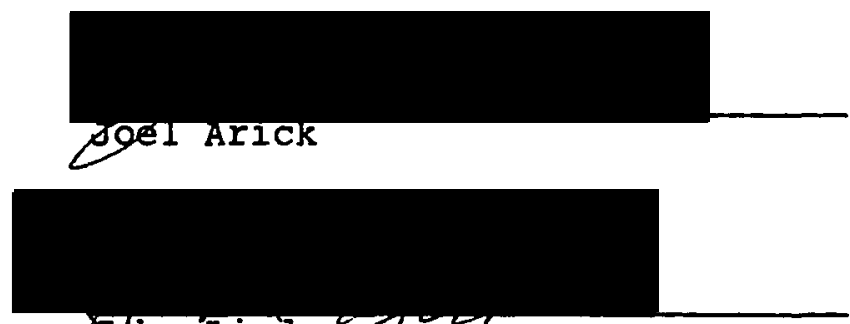
\$ohn Lind $>202$

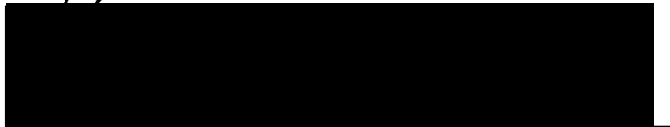

$$
\text { Shelly Mar } \phi n
$$

This study examined the sources of job satisfaction and dissatisfaction for classified employees in a large public suburban school district. The population included randomly-selected bus drivers, 
custodians, school and non-school secretarial

employees, instructional assistants, maintenance

workers, food service personnel and technical

employees.

Three research questions were posed: (a) What are the primary sources of job satisfaction and

dissatisfaction for classified employees? (b) Is there a significant difference in job satisfaction among the specific categories of classified employees? (c) Are demographic/personal variables of classified employees related to overall job satisfaction?

The study incorporated both qualitative and quantitative methodology. Focus groups were convened to identify satisfiers and dissatisfiers, which then served as a basis for questionnaire development. Sixty-four individuals participated in focus group discussions; 490 questionnaires were returned for a response rate of 788 .

The self-designed questionnaire contained 100 job variables, including a single direct question of overall satisfaction. The assessment also included twelve demographic/personal variables and two open-ended questions.

Data were statistically analyzed using ANOVA, ANCOVA, the Chi square test, multiple regression, and paired comparisons. 
The primary job satisfiers for all classified employees were: co-workers, students, work itself, work variety, autonomy, and work schedule. Dissatisfiers were: work overload, district policies, and job insecurity. There was a significant difference in job satisfaction among employee groups. There was also a significant difference in job satisfaction for the demographic variables of gender, work setting, and number of hours worked, even after the influence of job category was eliminated.

The research suggests that there are issues which influence the job satisfaction of classified employees. In their quest for excellence, school district administrators, and business leaders, alike, can benefit from listening to the needs and recommendations of their support personnel. 
CHAPTER I

INTRODUCTION

Excellence within America's best-managed companies, according to Peters and Waterman (1982), comes from "treating people decently and asking them to shine" (p. xxiii). Successful organizations, they assert, "turn the average Joe and the average Jane into winners" (p. 239). If educational institutions aspire to success, or in contemporary terms, "pursue excellence," managers must (a) identify Joe and Jane, (b) explore how the employees perceive their present treatment, and (c) define the winning ingredients. In all, it may come down to asking employees: "Are you satisfied with your job? What factors contribute to your satisfaction?"

Instead, it appears that the noncertified Jane and Joe in educational settings have been largely ignored. Research on the job satisfaction of classified public school employees is conspicuous in its absence. As will be discussed in the literature review, studies of employee satisfaction in the educational field focus almost exclusively on district-level administrators, principals, and teachers. 
Statistics gleaned from the Oregon Department of Education indicate that 18,780 individuals, or approximately $40 \%$ of the state's public school workforce, occupy positions presently categorized "classified" (B. Jones, personal communication, December 23, 1988). This includes bus drivers, food service workers, secretarial/clerical staff, instructional assistants, maintenance workers, custodians, and technical personnel. The contributions of two out of five employees of public school districts can no longer be ignored.

The significance of addressing this population intensifies when the fact that certified personnel are historically overlooked in educational research is coupled with recent labor market statistics reflecting a shrinking entry-level labor pool. In this context, the purpose of amassing data on job satisfaction may be twofold: (a) to equalize knowledge of varied populations in schools, and (b) to assist in retaining our present work force and averting the crunch already occurring in the fast food industry, for example. In two early reviews of the literature on correlates to job satisfaction (Brayfield \& Crockett, 1955; Herzberg, Mausner, Peterson \& Capwell, 1957), the researchers posit a strong relationship between satisfaction and turnover and between satisfaction and absenteeism. The 
benefit of retaining present employees appears to extend beyond maintaining a labor force. When existing employees are satisfied and secure in their positions, they become the organization's best recruiting tool (Davids, 1988).

The present study examines job satisfaction of classified employees in one public school district which is actively involved in a mission of school improvement. Most of the studies which constitute the meager existing body of literature on job satisfaction of classified school district employees (Casanova, 1986; Collins and Masley, 1980; Kuiper and Van Huss, 1981; Pyles, 1983; Simon, 1972; Young, 1982) utilized homogeneous populations such as custodians or school secretaries. This study contributes comparative data across job categories within the classified cluster.

\section{PURPOSE}

The purpose of this study is to examine the job satisfaction of public school district classified employees; the study serves as a vehicle for taking a composite contentment pulse of this group. The population studied is one large suburban school district, Beaverton School District, near Portland, Oregon. At the time of research initiation, the district served approximately 22,500 students with a 
staff numbering over 2,400. Classified personnel formed 418 of total employees.

\section{STATEMENT OF THE PROBLEM}

There may be aspects of work which affect a classified employee's job satisfaction and which can be controlled by school district administrators. These aspects, or factors, may vary by job category and/or the demographic and personal characteristics of the employee.

Questions to be studied are (a) What are the primary sources of job satisfaction and dissatisfaction for classified employees? (b) Is there a significant difference in job satisfaction among the specific categories of classified employees? (c) Are demographic/personal factors of classified employees of the selected public school district related to overall job satisfaction?

\section{SIGNIFICANCE OF THE PROBLEM}

Few would disagree that a positive school climate is contingent, in part, on satisfied staff. Presently, however, school district administrators can only speculate as to the factors of a classified job that contribute to, or detract from, worker satisfaction. If those factors, job satisfiers and job dissatisfiers, 
were identified and if the factors were governable, or manipulatable, school climate could be enhanced. The results for education would be to maximize a positive learning environment for students and to increase the personal and professional satisfaction of workers.

\section{SIGNIFICANCE OF THE STUDY}

The information garnered from this project is important for both managers and employees. Answers to the research questions can provide management with insight into actual roles, which may differ from written job descriptions, and knowledge of present working conditions. Employee attitude studies have been described as "media for managing innnovation and for developing employees" (Myers, 1981, p. 244). Results can ultimately assist personnel supervisors and others in structuring jobs that are satisfying.

For the worker, results have implications for self-esteem and sense of identity. The link between work and self-esteem is described as dual in a report entitled Work in America (U.S. Department of Health, Education, and Welfare, 1973). First, if work is challenging, it generates in the worker a sense of mastery over oneself and the environment. Secondly, a job consistently reminds the worker that he/she has something to offer; the unemployed individual may 
receive no evidence of being needed by others. "The workplace," the study asserts, "...is one of the major foci of personal evaluation" (p.5).

Further implications of worker satisfaction in the arena of performance and productivity are included in the literature review.

\section{RATIONALE}

Results of this study can contribute to school effectiveness in the processes of enhancing school climate, funding public education, creating dynamic organizations, optimizing personnel policy, and, possibly, increasing employee productivity. The significance of research on job satisfiers is amplified in the context of contemporary labor market statistics.

\section{School Effectiveness}

Educational researchers and practitioners agree that school climate is important. Howe (1985) suggests that a school's internal atmosphere is more important than its curriculum in producing learning. School climate has been inextricably linked to the satisfaction and productivity of both students and staff (Slezak, 1984). However, the research on school district staff satisfaction is, to date, limited in scope; subjects of the research are primarily 
superintendents, school principals, and teachers. The environmental factors which together define the construct of school climate are affected by all personnel, including secretaries, custodians, cooks, and bus drivers. Each of these classified staff members has daily contact with students and other employees and, therefore, contributes to the working and learning conditions in an educational facility. The import of climate has ramifications beyond the immediate worksite. Where school districts rely on financial support through referendum, public image is a major concern. Energy is expended on packaging an accurate, appealing profile and selling it to the constituents. But the most convincing argument for educational support may be laid aside if the packaged picture contradicts the experience of a visitor to the school. Most likely, the visitor will first encounter the school's secretary or an office clerical aide. Perhaps the custodian is working near the entrance. or, maybe, the visitor will report to the cafeteria's food service staff for lunch with a child. Human interaction is a popular, firsthand source of information, and, according to Stellar and Pell (1986), "clean buildings are powerful incentives for learning and public support " (p.3). Our demeanor on the job clearly reflects our level of satisfaction. A 
satisfied employee is more likely to interact with warmth and concern. A disgruntled secretary is not apt to transmit a welcoming or accommodating energy. The public's view of education, then, can be equally influenced by classified staff, principals, and teachers.

Identifying job satisfiers has implications beyond potentiating a more positive school climate. Sergiovanni and Starratt (1971) stress the importance of classified employees in building effective organizations. They imply that a homeostatic state must be maintained both within and among employee groups. Young $(1982)$ suggests that the initial process in securing such a condition is information gathering. It appears that information on job satisfiers is relatively sparse for the classified employee group in public schools.

Such knowledge, paired with subsequent efforts to redress employee dissatisfaction, is also critical to organizational efficiency. According to Casletter (1971):

In the fundamental sense, the satisfaction of human needs is essential to the attainment of institutional objectives. The will of members of school organizations to cooperate in, or to resist, attainment of objectives is strongly influenced by the extent to which each is able to achieve work satisfaction ( $p$. 21-22). 
Employee productivity is, historically, a concern of organizations. Business literature assessing the link between job satisfaction and worker productivity is mixed. Peters and Waterman (1982), in their "search for excellence," advised, "Get the incentives right and productivity will follow" (p. 43). Incentives and satisfaction may be but two ingredients in the productivity formula. Fantini (1986) reviewed Peters and Waterman's eight attributes of successful companies. He views their element of "productivity through people" ("creating in all employees the awareness that their best efforts are essential and that they will share in the rewards of the company's success" p. 29) as a critical hurdle in "regaining excellence in education." The extent to which this principle is incorporated within public school bureaucracies has yet to be measured.

In scrutinizing educational settings, Sergiovanni and Carver (1975) assert that "administrative effectiveness is ultimately determined by human conditions which exist in the schools." Consider Sergiovanni's anecdote about the man who visits a village in Greece (J. Carlile, personal communication, Jan. 30,1989$)$. He sees three men cutting stones along the roadside and asks the first, "What are you doing?" The man replies, "I'm cutting a stone." The question 
is repeated to the second workman who answers, "I'm building a cornerstone." Finally, the man asks the third laborer, "What are you doing?" The third man declares, "I'm building a cathedral." In a school district, as elsewhere, a task, while minute or inconsequential in and of itself, may be viewed as a purposeful and necessary piece of the whole. For example, applying the above tale to a public school, a visitor might ask two custodians, "What are you doing?" one reply: "I'm sweeping the floor." The second: "I'm contributing to the education of children by maintaining a clean learning environment." To what may we attribute the differing responses? It appears that "administrative effectiveness" may have a powerful role in determining the extant human conditions in schools and an employee's perception of work. Observed Albert Camus lquoted in U.S. Department of Health, Education, and Welfare, 1973), "Without work all life goes rotten. But when work is soulless, life stifles and dies" (p.xix) . High worker satisfaction presumably correlates with soulful work and supervisor behavior may be a causal factor.

Job dissatisfaction does affect an individual's physical health, rate of absenteeism, job turnover, grievances, and the employee's other attitudes (Locke, 1976; Porter \& Steers, 1974). Research by Jenkins 
(1971) identified a link between job satisfaction and low cholesterol levels and reduced incidents of coronary heart disease. Further, a high positive correlation has been found between mental health and job satisfaction (Kornhauser, 1965). It makes good sense, then, to identify the sources of satisfaction for all employees. For instance, if support staff are dissatisfied with their jobs and, therefore, not performing tasks necessary to the organization's efficient operation, then administrators and teachers, already notoriously overworked, will have to compensate in time and energy.

In the district studied, a project to assess job satisfaction and dissatisfaction of teachers (Leslie) was completed in 1987. At least $30 \%$ of the teachers surveyed listed time for teaching and conferencing, time to plan, number of students per period, and number of students per day as dissatisfiers. That is, some teachers feel they are already overworked in the area of working conditions, which may directly affect their professional purpose--provision of quality instruction. In a study by Borquist (1986), administrators in this same district identified amount of work as a main source of job dissatisfaction. Related comments included, "'Not enough time or support to be an instructional leader'" (p.103). Intuitively, 
educational institutions will benefit by ensuring a secure foundation of support staff who can minimize additional potential stressors to certified personnel. A starting point is to assess classified employees' present level of job satisfaction and to identify contributing factors.

Work overload, as discussed above, has been found to produce low self-esteem, tension, embarrassment, and increased heart rate, skin resistance, and cigarette consumption (French \& Caplan, 1972). Matteson and Ivancevich (1987) hypothesize a connection between work overload and decreased decision-making, impaired interpersonal relations, and increased rate of accidents.

Stress, oft associated in education with overwork and, ultimately, "burnout," is customarily viewed as an individual issue. Burnout can be defined as "...a psychological process, brought about by unrelieved work stress, that results in emotional exhaustion, depersonalization, and feelings of decreased accomplishment" (Matteson \& Ivancevich, 1987). The afflicted employee may be encouraged to utilize benefits of an Employee Assistance Program or to enroll in a time-management course. But in the organizational context, an environmental stressor may be affecting many employees in that same setting. In fact, there is 
a more extensive literature base on stressors in organizations than exists for either physical environment stressors or extraorganizational stressors, including family and economic factors (Matteson \& Ivancevich, 1987). Identifying job dissatisfiers, or stimuli for stress responses, for one employee or employee subgroup can contribute to the well-being of all employees.

A knowledge of job satisfiers and dissatisfiers could benefit personnel administrators and business educators. As policies are developed, consideration would be given to enhancing the sources of satisfaction and delimiting the known obstacles. The information would assist in planning in-service training programs for both classified employees and their managers. Vocational trainers, with this broadened base of information, could better prepare individuals to enter new roles.

Finally, let us not discount school district employees as role models for vocational education. Not all children aspire to careers in business or school administration. Those non-college-bound youth, referred to as "The Forgotten Half" (Whitman, 1989; William T. Grant Foundation Commission on Work, Family and Citizenship, 1988), will seek employment immediately following high school. This population, in 
pursuit of satisfying career choices, will have molded their stereotypes of a secretary, bus driver, or instructional assistant after images presented to them. If custodians in one school district are uniformly dissatisfied with their jobs, the student could, theoretically, leave high school with a distorted impression of a custodial career.

Studies of job satisfiers must be extended to the school's operative level. All classified employees contribute to the education of children by providing a safe, clean environment, supporting instructional staff, preparing and serving nutritious meals, transporting students, and building that caring, therapeutic mileau so important to the enrichment of all human lives and to the general purported mission of excellent public education.

\section{Labor Market}

Mark Shepherd, Jr., Chairman of the Board at Texas Instruments, a company touted for organizational excellence, stated: "Management's role in attracting, challenging, and retaining the members of the coming generation is as vital to an organization's success as any breakthrough in technology or newly designed production equipment" (Myers, 1981, p.ix). Shepherd's 
words ring true today, in light of present labor market statistics.

An intense labor shortage is beginning to materialize as the "Baby Bust" generation--those born between 1965 and 1979--come of age (Davids, 1988). The "bust"'s first aftershocks have already resounded through fast food chains, vacation resorts, and hotels, who rely heavily on an entry-level labor pool. The Bureau of Labor Statistics predicts a 19 percent decline in 20 - to 24 -year-olds, the traditional entry-level workforce core, between 1981 and 1997 (Davids, 1988). As a result, employers are broadening their vision of potential job candidates to a nontraditional scope. On a trip to their favorite fast-food chain, consumers can already evidence consequences of the labor crunch in viewing teenagers and senior citizens, as "burger-flippers," side-by-side at the grill.

An equally tenable solution is to retain existing employees by making inherently low prestige, minimum-wage positions more attractive. Starting wages equal to, and exceeding, $\$ 4$ per hour and benefits, including child care allocations, vacations, and bonuses for long-term workers, are becoming the norm (Rooks, 1988). The level of energy exerted to reduce turnover may eventually differentiate the successful 
organization from its failing counterpart. One researcher describes the labor shortage as "an acid rain problem," as opposed to "a Tylenol-type crisis," explaining, "By the time many organizations realize there's a problem, the damage will pretty much be done" (Davids, 1988, p.59).

In oregon, site of this study, demographers echo the national trend. According to the oregonian [Portland, Oregon], statistics from Portland state University's Center for Population Research and Census reflect a shrinking entry-level labor pool, especially in the state's large metropolitan areas (Rooks, 1988). Qualified job candidates for both entry-level and some skilled positions, it reports, are "increasingly difficult to locate... as employers face slimmer pickings" (P.D12).

Specific to the Portland Metropolitan Area, which includes the county housing the studied school district, the State Department of Human Resources (1988) concludes, "As a result of a diminished rate of labor force growth and a smaller pool of qualified workers, particularly at the entry level, some employers may face skill shortages" (p.6).

What are the implications of the labor shortage for public school districts? This researcher perceives the answer as twofold. Superintendents and personnel 
administrators must (a) obtain information from present employees on job factors which satisfy and dissatisfy, and (b) utilize this data to maintain and/or restructure positions and programs which will retain present employees and attract qualified newcomers from the shrinking supply. This project accomplishes the former and, in so doing, facilitates the latter, in the context of classified employees.

\section{ASSUMPTIONS}

Certain facets of our lives determine whether we are generally happy or unhappy people. These include meaningful work, a love relationship, friendships, and spiritual beliefs. When one or more element is lacking or demanding a disproportionate amount of energy, we lose balance and our behavior changes. Health is often adversely affected. In the work context, absenteeism, grievances, and turnover have been shown to reflect workers' attitudes about their jobs. Such ramifications of job dissatisfaction are costly. Employee morale is not solely an intrapersonal issue. We tend to share our attitudes with co-workers, either directly or indirectly, through our behavior and often those attitudes influence the morale of others. Consequently, our outer environment mirrors our inner 
state and, conversely, our cognitive and emotional realms are touched (or rocked) by our environment.

Our feelings about work and the feedback we receive in the work setting impact other facets of our lives. A worker who receives recognition and values that recognition, for example, is likely to share the excitement in the home environment or to celebrate with close friends. Such is the importance of satisfying work that, given the opportunity to voice concerns or effect change, workers will respond. The likelihood of eliciting honest responses to inquiries about work is increased where anonymity is guaranteed. If respondents to a questionnaire believe that their opinions will jeopardize job security, they are less likely to provide objective data; confidentiality increases objectivity.

Some sceptics of self-report data question the validity of respondents' perceptions, while psychologists hold that perception is synonymous with reality. "Perception", by definition, is a mental image of what exists in the environment. Whether the holder's perception has been influenced by his beliefs or interpreted in the process of perceiving, the vision is still closely comparable to what exists. And, even where disparity occurs between perception and reality, perception is valuable information in a study of 
satisfaction. In reference to specific job characteristics, Hackman and Lawler (1971) assert that "it is not their objective state which affects employee attitudes and behavior, but rather how they are experienced by the employees" (p.264). That is, in a study of job satisfaction, it may be more important to know how much recognition, for example, the worker perceives that he is receiving than to know how much he actually receives.

Related to the foregoing discussion, this study is predicated on the following assumptions:

1. The feelings people have about their jobs affect their behavior.

2. Job satisfaction of school district employees is worth studying.

3. Classified employees will report accurate perceptions.

4. Perceptions that individuals have regarding their jobs reflect the "reality" of their experience.

\section{LIMITATIONS}

The limitations of this study include the usual limitations of survey research and several particular to the subject and to the research process. 
The survey responses represent the self-reported views of a group of randomly selected employees. The study did not attempt to question 1008 of the classified employees and a 1008 response rate for those. selected was not achieved.

The self-reporting format may have limited objectivity of response. In an effort to secure confidentiality, no attempt was made to interview questionnaire respondents regarding their views. This limitation may also apply to the focus group format. Although participants were encouraged to explain their answers, they knew that the study received in-district sponsorship. They may have, consequently, minimized their criticism of district personnel and practices. Focus discussions were convened in the Administration Center.

The population studied is employed by one Pacific Northwest suburban school district. A local study may impair the generalizability of the results. However, a thorough, systematic process for ascertaining the level of job satisfaction for school district classified employees did not exist prior to this study. The study presents a process for replication by administrators in other work settings and/or other geographical areas.

Hoy and Miskel (1982) caution job satisfaction researchers to acknowledge the "socially biased 
response set" of professional educators. Teachers, they assert, have "always been told that they should derive satisfaction from serving children. Consequently, it may be socially unacceptable ... to voice low job satisfaction" (p. 337). This conjecture may apply to all school district employees, who all, either directly or indirectly, facilitate the educational process.

It should be noted that, from the period immediately preceeding initiation of this study through completion of data collection, this school district was assessing the advisability of privately contracting food services. The fear of imminent job loss, or loss of seniority, may have affected employee responses; a contemporary event constitutes an extraneous variable.

A final limitation concerns the difficulty of establishing validity in a study of job satisfaction. Norms, in the conventional sense, may be impossible to measice since no index of high or low job satisfaction exists. The norm employed here is derived from focus group discussions. The construct is quantified and measured on the questionnaire as a single-item response and defined in terms of the factors which together constitute it. 
DEFINITION OF TERMS

For the purpose of this study, the following definitions will be used.

Certified Employees:

Individuals whose positions require special state certification.

Classified Employees:

Individuals occupying one of the following positions in the school district: instructional assistant, school secretary or clerical employee, custodian, food service worker, bus driver, non-school-based secretary or clerical employee, technical worker, maintenance worker, or support service worker whose position does not require special certification. (These categories are listed in Beaverton School District's Classified Employees Handbook 1985-88.)

Dissatisfiers:

Factors which, in their absence, operate to produce negative feelings about one's job. (Herzberg, 1968)

Elementary level:

- Grades kindergarten through six 
Focus Group:

A carefully planned discussion group designed to obtain employee perceptions in a nonthreatening environment.

Intermediate level:

Grades seven through nine

Issues:

Areas of concern raised by an employee or group of employees related to their job or job category. An issue may be either a satisfier or dissatisfier.

Job Dissatisfaction:

"the unpleasurable emotional state resulting from the appraisal of one's job as frustrating or blocking the attainment of one's job values" (Locke, 1969, p.316)

Job Satisfaction:

Any combination of psychological, physiological, and environmental circumstances that cause a person to say, "I am satisfied with my job." (Hoppock, 1935) Satisfiers:

Factors which motivate employees; those which operate to produce feelings of job fulfillment (Herzberg, 1968).

Secondary level:

Grades ten through twelve 


\section{Staff:}

All individuals employed by a public school district; both certified and classified employees.

\section{ORGANIZATION OF THE STUDY}

This document is divided into five chapters. Chapter I has covered the purpose and importance of the study, as well as the questions to be addressed. Chapter II includes a review of selected research related to the topic of job satisfaction, in general, and in the context of classified employees in an educational setting. Chapter III addresses the methodological considerations and processes involved in answering the research questions set forth in Chapter I. Chapter IV describes the statistical analyses and results of the study. Lastly, Chapter $\mathrm{V}$ reports conclusions and offers recommendations inferred from the results. 
CHAPTER II

REVIEW OF THE LITERATURE

INTRODUCTION

\begin{abstract}
According to Lawler (1971) and Locke (1969), the interest of researchers in the nature and causes of job satisfaction dates back to Roethlisberger and Dickson's Management and the Worker and Hoppock's monograph Job Satisfaction. Before the $1930^{\prime} \mathrm{s}$, quantitative research had not been done on the subject. Prior studies, spurred by industrialization and an awareness of the importance of work, had focused on the relationship between workers' "attitudes" and actions in the job environment--usually an industrial setting. In 1969, Locke estimated a body of literature addressing job satisfaction in excess of 4,000 articles. One can assume that the corpus has continued to grow as studies are replicated, reviewed, redesigned, and challenged. Study site and sample population have expanded and contribute to what Pyles (1983) termed an "explosion of studies dealing with man and factors as they relate to his employment" (p.16). In an analysis of research on the influence of organizational structure and worker
\end{abstract}


attitudes between 1964 and 1976, Cummings and Berger (1976) cited studies whose samples include business, government, and military employees. A computer search on job satisfaction, and related terms, today, turns up representative samples of greater diversity including educators, health professionals, and librarians. Considering an expanded contemporary awareness that "of the half-million hours of conscious existence...about one fifth of the total will be spent on the job" (Bailey, 1976, p.43), the "explosion" is understandable.

The construct of job satisfaction is closely related in theory and research to other concepts, such as morale and job involvement. However, this review of the literature will focus on satisfaction and include only selected studies.

\section{A FRAMEWORK}

In Locke's (1976) effort to summarize the literature on job satisfaction, he identified three historical trends as (a) the "Physical-Economic" school of thought, (b) the "Social" orientation, and (c) the "Work Itself" theme. While such a framework necessitates theoretical imbracation, it is useful in the organization of a research review. Two theories have recently emerged and are added here to supplement 
Locke's original framework. These are the equity theory and the expectancy/valence theory.

\section{Physical-Economic School}

The physical-economic trend had its roots in Frederick Taylor's thesis, The Principles of Scientific Management. According to Taylor (1916), organizational management should be approached scientifically with a primary goal of securing "...the maximum prosperity for the employer, coupled with the maximum prosperity for each employe" (p.9). Taylor equated prosperity with productivity. His key to engendering organizational efficiency was to choose the right man, to train him scientifically (mechanistically) for "maximum output," and to reward his labor. His techniques included goal setting, time study, standardization, scientific selection, rest pauses, and using money as a motivator. Taylor reduced his theory to five basic elements:

1. Science

2. Harmony

3. Cooperation

4. Maximum output

5. Development of each worker to his greatest efficiency (p.140)

Worker satisfaction, according to Taylor, is linked to physical and economic factors. Job 
satisfaction and dissatisfaction are viewed as endpoints on a continuum. Researchers of this persuasion would likely study the physical setting, job design, and pay, or what Bennis (1959) termed "organizations without people" and the processes employed.

Taylorism is not without critics. Bacharach and Mitchell (1983) observed that scientific management eliminated the worker's ability to decide how a task is accomplished. The process, instead, was routinized and compartmentalized, accompanied by closer supervision of workers and scrutinization of work.

In the 1973 volume Work in America, a special task force to the Secretary of Health, Education, and Welfare labeled Taylorism "anachronistic" because:

1. "The workforce has changed considerably since his principles were instituted."

2. "Traditional values that depended on authoritarian assertion alone for their survival have been challenged."

3. "Simplified tasks for those who are not simple-minded... and jobs that have nothing but money to offer in an affluent age are simply rejected" (p. 18).

Based on an analysis of 100 studies, the authors summarized what workers want most. The list includes: 
autonomy, opportunity to increase their skills, increased participation in work design, and rewards which relate to the intrinsic aspects of work. Each item on this list seems to run counter to the premises of scientific management.

Locke (1982), on the other hand, defended Taylor as never having been "fully understood or appreciated by his critics" (p.14). The techniques of scientific management, he argued, have been proven successful and accepted by management. Seconding Johnson (1980) in terming Taylor a "genius," Locke (1982) asserted:

Considering that it has been over 65 years since Taylor's death and that a knowledge explosion has taken place during these years, Taylor's track record is remarkable. The point is not, as is often claimed, that he was 'right in the context of his time' but is now outdated, but that most of his insights are still valid today (p.23).

Myers (1981), like Locke, recognized remnants of scientific management in today's organizations-namely, in programs for "merit rating," "motivation," "recognition," and "morale." However, in admitting the proven short-term gains of this philosophy, Myers added, "their ultimate impact... is usually alienation and net loss" (p.87).

The success of organizations utilizing these techniques may be refuted if the spotlight moves from organizational productivity to employee satisfaction. 
Pfifferling and Eckel (cited in Matteson \& Ivancevich, 1987) offer a checklist of indicators of burnout potential in an organizational setting. The following descriptors, from that checklist, are likely present in a scientifically-managed institution:

1. Repetitive work activities.

2. Rigid role typing for workers.

3. Discouragement of hierarchical staff interaction.

4. Constant demands for perfection.

5. A belief that playfulness is unprofessional. If Pfifferling and Eckel's checklist holds true, it follows that scientifically-managed companies have employee burnout potential.

Bacharach and Mitchell (1983) speculated that the Human Relations school may have emerged in reaction to Taylor's neglect for community.

\section{Human Relations Movement}

The Social, or Human Relations Movement, had underpinnings in the Hawthorne Studies, initiated in the late 1920's. Elton Mayo and a team of researchers studied employees at the Hawthorne Works of the Western Electric Company in Cicero, Illinois, between 1927 and 1932, in relation to plant lighting. The study focused on morale and the role of informal work groups in 
shaping attitudes and performance. Mayo attributed variations in his experimental groups not to a change in manipulated variables but, instead, to the act of participation in the experiments, which gave workers a sense of importance. This came to be termed the "Hawthorne Effect."

Mayo's recommendations to management included

... improved communication to give management and labor a better understanding of one another, supervisors who were more understanding and cooperative, and greater expression of concern for the individual through better employee benefits and a fostering of team spirit (Dickson, 1975, p.10).

worker satisfaction, then, is viewed as a function of co-worker and employee-management relations. Subjects under study are looked upon as individuals with unique responses and individual needs.

This focus on interpersonal relations within the work environment fueled the acceleration of research correlating job satisfaction with job performance, including employee productivity (Lawler \& Porter, 1967). According to Hoy and Miskel (1982), "proponents of the human relations approach convinced both theorists and administrators that a happy worker is a productive worker" (p.333). It appears that researchers were eager to embrace the belief and proceed on the assumption that a positive relationship 
existed. Brayfield and Crockett (1955), in the first review of the literature on the topic, found minimal evidence for the link between worker attitude and performance that appears to have been grounded on faith rather than figures. Iawler and Porter (1967), citing two additional reviews (Herzberg et al., 1957; Vroom, 1964), summarized, "The evidence indicates that a low but consistent relationship exists between satisfaction and performance" (p.91).

A reversal of this relationship, as viewed by human relations theorists, was presented by Greene (1973). Greene suggested that better job performance may precede higher job satisfaction, especially if the performance is rewarded with praise, salary increase, and/or promotion.

Schwab and Cummings (1975), in an exhaustive reexamination, traced the theoretical axioms underlying the relationship research. In conclusion, they advised separating the concepts because "focusing on relationships between the two has probably helped obscure the fact that we know so little about the structure and determinants of each" (p.241). Scientific management and the human relations movement, together, have served to mold our vision of work in the Western World. According to Dickson 
(1975), Taylorism still permeates management--in industry, offices and the service industries.

Work Itself Theme

The Work Itself theme was founded on the labor of psychologists Maslow and Herzberg, who looked to job content as a source of employee motivation. Maslow (1943) outlined his now-famous "Hierarchy of Needs" in his work Motivation and Personality. Maslow was among the first to suggest that human motivation comes from within and that life is motivated by a progression of needs including: Physiological, Safety, Social, Self-esteem, and Self-actualization (Figure 1). He proposed that, as each of the first and more basic sets of needs is met, another higher set emerges. Further, satisfied needs no longer motivate behavior. In Maslow's (1943) words, "Human needs arrange themselves in hierarchies of prepotency...the appearance of one need usually rests on the prior satisfaction of another, more pre-potent need" (p.370). To managers, this meant that an increase in employee-supervisor discussion groups or an improved communication network was labor lost. Instead, the job itself had to be restructured for satisfaction of lower order needs to allow individuals to strive for self-actualization. With Maslow, employee 


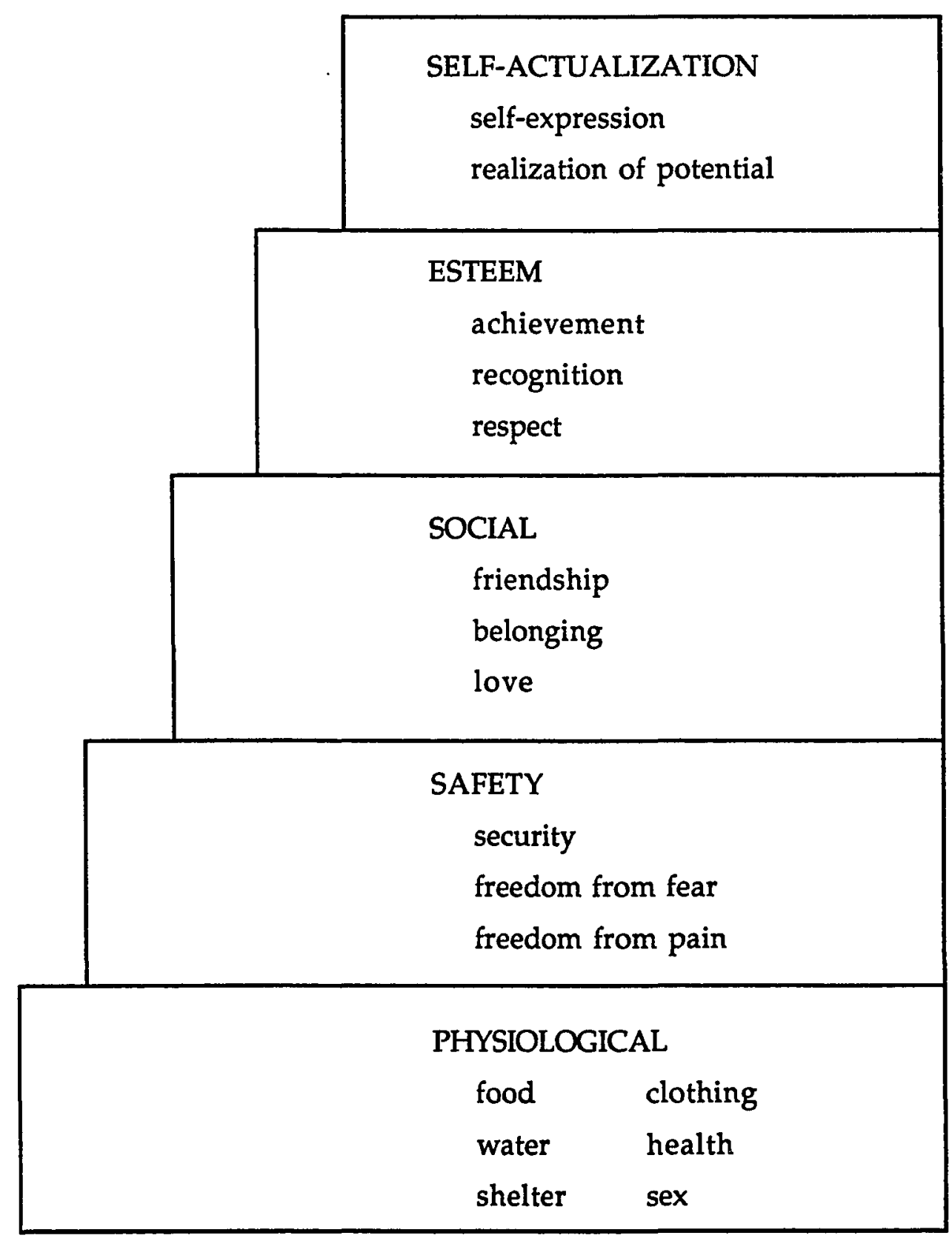

Figure 1. Adaptation of Maslow's hierchy of needs (1943). 
effectiveness was redefined as an outcome of matching job opportunities to one's position on his need hierarchy (Myers, 1981). Job satisfaction became a function of the work performed.

Cummings and Berger (1976), in an analysis of studies contrasting the job satisfaction factors of blue collar workers with those of managerial employees, cited Maslow's theory as a tentative explanation for why the former group appeared to derive greater satisfaction and dissatisfaction from money earned. However, they dismissed the possibility on the grounds that the "notion of a simple hierarchy of needs has been generally refuted by a number of empirical studies during the last decade" (p.39).

Maslow (1943), himself, decried the fixity, or simplicity, of his hierarchy and sought to hypothesize exceptions. For example, he explained that a reversal of needs could occur when a lower-order need has long been satisfied and, therefore, undervalued. "Thus," summarized Maslow, "a man who has given up his job rather than lose his self-respect, and who then starves for six months or so, may be willing to take his job back even at the price of losing his self-respect" (p. 387) .

Further criticism of Maslow's work was reviewed by Locke (1976) and included: 1) lack of proof of needs 
(particularly self-esteem); 2) unintelligibility in defining "self-actualization"; 3) confusion between needs and values; and, 4) confusion between actions and desires. His critique, then, rests primarily on Maslow's inadequate definition of terms and unsubstantiated assumptions. Locke argued, "It is not necessarily what a man needs but what he values most strongly that dominates his thoughts and actions" $(\mathrm{p} .1309)$.

Judgement aside, the evolution of man toward increasing affluence, particularly in the West, has consequences in the context of Maslow's theory (Myers, 1981). Whereas the existence of primitive man necessitated a preoccupation with survival, modern man, relatively, is in a position to self-actualize. Myers (1981) credited Taylor's scientific management and unions with readying the worker for realization of his potential.

Another major content theory of job satisfaction, Herzberg's Motivation-Hygiene Theory, emerged, in part, from his analysis of prior studies. Herzberg speculated that, counter to Taylor's satisfaction continuum premise, job satisfaction and dissatisfaction derive from different sources. "The opposite of job satisfaction is not job dissatisfaction," he wrote, "but, rather, no job satisfaction; and, similarly, the 
opposite of job dissatisfaction is not job satisfaction, but no job dissatisfaction" (Herzberg, 1968, p.56).

Herzberg tested his theory by interviewing 200 engineers and accountants. He found, through classification of critical incidents, that feelings of satisfaction came from the job itself (content) whereas dissatisfaction stemmed from the job's surroundings (context). The former were rooted in factors he termed "motivators"; the latter were called "hygienes." Specific motivators and hygienes are presented in Figure 2 .

Herzberg extended his principles in formulating the concept of "job enrichment"--"a systematic attempt to motivate employees by manipulating the motivator factors" (Herzberg, 1968, p.59). He distinguished "enrichment" from "enlargement"--enlarging the "meaningless of the job." Job enlargement, according to Herzberg, was synonymids with "horizontal job loading" or, as Dickson (1975) described, "adding more dumb tasks to a dumb job" (p.46). Job enrichment, on the other hand, involved "vertical job loading," or, as geographically implied, building upward. The principles of vertical job loading are presented in Figure 3 . 


\section{HYGIENES}

(Job factors associated with dissatisfaction)

Company policy and administration

Supervision

Relationship with supervisor

Working conditions

Salary

Relationship with peers

Personal life

Relationship with subordinates

Status

Security

\section{MOTIVATORS}

(Job factors associated with satisfaction)

Achievement

Recognition

Work itself

Responsibility

Advancement

Growth

Figure 2. Herzberg's motivator and hygiene factors presented in order of magnitude (adapted from Herzberg, 1968). 


\begin{tabular}{|c|c|}
\hline PRINCIPAL & MOTIVATORS INVOLVED \\
\hline $\begin{array}{l}\text { 1. Remove some controls while } \\
\text { retaining accountability }\end{array}$ & $\begin{array}{l}\text { Responsibility and personal } \\
\text { achievement }\end{array}$ \\
\hline $\begin{array}{l}\text { 2. Increase accountability } \\
\text { of individuals for their } \\
\text { own work }\end{array}$ & $\begin{array}{l}\text { Responsibility and } \\
\text { recognition }\end{array}$ \\
\hline $\begin{array}{l}\text { 3. Give a person a complete } \\
\text { natural unit of work } \\
\text { (division, area, etc.) }\end{array}$ & $\begin{array}{l}\text { Responsibility, achievement, } \\
\text { and recognition }\end{array}$ \\
\hline $\begin{array}{l}\text { 4. Grant additional job } \\
\text { authority to an employee }\end{array}$ & $\begin{array}{l}\text { Responsibility, achievement, } \\
\text { and recognition }\end{array}$ \\
\hline $\begin{array}{l}\text { 5. Make periodic reports } \\
\text { directly available to an } \\
\text { employee }\end{array}$ & Internal recognition \\
\hline $\begin{array}{l}\text { 6. Introduce new and more } \\
\text { difficult tasks not previously } \\
\text { handled }\end{array}$ & Growth and learning \\
\hline $\begin{array}{l}\text { 7. Assign individuals specialized } \\
\text { tasks, allowing them to } \\
\text { become experts }\end{array}$ & $\begin{array}{l}\text { Responsibility, growth, } \\
\text { and advancement }\end{array}$ \\
\hline
\end{tabular}

Figure 3. Herzberg's principles of vertical job loading (adapted from Herzberg, 1968). 
A potential criticism of Herzberg's work as solely theoretical was answered in the studies of R.N. Ford, a manpower utilization specialist. Ford spearheaded a series of nineteen field experiments at American Telephone and Telegraph in the mid-sixties which served to prove Herzberg's thesis (Dickson, 1975).

Herzberg's Motivation-Hygiene Theory has been attacked for inconsistencies and lack of justification (Cofer \& Appley, 1964; Herzberg, Mausner \& Snyderman, 1959; Vroom, 1964; White, 1959). King (1970), for example, uncovered five distinct versions of the theory from Herzberg's writings. Efforts to replicate his findings are wrought with failure due to flaws inherent in the original study (Locke, 1976). Cummings and Berger (1976) agreed in labeling Herzberg's findings "overly simplistic and not generalizable" (p.40). The merits of Work Itself theorists, Herzberg and Maslow, are acknowledged in the writings of Myers (1964, 1981), who consolidated their theories into his own employees needs format (Figure 4). Myers "maintenance needs" are synonymous with Herzberg's hygienes and Maslow's lower-order needs, and so named to denote the concept of servicing people much "like buildings and machines" (1981, p.10). According to Myers (1964), "Peripheral-to-the-task and usually group-administered maintenance factors have little 


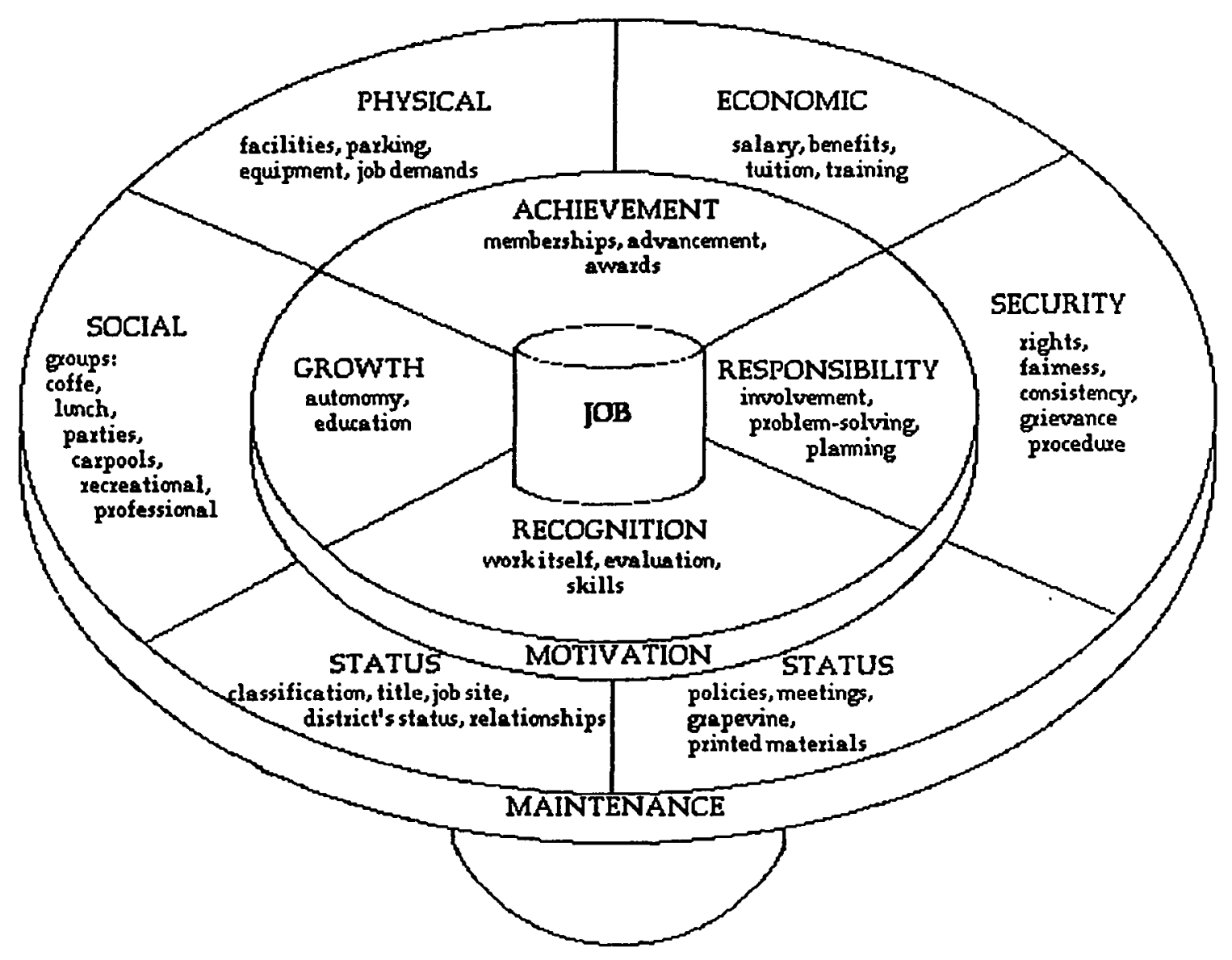

Figure 4. Needs of school district employees (adapted from Myers, 1964). 
motivational value, but their fulfillment is essential to the avoidance of dissatisfaction" (p.85). Job satisfaction, on the other hand, is linked to the fulfillment of "motivation needs," which parallel Herzberg's motivators and Maslow's self-actualization needs.

In its revised form, Myer's graphic synthesis is applicable to school district workers, from classified employees to certified teachers to administrative personnel. For example, borrowing from Myers (1981), once air conditioning, a physical maintenance factor, becomes an employee expectation, their attitudes toward it can only go downward. Absence of air conditioning, then, elicits dissatisfaction and distraction from motivators. And its reinstatement instills, not satisfaction, but absence from dissatisfaction, allowing the employee to once again pursue self-actualization.

Another illustration arises from periods of contract negociation. A threat to salary or benefits arrouses dissatisfaction. Once settled, financial conditions maintain the employee, allowing him to reallign with avenues to satisfaction. 


\section{Equity Theory}

According to equity theory, an employee's job satisfaction or dissatisfaction and his/her behavior are directly rooted in the individual's perception of personal equity in the workplace--that is, a worker who believes treatment is inquitable will be dissatisfied and will respond by attempting to reduce the inequity. Adams (1963), who most thoroughly developed the theory (Steers \& Porter, 1975), defined "inequity" as a perceived imbalance between the ratio of "Person"'s "outcomes" to "inputs" and the ratio of "Other"'s "outcomes" to "inputs." "Person" was defined as one who perceives equity or inequity, while "Other" denoted an individual who is in an exchange relationship with Person. "Outcomes" included the many forms of pay and benefits a worker (in this context) realizes. "Inputs" signified the demographic and personal variables that define the individual, including education, experience, and inteligence.

Several notable theorists have independently formulated variations on the equity theme. Such comparable concepts include (a) "cognitive dissonance" theory (Festinger, 1957), (b) "distributive justice" or "exchange" theory (Homans, 1961; Jacques, 1961; Patchen, 1961), and (c) "equity" theory (Adams, 1963; Weick, 1964) (Steers \& Porter, 1975). 
In contrast to preceding frameworks, which contended that individual behavior is attributable to specific factors in the individual or in the environment, equity theory assigned greater importance to the processes of behavior and interaction. For this reason, Steers and Porter (1975) have described both equity theory and expectancy theory as "dynamic" "interactive" frameworks.

\section{Expectancy Theory}

Expectancy theory, another process theory, incorporated a third set of interactive variables into the formula for understanding human behavior. Based on the work of Lewin (1935) and Tolman (1932), it postulated a relationship among an organizational environment (including climate and supervisor's style), the nature of the job itself, and an individual's attitudes.

Implicit in the construct of attitude, for these theorists, are the concepts of valence and expectancy. Valence can be defined as "the attractiveness of an outcome" and expectancy conveys "the likelihood that an action will lead to a certain outcome or goal" (Lawler, 1975, p.190).

Numerous investigators have developed mathematical formulas for the association among the variables in 


\begin{abstract}
expectancy theory (Vroom, 1964). Perhaps the simplest statement of the relationship was stated by Steers and Porter (1975) as: the "motivational force to perform-or effort--is a multiplicative function of the expectancies, or beliefs, that individuals have concerning future outcomes times the value they place on those outcomes" (p.181).
\end{abstract}

ORGANIZATIONAL MANAGEMENT THEORIES

The research of Mayo, Maslow, Adams, Lewin and others has implications for job satisfaction from the perspective of employee needs and/or expectations. Meanwhile, organizational theorists have looked at managerial style and organizational structure as they relate to employee performance, human effectiveness, and job satisfaction. Steers and Porter (1975) termed these theories "Human Resources Models." Their commonality is that "employees are looked upon as reservoirs of potential talent and management's responsibility is to learn how best to tap such resources" (p.19).

McGregor believed that a manager's style is grounded in that manager's assumptions about human nature. In his words, "The way a business is managed determines to a very large extent what people are perceived to have 'potential' and how they develop" 
(McGregor, 1960, p.vi). Traditional assumptions, which he termed Theory $\mathrm{X}$, characterize employees as fundamentally irresponsible, lazy, resistant to change, in need of close supervision and indifferent to organizational needs (Hinrichs, 1974).

The problem inherent in Theory $x$, which McGregor traced to the punishment of Adam and Eve and viewed as the buttress of existing organizational literature, is its supposition that the fulfillment of lower-level needs grants worker satisfaction. A manager, restricting his vision of employee wants to "good wages," "excellent fringe benefits," and "steady employment" neglects the import of Maslow's higher-level human needs (McGregor, 1960). Salaries and benefits--labeled "carrot and stick" motivators-"yield needed satisfaction only when the individual leaves the job" (McGregor, 1960, p.40). That is, they can be used or enjoyed only outside the worksite. Theory $x$, oft referred to in organizational literature as "paternalistic management," invariably depends upon an external control system. But, as McGregor described, the "philosophy of management by direction and control is... of limited value in motivating people whose important needs are social and egoistic" (p.42). He equated the deprivation of higher-level needs with "severe dietary deficiency" to 
emphasize that both elicit behavioral consequences which, in turn, affect worker motivation.

McGregor decried the premises of Theory $\mathrm{x}$ as fallacious (Hinrichs, 1974). In response, he formulated Theory $Y$, which is firmly rooted in Maslow's work, to facilitate the integration of individual and organizational goals and to keep pace with social science literature. McGregor defined the Theory $Y$ manager as one who believes workers are inherently. responsible, self-directed, and hard-working. With these "dynamic" assumptions, as differentiated from Theory X's "static" notions, the manager provides only support and encouragement. As McGregor abstracted, the distinction between $\mathrm{X}$ and $\mathrm{Y}$ management "is the difference between treating people as children and treating them as mature adults" (McGregor, 1972, p.316).

Vroom and Deci (1972) outlined three basic elements of the participative management that McGregor theorized. The first pertains to endowing the employee with responsibility for determining how to meet organizational goals. This change from tradition is comparable to what Drucker (1976) termed "management by objectives." According to Vroom and Deci (1972),

The basic assumption is that if a person has freedom...then he will regard his job as more 
of a challenge than if he is told exactly

what to do and when to do it (p.15).

This autonomy has been identified in numerous studies (Kohn \& Schooler, 1973; Shepard, 1973; Stone, 1976) as a key ingredient of job satisfaction.

Secondly, the manager's role is supportive, not authoritative. Leavitt (1962) called the relationship "power equalization." Likert (1961) credited the "principle of supportive relationships" as a requisite for "high-producing managers." In the field of psychotherapy, Rogers (1951) coined the parallel term "client-centered therapy." In any case, the supportive manager is a resource or facilitator to those he serves.

Finally, employee work groups are utilized as decision-making bodies. As problems arise in organizations employing participative management, workers and supervisors meet jointly as problem-solving units.

Ouchi (1981) extended McGregor's work to include Type $\mathrm{z}$ organizations--those incorporating the techniques traditionally associated with Japanese corporations. The Theory $\mathrm{Z}$ manager recognizes the link among productivity, trust, and subtlety, both professionally and personally. He demonstrates an 
interest in the human side of workers and nurtures intimacy in the workplace.

Moving in step with Ouchi, Peters and Waterman (1982) surveyed 62 of this country's most successful companies to create a composite recipe for "excellence." In the text of the chapter entitled "Productivity through People," the authors asserted, "There was hardly a more pervasive theme in the excellent companies than respect for the individual" (p.238). This theme was extended by Peters and Austin (1985) in A Passion for Excellence. A common thread among companies exhibiting this "passion" was the use of the term "family" to describe their organizations.

\section{EDUCATION}

While the business sector has embraced some of the recommendations from these exhaustive studies, educational torchbearers have been slower to recognize their applicability to the business of school management. Researchers interested in the job satisfaction of school district employees, for example, have focused on administrators and teachers to the near exclusion of classified staff. Only a handful of studies have addressed the job satisfaction of noncertified school district employees. Most of these concern the secretarial staff of schools. 
Simon (1972) adapted the use of the critical incident technique, traditionally used in industrial research, to identify positive and negative motivating factors which affect the school secretary. In contrast with Herzberg's industrial findings, Simon confirmed that motivators also act as dissatisfiers for this population. The five strongest satisfiers were recognition, achievement, interpersonal relations with peers and with pupils, and work itself. With a sample size of 65 , Simon generalized that school secretaries are satisfied with their work.

In a study of the female labor force, Harrison (1979) summarized job dissatisfiers of the nation's 4 milizon secretaries and typists. The dissatisfiers, Harrison asserted, are synonymous with characteristics of clerical positions, including: poor pay, lack of job security, inadequate opportunities for advancement, and poor working conditions. These may also apply to the school secretary and clerical employee. Collins and Masley (1980) surveyed a district's employees, including aides and clerical workers, to assess stress factors that bear upon job satisfaction. Participants were asked to rate a list of job factors on a scale ranging from no stress to high stress. They found that involuntary transfer, reduction in force, and salary were high stress issues common to both 
subgroups. Low stress factors included: communication with teachers, administrators, and parents, public image, isolation, and decision-making.

Kuiper and Van Huss' (1981) study of a district's clerical and secretarial employees focused on job satisfaction and role ambiguity in a comparison of two groups, differentiated on the basis of cohesiveness, or physical proximity to peers. Using the Job Descriptive Index (Smith, Kendall and Hulin, 1969), the researchers measured satisfaction with work, pay, co-workers, supervision, and promotion. They found a negative correlation between role-ambiguity and job satisfaction for secretarial workers.

In a descriptive study of the school secretarial role, Casanova (1986) found that the secretary "plays a central role in the communications network of the school and the school district" (p.12). Unlike the business model of a secretary as a clerical worker, the school secretary is instrumental for school effectiveness. In support of this contention, Casanova cited "pervasive folklore" asserting "Secretaries run schools." Her study defined an "interdependence" between the principal and secretary. She concluded that, despite the "centrality" of the school secretary's work to the organization, the position is also characterized by lack of recognition and low 
salary. Based on Casanova's findings, the factors of recognition and salary may be dissatisfiers for this population; these two issues appear as a common thread among the works of Casanova (1986), Harrison (1979), and Simon (1972).

Custodial satisfaction was the subject of Young's (1982) research. Young looked at the leadership dimensions of consideration and initiating structure as they relate to employee job satisfaction. Young's study revealed that a custodian's level of job satisfaction varied according to the employee's perception of his or her administrator's consideration level.

Finally, in 1983, Pyles conducted a study to discern the factors related to job satisfaction of public school food service personnel. The sample represented ten districts. Pyles studied satisfaction relative to demographic and employment characteristics. For assessment, Pyles, like Kuiper and Van Huss (1981), used the Job Descriptive Index. Among her conclusions, she found that the longer the employment, the greater the employee's sense of dissatisfaction.

\section{JOB SATISFACTION AND DEMOGRAPHIC/PERSONAL VARIABLES}

Pyles' (1983) research, discussed above, is uniquely relevant to this study in that it both 
addressed job satisfaction of a group of noncertified school district employees and spoke to factors including age, marital status, educational level, and length of employment. Other pertinent studies, though peripheral in some way(s), are included here for what they offer to a deeper understanding of the contributing variables in the job satisfaction formula.

Pyles' (1983) study of food service workers was built upon responses from a sample of 201 employees representing ten public school districts in Michigan. To partially summarize her findings relative to food service workers:

1. Employees over fifty-five years of age were significantly less satisfied with their supervisors than younger workers.

2. Married workers and those employed less than three years in their present districts, respectively, were significantly more satisfied with their pay than non-married employees and those with greater tenure.

3. No significant relationship was found between job satisfaction and years of formal education.

Citing "a paucity of research on the public sector and worker satisfaction" (p.3), Schmidt, Anderson, and Clarke (1983) distributed Employee Attitude Surveys to 
20,000 federal workers. With a sample size of 13,862 , the researchers analyzed 263 items for factors influencing job satisfaction. They concluded that: 1) older workers (those 55 years and over) report significantly greater job satisfaction and satisfaction with salary than their younger counterparts; 2) those with higher levels of formal education are significantly less satisfied with their jobs and more dissatisfied with their salaries; and, 3) federal employees with the most tenure are less satisfied with their jobs and more satisfied with their salaries. In fact, they found a steady decline in job satisfaction among workers after four years of employment.

Another recent study (McNeeley, 1988), assessing the job satisfaction of 1,367 human services workers, also found that older workers were significantly more satisfied than others. This research, which included both professionals and "nonprofessionals" (clerical employees), reported a positive correlation between marriage and greater job satisfaction. However, no relationship was found between job satisfaction and the factors of educational level, length of employment, or gender.

Wheeless, Wheeless and Howard (1982) analyzed job satisfaction of classified personnel in an eastern university. Employing a modified version of the 
Smith-Hulin Job Descriptive Index (1969), used also by Pyles (1983), Wheeless et al. examined communication-related variables, participation variables, and employment characteristics relative to job satisfaction. They found that factors termed Communication Satisfaction with Supervisor and Supervisor Receptivity were more highly related to job satisfaction than the variables of age, salary, or length of service.

In 1983, Lynch and Verdin studied the satisfaction of 384 library employees in the context of work itself. They used a four-question scale to compare factors influencing the satisfaction of professional library staff with the satisfaction of nonprofessionals (including clerical, maintenance, and custodial employees). Among the latter group, the researchers found that age and length of employment were related to job satisfaction. Specifically, workers less than 25 years of age were the least satisfied and those with more years of experience reported higher job satisfaction. While there was no difference in satisfaction by gender, married workers of both sexes were more satisfied.

Finally, although she confined her job satisfaction study to teachers, Perko's (1985) research is included here because the selected geographical 
location (Portland metropolitan area) overlaps with this study's population and the research focused on the relationship between demographic factors and job satisfaction. Perko found that age and sex were significantly related to job satisfaction; older employees and female employees expressed higher levels of satisfaction. Therefore, although the research sample differed by occupational definition, the findings related to the age variable agree with the results of Schmidt et al. (1983) and McNeeley (1988).

\section{HYPOTHESES}

From the issues raised in Chapter $I$, the following Research Questions and Hypotheses have been formulated:

Research Question 1: Is there a significant difference in job satisfaction among the specific categories of classified employees?

Research Hypothesis 1: There is a significant difference in job satisfaction among classified employees relative to job category.

Research Question 2: Are the demographic/personal variables of classified employees related to overall job satisfaction?

Research Hypothesis 2a: There is a significant difference in overall job satisfaction among classified employees relative to gender. 
Research Hypothesis $2 \mathrm{~b}$ : There is a significant difference in overall job satisfaction among classified employees relative to educational level.

Research Hypothesis 2c: There is a significant difference in overall job satisfaction among classified employees relative to length of employment.

Research Hypothesis 2d: There is a significant difference in overall job satisfaction among classified employees relative to number of hours employed.

Research Hypothesis 2e: There is a significant difference in overall job satisfaction among classified employees relative to work setting.

\section{SUMMARY}

Researchers have probed the construct of job satisfaction for over five decades. Educators, pushed by the wave of school reform reports, began to follow the lead of business in pursuing "excellence." But studies, to this end, of employee job satisfaction have been myopic in scope. Educational researchers have focused on the administrative and teaching staff, resulting in a body of literature nearly devoid of studies representing the other end of the staff spectrum. Those few specifically directed at the classified population have addressed different aspects --motivators, dissatisfiers, stress factors, role 
ambiguity, and leadership dimension--as they relate to the job satisfaction of distinct subgroups. In addition, since measures of job satisfaction have varied across studies, the results cannot be summarized in comparable terms. Further, those studies which address demographic/personal factors in relation to job satisfaction vary in their samples, instrumentation, and/or foci, making conclusions, based on relevant, comparable research, difficult. With that caution in mind and based on the studies presented here, the only safe generalization is that workers' levels of job satisfaction may vary in relation to age, marital status, educational level, gender, and length of employment. Finally, there is no examination, to date, which attempts to compare the respective levels and sources of job satisfaction and dissatisfaction among all subgroups of school district noncertified employees.

The following chapter presents the methodology employed in this study, which seeks to fill a gap in job satisfaction research relating to classified employees. 


\section{CHAPTER III}

METHODOLOGY

INTRODUCTION

This study incorporated both quantitative and qualitative methodology. According to Best and Kahn (1986), "there is merit in using multiple methods, supplementing one with others to counteract bias and generate more adequate data" (p. 144). In a paper entitled "Integrating Quantitative Components into Qualitative Studies," Schofield and Anderson (1984) cite literature supporting the "complementary strengths" of these two research strategies, once considered dichotomous.

The use of triangulation in social sciences can be traced to Campbell and Fiske (1959) who identified "multiple operationism" as a process of validation (Jick, 1983). In a geometric sense, greater accuracy is derived from multiple viewpoints on a common problem; in research, multiple perspectives may serve to clarify interpretation of data.

The two techniques used were (a) focus groups, and (b) a questionnaire. The purpose of the focus groups 
was to identify major issues and concerns related to job satisfaction, which then served as a basis for development of the questionnaire. The questionnaire was used to sample a wider population of employees and to supplement the information garnered from the discussions.

As discussed in Chapter I, the population studied was the classified employee group of Beaverton School District. The group was composed of 1,014 individuals serving in 26 elementary schools, 6 intermediate schools, 3 high schools, the Administrative Center, and in other support sites throughout the 57 square mile district.

FOCUS GROUPS

Theory

According to Krueger (1988), who presents the most comprehensive discussion of focus groups to date, a focus group is "a carefully planned discussion designed to obtain perceptions on a defined area of interest in a permissive, nonthreatening environment" (p.18). Later in the volume, Krueger (1988) provides a definition highlighting the features which distinguish focus groups from other group processes. In this context, a focus group is a formation of "(a) people, who (b) possess certain characteristics, (c) provide 
data (d) of a qualitative nature (e) in a focused discussion" (p. 27). The procedure has been used extensively in commercial marketing research for several decades to evaluate existing programs, to plan new programs, and to support new marketing strategies (Krueger, 1988).

Although the collection of interview data is considered qualitative in that the attitudes expressed and the degree of conviction are neither measurable, nor statistically analyzable, the results do not necessarily constitute an unscientific effort. In fact, compilation of opinions based on everyday experience is distinct from scientific discourse only in "that scientific constructs are supposed to be more powerful and to be subject to more rigorous and critical verification than are everyday ideas" (Calder, 1977, p.354). Linda (1982) has approached the comparison in yet another way, "The focus group is to qualitative research what analysis of variance is to quantitative research. The technique is robust, hardy, and can be twisted a bit and still yield useful and significant results" (p.98).

The physical composition of a focus group, according to Krueger (1988) and Calder (1977), typically ranges from about six to ten people. The size determination seems to rest on providing 
individuals an opportunity to comfortably participate while also guaranteeing potential diversity of opinion through a large enough sampling.

Advantages of incorporating the focus group interview into a research endeavor are elaborated by Krueger (1988). They include:

1. It is a socially oriented, naturalistic method.

2. The facilitator can spontaneously probe.

3. The procedure has high face validity "if ... used carefully for a problem that is suitable" (p.41).

4. It is a relatively inexpensive method.

5. Information about attitudes can be ascertained quickly.

6. Sample size is inherently enlarged over conventional one-to-one interviewing techniques.

\section{Application}

The purpose of utilizing focus groups in this study was to identify issues of concern for the classified employee population, to discern the directionality of opinions, and to compare the ideas amassed across job categories. Ultimately, insights 
derived from focus group information served as a base for development of the questionnaire.

The first step in the research process was to organize focus groups which represented a cross section of the 1,014 classified employees of Beaverton School District. (Ten employees were deleted as occupying management positions.) Seven original job categories, derived from the District's Classified Employee Handbook 1988-91, were expanded to nine. The largest segment, secretaries and clerical workers, was split by worksite to differentiate school-based from non-school-based secretarial and clerical employees. Further, to facilitate scheduling of discussion groups, custodial workers were delineated by work hours to represent day shift and evening shift custodians. Rationale for the distinction centered on differences in work due to degree of contact with supervisor, students and staff; job satisfaction could vary based on relations within the work environment.

A homogeneous grouping of employees was used for focus discussions for two reasons: (a) to parallel the research question investigating group differences by job category, and (b) to facilitate debate of job content-related satisfiers and dissatisfiers. The resultant groups included: 
1. Non-school-based secretarial/clerical workers

2. School-based secretarial/clerical workers

3. Instructional assistants

4. Food service employees

5. Bus Drivers

6. Day custodians

7. Night custodians

8. Trades workers

9. Technical employees

Following designation of focus group categories, department coordinators were sent letters informing them of the study and soliciting names of individuals for participation in focus groups. The letter, Appendix A, asked for a list of 25 names which represented a cross-section of individuals

including those who have been with the District less than three years and those with more than 10 years experience; those who are supportive of the District and those who are not; and, employees who are strong union members and those who are not. (Appendix A)

The purpose of this process, as stated, was to garner a broad spectrum of opinions, inclusive of extremes.

From each list, 10 potential participants were randomly selected to receive invitations to a focus group session. There was no attempt to form groups in relative proportion to the greater employee population; groups were be formulated as information gathering 
assemblages. The letters (Appendix B) were sent to each employee's work address in late October, 1988. An alternate list, also randomly determined, was established and utilized to guarantee--as much as possible--that groups were evenly represented.

Focus groups met during the month of November, 1988. Sessions were convened outside of regular work hours. Employees were not monetarially compensated for their time. All nine sessions lasted approximately two hours.

The meetings were co-facilitated by a district employee with extensive experience in both the process of group facilitation and the construct of job satisfaction and the researcher. All of the sessions were tape recorded for later transcription to guarantee inclusion of all statements for later analysis. Only the transcribing secretary, the researcher and a third party, who was neither employed by the school district nor acquainted with the participants, had access to the tapes to ensure confidentiality. The researcher was present at every focus group meeting to ask for clarification of ideas or expansion on opinions.

A core of 26 questions (Appendix C) was developed by the facilitator and the researcher based on prior interviewing experience and the information base required for this study. Questions ranged from the 
specific "How do you feel about your salary?" to the open-ended "What other issues/questions had you hoped to address today?" Each question was asked exactly as worded and in the same order as listed for all nine groups.

At the closing of each session, participants filled out a one-page survey (Appendix D) for use in determining the characteristics of focus group members. One item asked the respondent to numerically rank his/her present level of job satisfaction on a five-point scale.

The data collected through focus group discussions was coded and analyzed using the framework presented by Bogden and Biklen (1982). In essence, and with modification, the process included: numbering pages, reading and rereading narratives, generating preliminary coding categories by emergent themes, experimenting with coding the data, and repeating the process as deemed necessary. The narrative data was analyzed separately by a second resarcher, who then conferred with the author to reach consensus. The final categories provided a structure for organization of focus group comments and viewpoints and for areas of questionnaire assessment.

Once organized into a manageable outline, the focus group results, in combination with an appraisal 
of the research, formed the basis for construction of the questionnaire.

\section{QUESTIONNA IRE}

Design

As discussed, compilation and analysis of focus group results provided the foundation for subsequent development of the questionnaire. The remainder of this section includes discussion of established measuring instruments and the formulation of the content and format used in this study. The classic definition of job satisfaction was advanced by Robert Hoppock in 1935 and is expropriated here. Job satisfaction is defined as any combination of circumstances that cause a person to claim, "I am satisfied with my job" (Hoppock, 1935). It follows that the most direct, unencumbered measurement of the construct may be to ask, "Are you satisfied with your job?"

Such is the approach of the Gallup poll which, since 1949, has asked "On the whole, would you say you are satisfied or dissatisfied with the work you do?" (Strauss, 1974) But the simplicity of the method also constitutes its invalidity and consequent unreliability. For example, Work in America (1973) cites a study in which auto and assembly-line workers 
reported overall job satisfaction, adding that they wished to change certain aspects of their work. Perhaps, in the context of Herzberg's theory, the single question evoked an absence of dissatisfiers instead of the presence of motivators, or intrinsic rewards.

Kahn (1974) speculates that the single direct question is too closely associated with one's self-esteem to elicit a reliable short response. He states:

The researcher asks the worker if he is satisfied with his job and leaves him to provide his own frame of reference--his own comparison group, his own range of accessible occupations, his own assessment of his talents and the opportunities of the labor market. To the extent that he has made a "successful adjustment," he reports some degree of satisfaction (p.204).

Notable efforts to measure job satisfaction, evidenced in educational research, include those by Hackman and Oldham (1975), Holdaway (19̣78), Miskel (1972), and Smith and Hulin (1969).

By design, the Job Diagnostic Survey (Hackman \& Oldham, 1974) is "an instrument for the diagnosis of jobs and the evaluation of job redesign projects" (p. 170). It was conceptualized in accordance with a theory, developed by Turner and Lawrence (1965) and Hackman and Lawler (1971), relating five "core job dimensions," three "critical psychological states," and 
four "personal and work outcomes." The scale is considered to have satisfactory internal consistency, discriminant validity, and psychometric characteristics (Hackman \& Oldham, 1974).

Holdaway (1978) constructed the 52-item Questionnaire Testing Job Satisfaction with Facets of Work. It was designed as a measure of teacher job satisfaction. The tool examines seven dimensions of work identified as: Recognition and Status, students, Resources, Teaching Assignment, Involvement with Administrators, Work Load, and Salary and Benefits. Holdaway's assessment incorporates an eight-point Iikert scale.

A third instrument of job satisfaction, evidenced in educational research, is Miskel's seven-item questionnaire. Like Holdaway's work, Miskel's was intended to assess level of teacher contentment. The author reports "adequate reliability" $(r=.81)$ and "high face validity" (Hoy \& Miskel, 1982). Sample items include (a) "If I came into enough money so that I could live comfortably without working, I would quit my job," and (b) "Most other educators are more satisfied with their jobs than I am."

A more generic measurement of job satisfaction was proposed by Patricia Smith and her colleagues (1969). The Job Descriptive Index (JDI) asks participants to 
respond with a yes ("Y"), no ("N"), or cannot decide ("?") to 72 descriptors of their job(s). The descriptive words or phrases are categorized under five headings: Work, Supervisor, Pay, Promotion, Co-workers. According to Smith, Kendall, and Hulin (1969) and Pyles (1983), advantages of the JDI include:

1. It addresses specific, distinguishable areas of job satisfaction.

2. It requires a low verbal level.

3. Descriptors, both evaluative and objective, are job-referent, not self-referent.

4. The format presents separate sections, each requiring a short attention span and appearing to be nonthreatening.

The questionnaire content for this study was built on the foundation of focus group results. Development of a format rested, in part, on the work of Smith et al. (1969). Specifically, steps in construction of this tool to assess classified employees' job satisfaction entailed (a) identification of themes, specific areas relating to job satisfaction and dissatisfaction, from focus group discussions, (b) organization of employee comments concerning each theme, (c) reduction of items to those most frequently and fanatically expressed across groups, and (d) random mixture of items to avoid a categorical response set. 
The questionnaire included 12 demographic/personal factors such as gender, occupational group, work setting, and hours employed to test the hypotheses for Research Question 2 .

The questionnaire also contained a single direct question of overall satisfaction and elicited a satisfaction response to the eight resultant theme groupings. For example, each participating employee indicated overall degree of satisfaction with co-workers, and responded to individual descriptors of co-workers. The statements, which constituted the body of the questionnaire were equally positively- and negatively-worded. Lastly, the questionnaire requested responses to two open-ended questions.

The measurement instrument incorporated a four-point Likert scale from "strongly agree" to "strongly disagree" for individual items and from "very satisfied" to "very dissatisfied" for overall theme areas. The option of a "neutral," "undecided," or "ambivalent" category was discarded as potentially resulting in minimal variation of responses. The alternative of a five- or six-point scale was rejected as adding unneeded complexity to the instrument. When a neutral position is included, the research instrument is generally assessing the respondent's knowledge. For the purposes of this study, a vote, or definite 
opinion, was desired. Therefore, the questionnaire was consciously designed to force a choice from the respondent.

The decision to formulate an original assessment for this study was rooted in the researcher's opinion that a questionnaire developed for a specific population may be preferable to established tools as long as the device is valid and reliable. In this case, there was an absence of established tools designed explicitly for assessing job satisfaction of classified employees in an educational setting.

As a final step in the questionnaire design, one representative from each of the nine original focus groups was randomly selected and invited to attend a meeting. The goal of the meeting was to review the proposed questionnaire, to individually highlight areas of ambiguity or redundance, and to reach group consensus on interpretation, omissions and additions to the assessment tool. Five individuals attended the gathering. As a result of this process, ten items were eliminated, one was rewritten for clarity, and two items were added. A secondary purpose of this step was to directly involve employees in the process of questionnaire development and, thereby, increase content validity of the instrument. 


\section{Administration}

The questionnaire was sent, via interschool mailing, to 630 classified employees 1628 of the total population). The number was determined by a research expert, based on the return needed to statistically analyze results. With the exception of one occupational group, the sample was randomly selected. All employees identified as Technical Workers received questionnaires because the total population is less than 40 and a larger proportion was needed for analysis. That is, in order to achieve truly representative and statistically analyzable data, one group was purposefully proportionally over-represented in the sample.

Each participant received an envelope containing the printed questionnaire (Appendix E), a cover letter (Appendix F), and a computer scan sheet for responses. The scan sheet was precoded with the employee's job category. Participants were asked to return response forms in the same envelope. Each envelope was printed with an employee identification number, used only to indicate questionnaire return. The envelope was discarded to ensure response anonymity. A second questionnaire was sent to nonrespondents three weeks after the first. A letter enclosure (Appendix G) again solicited participation. 
Validity and Reliability

According to Best and Kahn (1986), "basic to the validity of a questionnaire is asking the right questions, phrased in the least ambiguous way" (p.179). In this study, the instrument was built on an analysis of responses from focus groups. As discussed above, as a step in the questionnaire construction and to heighten content validity, the document was presented to a representative group of classified employees for discussion and refinement. Participants in the group were asked to respond to questions regarding the clarity and interpretation of the items and the instrument scale. The tool was also subjected to the scrutiny of experts in questionnaire design.

Internal consistency was checked using the split-half reliability correlation. The Spearman-Brown coefficient was computed as $r=.95$. The coefficient Alpha for all items was .96 . In review of the item reliability statistics (Appendix H), three of the 100 questions were found to be unreliable. Those items read, "My work is fast-paced," "My work area is cold," and "Overtime on my job is not compensated" (see Appendix E, items 47,49 , and 86). All remaining individual items were found to contribute to the reliability of the total instrument. 
The question of homogeneity among individual items was assessed using factor analysis. The items loaded in eight groupings (see Chapter IV), with the sole exceptions of questions 47 and 49 , found to be unreliable measures, and question 52, which reads, "My supervisor has high expectations" and which did not lcad with any of the eight factors. Item 86 , regarding compensation for overtime, loaded strongly with a benefits and salary grouping and was, therefore, retained. Question 100, which served as the single-item measure of overall job satisfaction, loaded strongly with a work itself factor but was removed because of its intended function as an independent variable in the study.

Finally, an estimation of reliability was attained by comparing results of the questionnaire with those of the focus groups. That discussion is found at the end of Chapter IV.

\section{APPROVALS}

Administrators of Beaverton School District approved the study. They included: (a) Boyd Applegarth, Superintendent; (b) Steve Lynch, Director of Elementary Schools; (c) Dell Squire, Director of Secondary Schools; and, (d) Ted Clibbon, Director of Classified Personnel. The study was also supported by 
Kathy Leslie, Director of Educational Public Relations. The Proposal for Research Projects in the Beaverton Schools was submitted to, and approved by, steve Carlson, Director of Planning and Program Evaluation. Portland State University's Human Subjects Research Review Committee reviewed and approved the study.

DATA ANALYSIS

The questionnaires were scanned and data were coded for computer analysis. All data were analyzed by the computer program the system for statistics (SYSTAT).

The first step, after reliability correlations were run, was descriptive analysis to determine frequencies, means, standard deviations, and distributions for the data. The process of identifying the primary sources of job satisfaction and dissatisfaction for classified employees, as a group, was considered prerequisite to addressing the two primary research questions. At the questionnaire item level, the means were compared to identify individual items of extreme high and low value (indicating high degrees of dissatisfaction or satisfaction, respectively). 
Factor analysis was employed to reduce data size and to determine the principal dependent variables for the study. Factor means and the distribution of responses for each factor were specified. Multiple regression was executed; factor means were regressed with the overall job satisfaction score (questionnaire item 100) to discover the percent of variance in job satisfaction due to the identified factors across the sample population of classified employees.

To address the first research question (Is there a significant difference in job satisfaction among the specific categories of classified employees?), stepwise multiple regression was employed. This time factors were regressed with overall job satisfaction (question 100) for each of the nine job categories. This

provided the data to compare the relative contribution of factors to overall satisfaction across employee groups.

Analysis of variance was calculated to determine if differences were significant among employee groups for each factor and if a significant difference existed among groups relative to the single-item measure of overall job satisfaction. Where differences emerged, they were analyzed using planned comparisons of certain job groupings with others. The purpose was to identify the nature of the computed differences. 
Research Question 2 (Are demographic/personal variables of classified employees related to overall job satisfaction?) necessitated the chi-square test to discern whether a relationship existed between job category and each of the targeted demographic/personal variables. Where the level was significant $(p<.05)$, analysis of covariance was applied. That is, the influence of job role was eliminated by using the variable of job category as the covariate. Where significant relationships appeared, the categories within each variable were analyzed using planned comparisons.

Finally, a second analysis of covariance was run. This time, the demographic/personal variable was the covariate. In this manner, the relationship between demographic/personal variables of classified employees and job role, each relative to overall job satisfaction, was determined.

\section{SUMMARY}

This chapter has outlined the procedures used in this study of classified employees in one public school district. Detailed methodology for focus group research and questionnaire development has been described, as well as the theoretical base on which it 
rests. Procedures for data analysis were defined. Chapter IV presents the results. 


\title{
CHAPTER IV
}

\author{
RESULTS
}

This chapter is devoted to a presentation of the findings of this study and an analysis of the collected data. The purpose of this study is to identify sources of job satisfaction and dissatisfaction of classified employees in one public school district, to compare responses among specific job categories and to distinguish other related variables. Due to minimal research in the area of job satisfaction of noncertified school district personnel, there are currently no standards of statistics for comparison. The study was designed to incorporate both qualitative and quantitative research techniques. In presenting the results, this chapter will be divided into the following sections:

(1) Description of focus group participants

(2) Presentation of focus group responses

(3) Description of questionnaire respondents

(4) Presentation of descriptive statistics from questionnaire responses

(5) Analysis of quantitative data to answer the following research questions: 
(a) What are the primary sources of job satisfaction and dissatisfaction for classified employees?

(b) Is there a significant difference in job satisfaction among specific job categories of classified employees?

(c) Are demographic/personal factors of classified employees related to overall job satisfaction?

(6) Results of open-ended questions

(7) Overview and comparison of qualitative and quantitative results

\section{FOCUS GROUPS}

\section{Description of Focus Group Participants}

Sixty-four classified employees participated in focus group discussions. Across the nine groups, differentiated by job category, group size averaged seven individuals. The job categories were: instructional assistants, school-based secretarial/ clerical staff, non-school-based secretarial/clerical staff, day custodians, night custodians, food service workers, bus drivers, maintenance personnel, and technical workers.

The composite demographic characteristics of the participants are presented in Table I. Women 
TABLE I

DEMOGRAPHIC CHARACTERISTICS OF FOCUS GROUP PARTICIPANTS

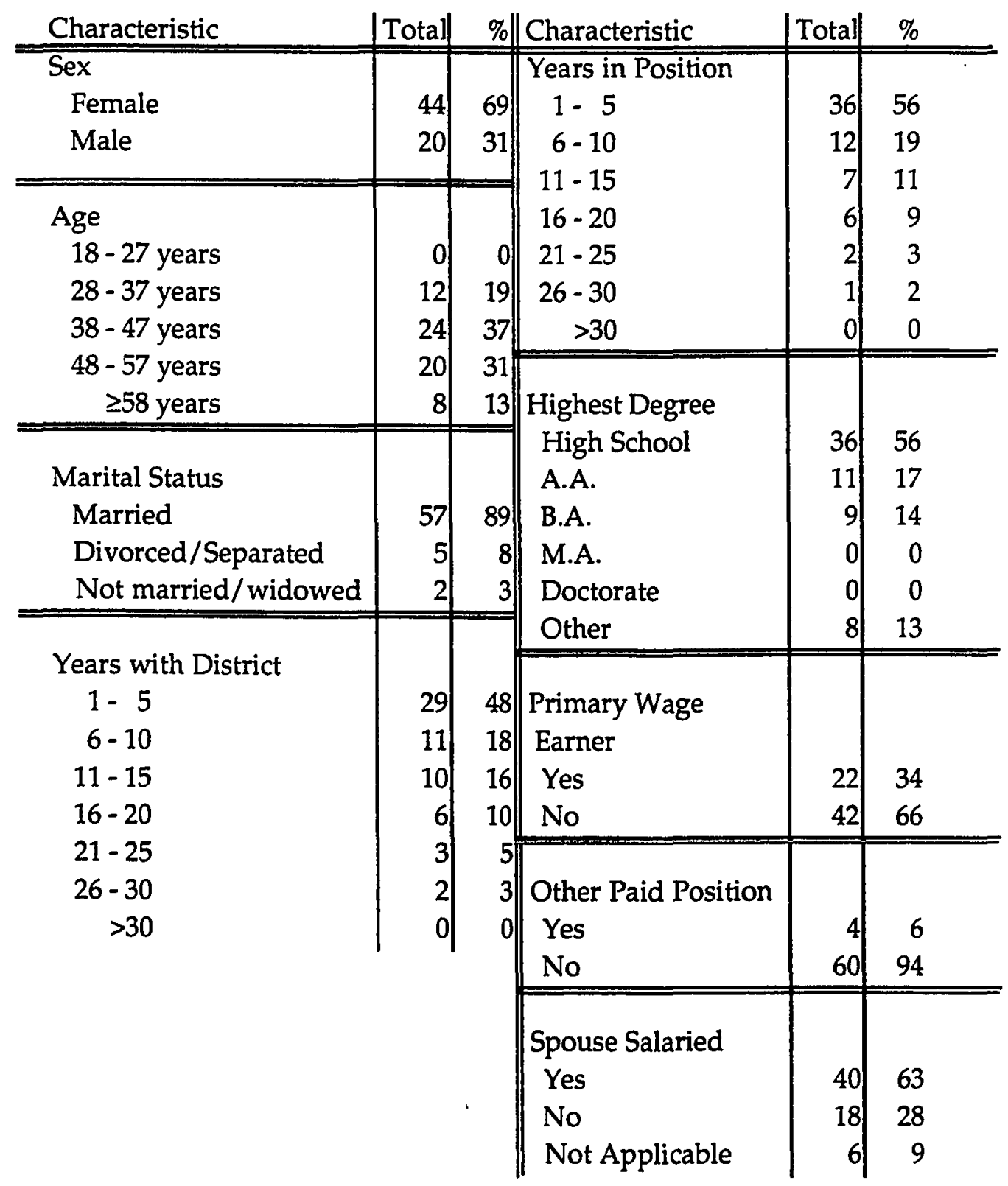


represented over two-thirds of the sample. No men were present in the instructional assistant, secretarial/ clerical, or food service groups while only men composed the night custodian and maintenance sections. Over $80 \%$ of the participants were age 38 or older. There were no employees less than 28 years of age. Three out of four have held their present position for 10 years or less while about the same proportion have worked for the school district in some capacity for 15 years or less. Only 58 have occupied their positions for more than 20 years. Most participants were married, have employed spouses, and hold one salaried position themselves.

There appeared to be little difference among the groups with regard to educational level. Approximately one-third of all focus group participants have earned, at least, an Associate's degree from college.

The participants representing male-dominated positions, day custodians and maintenance workers, indicated that they are the primary wage earners in their homes. Most of the participating instructional assistants, secretarial employees, and food service workers are not primary wage earners. The technical workers, bus drivers, and night custodian group were split on their financial roles in their households. 
Presentation of Focus Group Responses

For clarity of presentation, focus group responses

will be discussed in two phases. First, generalities

will be drawn across employee categories. Then, issues specific to individual job groups will be presented.

All Classified Employees. Each group of employees was asked a series of 26 questions designed to explore their feelings about work (Appendix C). In response to the questions and during accompanying discussion, there were common themes that emerged across job categories. These same topics arose when individuals were asked to identify three things they like and three things they dislike about their jobs. Individuals' issues were listed on a board and the unanimous or oft-repeated responses were tallied in each group. A composite view of the commonalities is presented in Table II and Table III. These will be detailed under the headings Job Satisfiers and Job Dissatisfiers below, followed by a section which outlines issues specific to the homogeneous job groupings.

Job Satisfiers: Areas receiving almost unanimous mention across employee focus groups as sources of job satisfaction were co-workers, students, and recognition. It appears that a primary job satisfier of classified employees, mentioned in eight of nine focus groups, is co-workers. As inferred from 
TABLE II

JOB SATISFIERS OF CLASSIFIED EMPLOYEES

AS PRESENTED IN

FOCUS GROUPS

\begin{tabular}{|c|c|c|c|c|c|c|c|c|c|c|}
\hline & & & & Job & & & & & & \\
\hline Satisfiers & 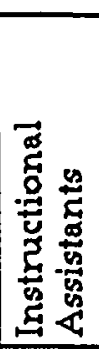 & 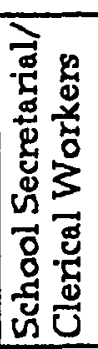 & 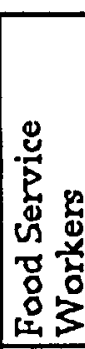 & 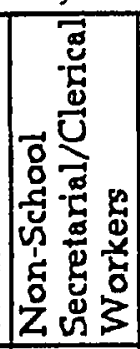 & 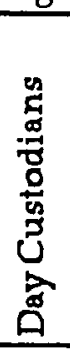 & 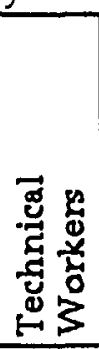 & 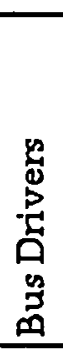 & 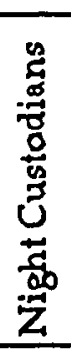 & 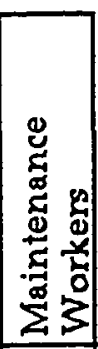 & $\stackrel{\vec{\sigma}}{0}$ \\
\hline Co-Workers & & $\overline{\bar{x}}$ & $\bar{x}$ & $\bar{x}$ & $\bar{X}$ & $\overline{\bar{X}}$ & $\overline{\bar{X}}$ & $\overline{\bar{X}}$ & $\overline{\bar{X}}$ & $\overline{8}$ \\
\hline Recognition & $\bar{X}$ & $\bar{X}$ & & $\bar{x}$ & $\bar{x}$ & $\bar{X}$ & $\bar{x}$ & $\bar{X}$ & & 7 \\
\hline Students & $\bar{X}$ & $\bar{X}$ & $\bar{X}$ & & $\bar{x}$ & & $\bar{X}$ & $\bar{X}$ & $\bar{X}$ & 7 \\
\hline$\overline{\text { Autonomy }}$ & $\bar{X}$ & $\bar{X}$ & & $\bar{x}$ & & $\bar{x}$ & $\bar{x}$ & & $\bar{X}$ & 6 \\
\hline Salary/Benefits & $\bar{X}$ & & & & $\bar{X}$ & $\bar{x}$ & $\bar{x}$ & $\bar{X}$ & $\bar{X}$ & 6 \\
\hline Daily Schedule & $\bar{X}$ & $\bar{X}$ & $\bar{x}$ & & & & $\bar{x}$ & & $\bar{x}$ & 5 \\
\hline Work Itself & & & $\bar{x}$ & $\bar{X}$ & $\bar{x}$ & & $\bar{X}$ & $\bar{x}$ & & 5 \\
\hline $\begin{array}{l}\text { Educational } \\
\text { Opportunities }\end{array}$ & $\bar{x}$ & $\bar{x}$ & & $\bar{x}$ & & $\bar{x}$ & & & & 4 \\
\hline Supervisor & $\bar{X}$ & $\bar{X}$ & & $\bar{x}$ & & $\bar{X}$ & & & & 4 \\
\hline Work Variety & & $\bar{X}$ & & $\bar{X}$ & $\bar{X}$ & & & $\bar{X}$ & & 4 \\
\hline $\begin{array}{l}\text { Work } \\
\text { Environment }\end{array}$ & & & & $\bar{X}$ & $\bar{X}$ & & & $\bar{X}$ & & 3 \\
\hline$\overline{\text { Creativity }}$ & & $\bar{X}$ & & & $\bar{X}$ & $\bar{X}$ & & & & 3 \\
\hline
\end{tabular}


TABLE III

JOB DISSATISFIERS OF CLASSIFIED EMPLOYEES AS PRESENTED IN FOCUS GROUPS

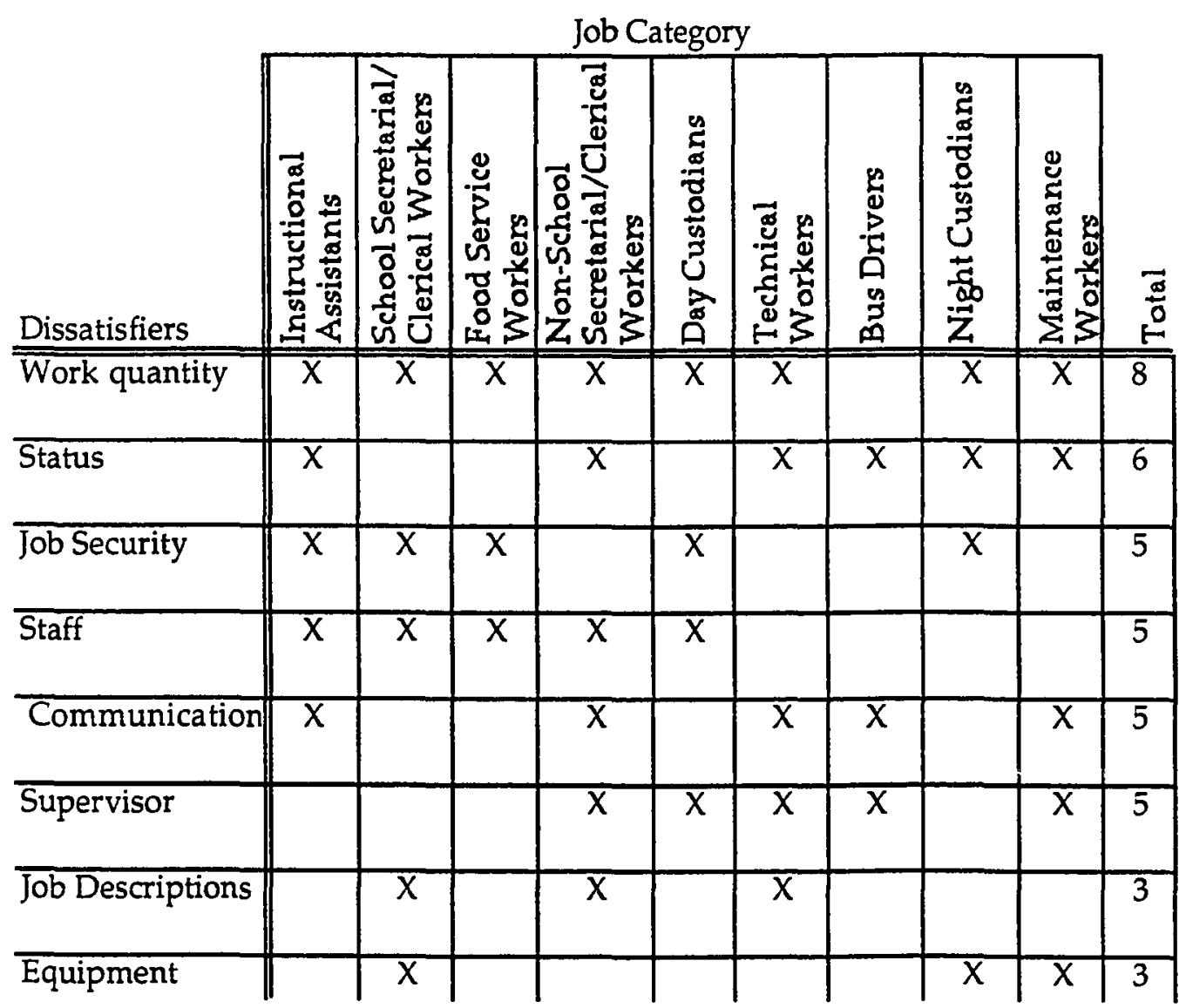


discussions, however, the term "co-workers", or "colleagues", had a different meaning for different groups.

School-based workers, specifically school secretaries, food service workers, and day custodians, spoke of co-workers as the whole school staff. To secretarial and clerical personnel, contact with teachers, administrators, and other classified employees approximates an extended family-type relationship. One secretary described her role as "very comfortable, a caring, family-oriented job." Food Service workers reiterated the family sentiment, particularly with regard to fellow workers. They find comments from appreciative staff members to be reinforcing, while "difficult staff" constitute a negative aspect of work.

For day custodians, the "positive attitude of staff" and the "personal satisfaction of working with people that care" were voiced as factors which strongly contribute to overall job satisfaction. Conversely, day custodians abhor the district's tolerance of co-workers' occasional rude behavior.

Non-school-based secretarial and clerical employees and technical workers also associate their satisfaction with co-workers with job site--in this case, immediate work setting or department. One 
technical employee, in a tone of admiration, shared, "My colleagues are good workers. They keep their chins up. They are under a lot of stress." Echoed an Administration Center secretary, "People in my areas do the best they can and work hard. I'm proud of the job they do."

The remaining employees, bus drivers, night custodians, and maintenance workers, cited colleagues as a job satisfier. However, in the context of discussions, the term clearly denoted workers in the same job category. Among bus drivers, there was general agreement that "support from fellow workers" contributes to job satisfaction. It is clear that night custodians, too, working in the absence of other employees, rely on each other for support and motivation. In identifying sources of job satisfaction, maintenance workers specifically named "crew people", as differentiated from leadmen and foremen within their department.

A second frequently cited source of job satisfaction among focus group participants, was children. Only non-school-based secretarial and clerical personnel and technical workers did not include contact with students on their lists of job "likes." In the case of night custodians, who topped their list of "dislikes" with "disrespect from kids", 
that disrespect was attributed not to the students, but to the staff who "sets the tone", or models, that disrespect. Bus drivers acknowledged, too, that children can be a source of noise, and consequent frustration, but ultimately credit administrators for failing to standardize expectations for students' bus riding behavior.

Those employees who, by nature of their work and work setting, have the most direct contact with students, reportedly derive the greatest satisfaction from them. Instructional assistants, for example, in recalling the happiest moments in their jobs listed: "When you see that kids know you care about them", "When a child realizes he is actually grasping a subject", and "When they come back and are working and doing well and want to share it with us."

For school secretarial and clerical workers, "student contact" topped the list of job satisfiers. In fact, for several of these employees, the "connection to kids" was a reason for initially having chosen the position.

Similarly, when day custodians were asked, "When you talk with your friends about your job, what do you tell them with pride?", all participants agreed that interaction with children ranked highest, along with building cleanliness. Among food service workers, 
"pleasing students" was valued as highly as the "nature of the work" in the context of job satisfiers.

A third area of job satisfaction for seven out of nine employee groups was recognition. Instructional assistants seemed fairly satisfied with the recognition they are receiving, with the exception of Classified Employees' Week, which they called a "joke." They prefer periodic personal recognition to, what they considered, an insincere composite "thank you" to all classified personnel. Participants stressed a desire for "genuine" recognition; they value a personal written or spoken thanks from teachers or administrators specific to their performance. Compounding the issue of recognition for instructional assistants is the feeling of being "not part of the staff, not part of the decision-making group." For example, staff meetings are often held at a time when aides are not working. Generally, they feel the presence of "too many bosses"--at the bottom of the totem pole.

School secretaries feel recognized and appreciated by administrators and parents, and less by staff, according to this group. One participant observed: the more public the position, the more recognition received. "I like hearing, 'What would we do without you?'", shared one member. Expression toward 
Classified Employees' Week was mixed. Though generally favorable, several employees said they were uncomfortable with a structured week of attention. Non-school-based secretarial and clerical employees are receiving some recognition from within their assigned departments. They would appreciate recognition from schools since they feel they are instrumental in the functioning of the district. When asked what one action could be taken to improve district operations, one secretary requested that importance be placed on the individual contributions of each employee. Classified Employees' Week is not important to this group. They prefer more thanks on a consistent, less structured basis.

Two-thirds of the day custodians favored Classified Employees' Week, saying there "needs to be more of it." Several employees, however, received no recognition during the scheduled event. For them, "it dian't exist" except for a doughnut and cup of coffee. These custodians appreciate praise from community visitors and employees from other districts. Elementary personnel value thank you's from children while employees at the intermediate level feel harassment from students in the form of disrespectful behavior and insulting remarks. All agreed that custodians should be included in school yearbooks. 
Presently they are excluded, at least on the high school level. In response to an inquiry on improving the district, one employee offered "recognize excellence more in all classifications."

Each participant in the technical services group could identify at least one individual who recognizes his/her work. There was agreement reijarding a lack of recognition, and noncompensation, for overtime work. These employees want credit for their work, honest compliments, and more feedback on projects. Iike instructional assistants, they stated a preference for personal thanks or a written note of praise. In answer to a question on the value of Classified Employees' Week, one respondent said, it "almost offends me." The general feeling was that, in schools, the event may serve a positive purpose. However, in an office setting, the activity only functions to further accentuate the difference between certified and classified employees--a distinction this group would rather minimize.

Bus drivers agreed that the degree of personal recognition seems to vary by the schools they serve. Generally, the bigger the school, the less contact with staff. At the elementary level, most recognition comes from parents. These employees want more recognition from their department administrators. They would also 
value the presence of a school administrator outside of the building as buses arrive or depart. One employee observed that the lack of recognition from certified staff may be linked to the issue of prestige, stating, "Teachers and principals look down and say, 'You're only the bus driver. "

Night custodians in intermediate schools feel that recognition is inconsistent. They would appreciate more from administrators. These employees, like their day-shift counterparts, experience disrespect from students. They become "go-fers" where students are allowed to give them orders. Elementary personnel feel they are receiving recognition. Classified Employees' Week was termed a "token", and "empty recognition." These participants shared several insights into the need of the night employee for recognition: (a) the work can be lonely and boring with little personal interaction; (b) they also serve as security personnel; and, (c) since others don't see the night custodian working, they don't realize the extent of his/her work. This group suggested that one avenue for recognition would be to give preference to night workers when day-shift jobs open.

Neither food service workers nor maintenance personnel listed recognition as a satisfier. Food service workers cited "being taken for granted", or 
absence of recognition, as a dislike. When questioned further, they agreed that recognition, in the form of verbal thanks, is coming from staff and students. The district's current consideration of privitization of food management appears to factor in the omission of recognition as a present source of job satisfaction. Food service workers, as represented, unanimously favored Classified Employees' Week.

Focus group participants representing maintenance voiced dissatisfaction with a "lack of recognition for what we know." The source of recognition seems to be an issue for these employees. While all participants felt that they get some recognition from school administrators and teachers, none felt recognized by their direct supervisors. Asserted one employee, "there are too many unqualified people making decisions" about our work. Regarding Classified Employees' Week, this group expressed neutrality explaining that they could not participate because they have no time off work.

Other job satisfiers (as presented in Table II) listed by at least four of the nine employee groups include: daily schedule of work, worthwhile work for work itself), autonomy, and salary and benefits. These will be discussed at length in the next section. 
Job Dissatisfiers: The two most frequently identified job dissatisfiers for classified employees, as cited by focus group participants, are work overload and job status. Of the nine groups, eight listed workload as a dislike. Bus drivers did not express dissatisfaction with work quantity.

One instructional assistant shared, "I feel overloaded--my work, office work, discipline!" The group agreed that there are not enough hours assigned to produce the work expected. The perceived presence of "too many bosses" results in an overload of work coming from a multiplicity of directions. When assistants do work overtime, they are not monetarily compensated; the constant need to catch up precludes the option of realizing compensatory time off work.

This sentiment was expressed by school secretarial/clerical workers as well. Compounding the frustration are the deadiines, and consequent last minute rushes, inherent in their work. Secretaries suggested that either more hours be alloted to present employees or more help be hired to alleviate the pressure.

Deadines are also an issue for non-school secretarial employees but in a slightly different context. These workers identified two related complaints. First, there appears to be inequity in 
workload related to position. That is, some clerical personnel occupy roles that consistently demand more output than other roles. Secondly, they described the uneven flow of work, characteristic of their positions. Secretaries are either consistently overworked or subject to the extremes of slow-paced work and periods of unrealistic demand.

Like secretaries, day custodians identified "excessive amount of work at certain times of the year" as a dissatisfier. This is exacerbated, in custodians' eyes, by the charge that "administrators have never done these jobs and don't know how long it takes." According to focus group participants, custodians are regularly delegated responsibilities extraneous to their job descriptions. For example, with cuts in food service hours (aimed at producing a more cost efficient program), "the custodian does a lot of work for the cooks." One custodian shared, "We have to do things like wipe tables that food service should be paying for."

Additional responsibilities appear to stem from teachers' creativity: "The teachers come up with these great programs--recycling, tree planting. They run it about a week and then the custodians get stuck with it." Custodians view staff as often insensitive to their time limitations. 
Participants summarized the custodial workload perspective in answer to the inquiry, "If there were anything that could be changed to make the job perfect for you, what would you change?". The response: Hire more crew people and get us out of cafeteria duty.

Food service workers directly experience the impact of staff cuts. "Sometimes", said one, "you feel you just can't get everything done because they have cut your staff." A major frustration of cutting staff is the unchanged amount of required work. It appears that food service employees have felt the pressure of work quantity as a result of the reduction in employee hours and/or personnel.

Dissatisfaction with workload, in the opinion of night custodians, is attributable to the discrepancy in expectations among school administrators, custodial services, and the custodial crew. Each group prioritizes the custodial job in a different manner, resulting in "three views on priorities" and, consequently, an "unrealistic workload."

Technical services employees confessed a feeling of being used by their supervisors. As stated, "When they get a person willing to give more, the district will take and take." Confirmed another, "Extra time and effort are expected once you give." The work of technical employees is characteristically segmented 
into projects. Job satisfaction, in part, is derived from project completion. However, the participants shared, as new work is delegated, projects overlap and workers feel ineffective. When the interviewer queried, "Could you tell me about a time when you felt exceptionally bad about your job?", one employee replied, "The most frustrating thing is when I have been working 10 or 11 hours a day and, come Friday afternoon, someone comes with a brand new project."

For maintenance workers, the dissatisfaction of work overload relates to a perceived lack of communication: "There's no continuity anywhere" and "Nobody seems to know or give a damn." Maintenance employees observe waste of materials and personnel and attribute it to inefficient management. While they feel the department is understaffed, the reported lack of crewpeople may be due to a "Do it and don't question it mentality" as much as to an excess of work.

The second most frequently cited source of job dissatisfaction is job status. Day custodians and food service workers were the only groups who did not list status among dislikes. As a measure of status, all participants in each focus group were individually asked to rate the prestige of their respective position on a scale from one to five, with one being low prestige (Table IV). The numerical average ranking for 
five of the focus groups was approximately four. The extreme exceptions were night custodians and bus drivers, who rated their job prestige (in the eyes of others) as two. Several groups chose to differentiate the rating by supposed rater. Namely, the prestige score was seen to vary considerably in the varying perspectives of administrators, school staffs, parents, and the community. Generally, classified employees view their own job status higher than their perception of how others view them. For example, food service employees rated their own job status as four, qualifying their response with the assertion that staff and others would rank it a three. While the question, "Do you feel like a second-class citizen?", drew a unanimous "no" from food workers, they listed "being taken for granted" as a dislike.

For classified employees, the rubric of job status translates to the unpopular, but existing, distinction between classified and certified employees. That distinction was acknowledged, discussed, and most vocally denounced by three groups: technical workers, instructional assistants, and those secretarial and clerical employees who are not based in schools.

Technical services personnel are dissatisfied with what they term "a caste system" for district employees. One avowed, "There are two groups, classified and 
certified. If you are classified, you are second-class citizens." Another worker, with the district for two years, shared, "I have been fortunate to deal with some very kind administrators in the buildings. They have been very kind and open and have treated me well, not as an equal." The qualification "not as an equal" appears to support this group's concern.

That perceived inequality of treatment is a frustration to these technical workers, who often have managerial responsibility and autonomy, unique among classified workers. "I am managing people in programs", observed a technical employee, "and my boss has been in my office twice in two years." Added a colleague, "I am not aware of having a boss." The implication, inferred from the subsequent discussion, was that, if individuals in this category of classified employees have managerial responsibility, and independence with limited performance evaluation, why, then, are they treated differently.

Treatment of instructional assistants appears to vary among supervisors. Six of the ten focus group participants agreed that they feel like second class citizens; four feel treated as equals. They all want to be included on the school's staff "team" and involved in decision-making. A symptom of the unwanted distinction among employees was cited. Even after many 
years with the school district, aides list job security as a dissatisfier. When released in June of each year, employees receive no assurance of placement in the fall: "You never know if you have a job until September." They also question the weight of their stated preferences in assigned job hours and location. The third job category to strongly state distaste for the classified employee distinction was non-school secretarial and clerical employees. One employee visually described, "There's a wall between classified and certified areas." That wall, in her view, impedes necessary and efficient communication in the district's Administration Center. Another secretary observed, "As long as you're a certified employee, you can have whatever you want. If you're classified, you're dirt." Such sentiment was indirectly expressed by school-based secretaries in numerically rating their job prestige as as "three" (compared with non-school secretaries" ranking of "four"). The school-based workers, however, voiced no dissatisfaction with treatment.

Clerical employees, in non-school settings, note the seeming discrimination among workers from the beginning of their tenure. Reflected a relatively recently hired employee, "When I first came here, it was a shock....I did feel I was looked down at." 
Other job dissatisfiers for classified employees, meriting comment by five of the nine focus groups, are job security, staff incompetence, communication, and supervisors. Where they constitute major issues for a job category, these topics will be included in the following section.

Issues Specific to Job Category. The preceding section focused on those job satisfiers and dissatisfiers that most often recurred across focus group discussions. The commonalities provide insight into the sentiment and views of classified employees, as a group. This portion serves to delineate the specific likes and dislikes of employees by job category and to highlight issues that merited lengthier discussion within each group.

Instructional Assistants: Job satisfiers mentioned consistently in this focus group include: students, autonomy, daily work schedule, and being a team member. The factors of working with children and schedule also influenced original selection of the position in several cases. When asked, "Can you describe in detail when you feel exceptionally good about your job?", one participant offered, "When a child realizes they [sic] are actually grasping a subject." "I feel good about the special ed kids when 
they come back and are working and doing heil and want to share it with us", another answered.

Most instructional assistants listed only one or two dislikes, when asked to note three of each. Those dissatisfiers include: job security, lack of training, status of not belonging, and work overload. The issue of security was summarized by one participant, "You never know if you have a job until september." To further complicate the issue, instructional assistants receive no guarantee of full-time employment. These employees regard hourly assignment decisions as "mired in the pay scale." They observe that the district appears to prefer hiring two half-time employees in place of one full-time, to avoid paying full benefits.

The request for specific training relates not only to instructional content. Focus group members also mentioned a need for workshops in behavior management and conflict resolution ("how to handle a troublesome situation").

Status concerns were discussed in detail in the previous section. While "being a team member" was highlighted by four employees in this group as a satisfier, three others described the absence of team sentiment as a job dislike. Six out of ten agreed that they feel like second-class citizens. These employees complain of "too many bosses", clarifying the standing 
of instructional assistants as, "Everyone in the building is over you." Queried one, "Who do I take orders from?" The perception of being overseen by many supervisors may also relate to the dissatisfier of work overload in that multiple bosses means multiple work assignments.

Another major issue discussed at length by instructional assistants can be categorized as dissatisfaction with district personnel policies. Discussion was spurred by the question, "Do you wish you were receiving more information?" Employees want access to specific job descriptions as openings are posted. They want equal access to jobs in practice. Expressed one:

When a job is posted and you apply, you are told the administrators go over all the applications. I know that isn't true because I have been told that the job was already given to someone else before the posting went out.

In addition, this group requests a "clear policy on hiring and firing classified employees." They also feel overlooked in the evaluation process; four participants disclosed that their administrators "never got around to it." They feel that the standard evaluation form is not appropriate to the role of instructional assistants. 
Other areas which merit the further attention of district management include: maternity leave, child care, recycling, vocational education, and an alternative education program. These topics were itemized as needs, primarily in response to the inquiry, "What other issues/questions had you hoped to address today?"

School-based Secretarial and Clerical Employees: The school secretaries' focus group unanimously named "appreciation" as their primary job satisfier. Other repeated responses include: personal contact with students, staff, and the community, professional growth opportunities, work variety, and availability of administrators. These employees seem to enjoy the visibility of their positions and the opportunity to assist people. Their favorite form of recognition was phrased by one participant: "When a teacher comes in and says, 'You are so organized.'" Secretarial employees reportedly take pride in their efficiency.

In response to the question, "What could be changed to make this the perfect job for you?", employees agreed that salary and job security are major areas of dissatisfaction. One participant, echoing a response of instructional assistants, stated, "All clerical employees are out of a job at the end of the school year....knowing that you will be rehired would 
be helpful." The other dissatisfier, which merited considerable support, was the need for practical first aid training in the absence of site-based school nurses. Other issues included unequal hiring practices, inaccurate job descriptions, outdated equipment, and lack of involvement in decision-making. Food Service Workers: In discussion, food service employees, unlike other focus group participants, focused almost exclusively on the issue of job security. As mentioned, the district was considering privatization of food services at the time of this study .

These workers voiced satisfaction with their work, colleagues, staff, and the work schedule. They particularly delight in pleasing students with their lunches. With unanimous support, one cook summarized, "We love the kids. We love the job. We love what we're doing."

What food service employees do not love is the present uncertainty of their positions, including staff cuts and feeling taken for granted. They feel that, should the district choose to contract privately for lunch service, their jobs would be jeopardized. Characteristic of the voiced concerns was: "There are quite a few people nearing retirement. What will happen to them if more changes are made?" 
Unlike other classified employees, food workers do not feel like second-class citizens. They rank the prestige of their positions high, adding that staff and others would rate it lower, as a three on the one to five scale.

Non-school Secretarial and Clerical Employees: These employees derive job satisfaction, in part, from their immediate supervisors. Five of seven participants praised their supervisors as "wonderful" and supportive. Co-workers was another listed satisfier. Shared one secretary, "There's satisfaction when we all work together to share the burden." In response to the question, "When you talk with your friends about your job, what do you tell them with pride?", a participant answered, "Cooperation with people within the office; the interaction between people." The only other factors listed as "likes" by more than one individual were independence, fast-paced stimulating work, and educational opportunities.

The list of "dislikes" for these secretarial and clerical employees was long and diverse, relative to other groups. It ranged from "lack of software compatibility" to office noise level to misuse of time by employees. Like school secretaries, food service workers, and technical employees, office-based secretaries also feel disillusioned by certain 
personnel practices. In this case, one employee voiced dissatisfaction with the internal process of filling vacancies, asserting, "You know that they've already chosen the person to fill the job before they were ever posted, so why should you bother to apply for it?" Based on discussion content across all focus group questions, the major issues appear to be inconsistent communication, "walls" between classified and certified employees, inadequate recognition, overwork due to understaffing, and nonparticipation in decision-making. one employee suggested regular meetings as a vehicle for resolution of frustrations, stating, "There isn't any place to go to complain.... If you're not certified, there's no place to go."

Day Custodians: In the context of job satisfiers, day custodians value interaction with students, staff and the community, praise, working with people who care, salary and benefits, and the positive attitude of school staffs. They are proud to interact with children and to provide clean, well-maintained buildings. One custodian shared his pleasure "dealing with personnel who will work with and for me, understanding that we are all in it together." overall, participants in this focus group portrayed their role as one necessary component in supporting the education of children. 
Issues constituting dissatisfiers for day custodians include job security, overwork, insensitive administrators, waste, intradepartmental communication, and personnel procedures. Specifically, these employees have been affected both psychologically and in daily workload by the reduction of food services staff. They question the permanence of their own positions while assuming cafeteria jobs (washing tables, supervising students, and dispensing milk) for their food service colleagues, especially at the elementary level.

All participants agreed with the individual who, in discussing the cooks' dilemma, observed, "They don't feel secure and that makes us feel insecure about our jobs." Another perspective on security arose in the context of the classified label: "Teachers are hard to replace; classified are down the road fast."

Custodians complain that administrators do not understand custodial work and, consequently, may hold unreasonable expectations regarding the process or timeline of particular jobs. Shared one custodian, "Some administrators don't talk to you--you are just low life to them." This lack of communication may be a factor, according to this group, in the inadequate evaluation process which employees labeled "a big joke." 
More communication needs to occur, say these employees, within schools, with custodial services, and with the maintenance department. They attribute the problem to the bureaucratic nature of a large school district. Voiced one, in regard to district administrators, "I really feel like we are in Oregon and they are back in Washington, D.C.." This group suggests that a newsletter be developed to announce decisions and policy changes which affect their role.

Technical Employees: Technical workers, as represented in the focus group, all listed co-workers as a job satisfier. One participant described her colleagues in this way: "They keep their chins up. They are under a lot of stress. They understand the purpose of the work they do."

Half of the group also listed project completion and service to people as satisfiers. The absence of time to complete work reappeared as a dissatisfier. A technical employee explained, "My job is so fragmented .... n never have the feeling I have completed anything."

Like school secretaries, these employees derive job satisfaction from helping others, both within the district and in response to public requests. "I feel good about my job", asserted a participant, "because I 
do help a lot of people--people under stress, administrators."

In discussion, these employees agreed that they are proud to work for a school district with a good reputation. By the nature of their positions, technical employees enjoy a degree of independence not mentioned by other classified groups. This valued autonomy was defined: "I am trusted and left on my own to see things that need to be done, to get them done, and to ask questions if I need to."

The flipside of autonomy appears to be the dissatisfaction of job isolation. One employee explained, "We are an entity unto ourselves. We don't belong to any division.... I was hurt when I was told I 'didn't belong anywhere.'" As discussed in the overview of classified employees' sentiments, technical workers experience frustration with work overload and the overlapping of projects and deadlines.

This focus group offered several suggestions which might serve to alleviate the weight of job dissatisfiers. One employee suggested that the district's top administrators rename positions; "classified" should be eliminated, allowing for only two personnel distinctions, "administrators" and "support staff." Employees would still be identified by position, but the additional levels of "certified" 
and "classified"--which serve no functional purpose, according to classfied workers--would be dropped.

Other suggestions for improved employee relations included awards for employees' innovative suggestions and departmental employee boards. The first idea relates to the waste of materials and manpower some employees witness throughout the district along with the recognition of employees as management resources. It was suggested that cash awards be given for recommendations utilized in saving district resources. One participant pointed out that such incentive programs are used in private industry. Another technical worker offered this rationale, "It gives people the idea to create, share, and get a little credit for it...instead of griping about something."

The last idea is to post photographs of employees by department, particularly in the Adminstration Center, to allow individuals to establish "face familiarity as well as name familiarity" with their fellow workers. In support of the idea, one technical worker confessed that, after two years of employment in the administrative offices, she still was not sure she could recognize the superintendent.

Bus Drivers: The atmosphere of this focus group was somewhat different than the rest; the participants knew one another, held similar views, and joked among 
themselves throughout the session. At times, their responses, though justified and usually seriously intended, were shared with humor and lightheartedness. For example, when asked what they like about their job, one bus driver asserted, "We get to sit down while we work."

Among job satisfiers receiving majority support were: benefits and salary, colleagues, students, and recognition. Participants also voiced satisfaction with the yearly schedule, autonomy, and training on in-service days. In response to the query, "Can you describe in detail when you feel exceptionally good about your job?", one driver answered, "When I got my first paycheck."

From discussion analysis, it appears that bus drivers, though appreciative of the recognition they receive, feel they deserve more. Drivers of special education buses receive more appreciation from parents. All drivers, as represented here, request more interaction with school principals: "I would like to know the principals better. They take it for granted that the bus will be there." Another employee asked that principals make the effort to visit with drivers, at least occasionally, between bus runs. According to drivers, larger schools maintain less contact with them. As summarized by one driver, "What 
you mostly like is contact with the schools and an awareness that you're participating in the educational process."

In the context of co-worker support, the question, "How important is it for you to socialize with your colleagues?", drew a unanimous, "Very important!" One driver added, "You get awfully tired of talking to those six-year-olds." Uncharacteristic of other classified employees, bus drivers spoke with pleasure of weekly breakfasts together, bowling, skiing, pinochle, and daily conversational time. They describe their colleagues as "helping", "caring", and "doing their jobs well." "We're a big family", they offered. on the subject of job dissatisfiers, drivers emphasized lack of communication with, and within, the Transportation Department and various ramifications of "office confusion." With characteristic humor, when asked to list job "dislikes," one participant included, "I hate driving."

According to these representative bus drivers, "Communication dies someplace after it gets to the Transportation Center." They cite lost invitations to classified appreciation events and emergency messages from spouses. "There are too many people in the office and jobs not specifically defined." Reworded another, "Too many chiefs, not enough Indians." The lack of 
communication and disorganization, employees report, is responsible for bus overcrowding, out-of-date route sheets, and slow response to problems. When asked, "What is management doing that is right?", one driver declared, "Management is not visible, so there's no way to measure."

Other issues of concern relate to morale, job prestige, security, and student discipline. Throughout the discussion, participants referred to derogatory job-related remarks from district employees and others, such as, "You're only the bus driver", or "You don't look like a busdriver." When asked to rate the prestige of their job on a scale of one to five lone being low), the average was two (Table IV).

Along with night custodians, who also averaged a two, this was the lowest among classified employee groups. Highest prestige was ranked, as a four, by non-school secretaries, day custodians, and technical workers. Low morale among bus drivers is reportedly attributable to two factors, dissatisfaction with the department's leadership and the low prestige of their job, as they perceive that others would rate it. Like cooks and custodians, bus drivers feel threatened by the proposed privatization of food services. When asked if they feel secure in their positions, drivers expressed concern over the 
TABLE IV

SELF-REPORTED LEVEL OF JOB PRESTIGE OF CLASSIFIED EMPLOYEES IN FOCUS GROUPS

\begin{tabular}{|c|c|}
\hline Job Category & |*Level \\
\hline Non-School Secretarial/Clerical Workers & 4.0 \\
\hline Day Custodians & 4.0 \\
\hline Technical Workers & 4.0 \\
\hline Maintenance Workers & 3.8 \\
\hline Instructional Assistants & 3.7 \\
\hline School Secretarial/Clerical Workers & 3.0 \\
\hline Food Service Workers & 3.0 \\
\hline Bus Drivers & 2.0 \\
\hline Night Custodians & 2.0 \\
\hline
\end{tabular}

*measured on a scale of one to five, where one is low 
possibility of contracting private transportation services.

Finally, in the area of student discipline, drivers request support from principals in developing a consistent district policy for student bus conduct. They recognize a discrepancy not only between schools, but within one school's student population, depending upon the clout of the parent. Referring to the son of a Parent-Teacher Club president, one driver related, "He'd practically have to set fire to the bus before something happened."

Night Custodians: Night custodians derive satisfaction from their co-workers, the challenge of their work, accomplishment, and their contribution to education. Based on the discussion with these employees, many of their satisfying moments on the job are short-lived. For example, participants cited evening events as a setting where "you feel like a host." In addition, the concentration of summer work allows them to create "perfect" buildings in August, but the perfection "doesn't last long." As relatively isolated workers, night custodians wish for more opportunities to socialize with co-workers. They formally visit with their colleagues approximately three times each year. They particularly appreciate 
the employment benefits which accompany their salary, such as medical and dental insurance. It appears that night custodians have some issues in common with other employee groups. However, they have other concerns, job dissatisfiers, associated specifically with working the night shift. For example, they experience frustration with vandalism, an unrealistic workload, and involvement in non-custodial duties, like their day-shift counterparts. Night custodians recognize a lack of necessary equipment like the school secretarial and clerical workers' group. They feel insecure about their jobs like food service workers, bus drivers, day custodians, instructional assistants, and school secretaries. In fact, the "cooks' issue" has "hurt morale worse than budget problems."

The differences in sources of job dissatisfaction, in particular, seem to relate to perceived disrespect from students and those who use school facilities for evening events, and a lack of self-esteem which, according to the custodians, is rooted in society's view of "janitors."

While these employees personally feel that they are making a contribution to education, they acknowledge that they are treated as "go-fers" by intermediate students who deliver orders to them. 
Night custodians feel that "some teachers don't seem to care" about the disrespect and "don't set a tone for the kids." Disrespect from students topped their list of "dislikes."

According to this representative group, most night custodians would welcome day-shift jobs and prefer elementary school placement to the intermediate or high school levels. Participants listed the personal disadvantages of night work as: (a) we can't participate in night activities, (b) we never see our own children, and (c) we don't see our wives.

They find it "very disturbing" when day custodians are hired outside of the school district. These workers request more information and training opportunities to better prepare themselves for day job openings.

Maintenance Workers: Personnel representing maintenance identified primary job satisfiers as benefits, crew people, students, and pay. They were alone among classified groups in highlighting working conditions as an additional source of satisfaction.

The tone of this discussion was relatively negative with a greater focus on job dissatisfiers. These employees arrived at their meeting with specific grievances to share. Even when asked to identify sources of job pride, one employee responded, "Doing a 
good job", with the added qualifier, "if we're allowed to."

The high level of frustration expressed by maintenance workers centered on lack of communication between crews and with supervisors. They agreed that a "Do it and don't question it" mentality pervades their department. "Nobody seems to know or give a damn", shared one participant. "Feedback is not wanted by anyone above us", added another. "There's no continuity anywhere", said a crewman, explaining that each building has its own maintenance policy.

Participants confirmed that employees fear sharing their views. Referring to the boundary between supervisors and crewmen, a worker cautioned, "You don't walk across that line", adding, there's a "closed door policy." Maintenance personnel observe that over the last four to five years "attitudes have gone down." One detrimental result of this noncommunicative atmosphere, in addition to poor morale, is tremendous waste of personnel and materials, according to these maintenance representatives. "Education people" are making facilities decisions; the Athietic Director is making playing field decisions. "Crewmen are told 'Go do it"", while they may be best qualified to do the preliminary decision-making. Associated with the lack of decision-making power maintenance workers are 
experiencing, they cite "lack of recognition for our knowledge" as a dissatisfier.

Unlike their classified colleagues in other positions, maintenance workers do not identify job security as an issue. When asked, "What would make this the perfect job for you?", participants unanimously reiterated communication and the opportunity to participate in decisions.

Summary of Focus Group Results

The job satisfiers listed by more than half of the focus groups include: co-workers, recognition, kids, autonomy, salary and benefits, daily schedule, and work itself. Some additional aspects of job satisfaction differ according to specific job category.

Factors of work identified as job dissatisfiers by more than half of the focus groups include: work quantity, job status, security, incompetent co-workers, communication, and supervisors. Again, additional factors constituting dissatisfiers varied across focus groups by school district position.

As a supplementary measure of job satisfaction, in each focus group participants were asked to rate their present level of job satisfaction on a scale from one to five, with one being low. The quantitative results are presented, as group averages, in Table $\mathrm{V}$. 
TABLE V

SELF-REPORTED LEVEL OF JOB SATISFACTION OF CLASSIFIED EMPLOYEES IN FOCUS GROUPS

\begin{tabular}{l||r} 
Job Category & *Level \\
\hline \hline & \\
Day Custodians & 4.8 \\
Food Service Workers & 4.8 \\
Maintenance Workers & 4.3 \\
Instructional Assistants & 4.2 \\
School Secretarial/Clerical Workers & 3.8 \\
Bus Drivers & 3.8 \\
Non-School Secretarial/Clerical Workers & 3.7 \\
Night Custodians & 3.5 \\
Technical Workers & 3.4 \\
&
\end{tabular}

*measured on a scale of one to five, where one is low 
According to this single measure, day custodians and food service workers appear to be very satisfied with their jobs. At the opposite end of the ranking are technical workers and night custodians, who still rate themselves well above the midpoint on the satisfaction spectrum.

\section{QUESTIONNAIRE}

\section{Description of Questionnaire Respondents}

of the 630 questionnaires mailed, a total of 490 usable forms were returned for a response rate of $78 \%$. According to Babbie (1973), a return of 508 is "adequate," 608 is "good," and 708 is "very good." The return represents 488 of the total classified employee population.

The percentage of representation in this study by job category is presented in Table VI. The representation of each job category compared with the total population for each group at the time of this study ranged from 328 for custodians to 778 for technical employees. The category of technical workers includes: computer programmers and analysts, engineers, Risk Management Specialist, Transportation Safety officer, and other diverse positions. As discussed earlier, every technical worker received a questionnaire to guarantee a statistically analyzable 
TABLE VI

PROFILE OF QUESTIONNAIRE RESPONDENTS BY JOB CATEGORY

\begin{tabular}{|c|c|c|c|c|}
\hline Job Category & \#mailed & \#returned & \%returned & $\begin{array}{l}\% \text { of total } \\
\text { respondents }\end{array}$ \\
\hline Instructional assistants & 106 & $\overline{93}$ & 88 & $\overline{19}$ \\
\hline $\begin{array}{l}\text { School secretarial/ } \\
\text { clerical workers }\end{array}$ & 99 & 65 & 66 & 13 \\
\hline Food service workers & 80 & 59 & 74 & 12 \\
\hline $\begin{array}{l}\text { Non-school secretarial/ } \\
\text { clerical workers }\end{array}$ & 56 & 43 & 77 & 9 \\
\hline Custodians & 69 & 49 & 71 & 10 \\
\hline Technical workers & 35 & 27 & 77 & 5 \\
\hline Bus drivers & 58 & 45 & 78 & 9 \\
\hline Maintenance workers & 45 & 37 & 82 & 8 \\
\hline $\begin{array}{l}\text { Other support service } \\
\text { workers }\end{array}$ & 82 & 72 & 88 & 15 \\
\hline Total & 630 & 490 & $\overline{78}$ & 100 \\
\hline
\end{tabular}


response number, whereas the remaining employees were randomly selected from the total population of classified personnel. The mean representation across job categories was $50 \%$. That is, in the sample total, respondents represented, on the average, approximately one-half of their respective co-workers.

The next eleven tables present the respondents' answers to questionnaire items which provide personal and demographic information, and working conditions.

of the 489 classified employees who indicated educational level, almost 738 have, at least, some college training or a university degree (Table VII). only 48 did not graduate from high school. The respondents who work full-time or more (538) slightly outnumber those who work less than 40 hours each week (478) (Table VIII). Characteristically, employees categorized as food service workers, instructional assistants, bus drivers, and secretarial and clerical personnel would be more likely to be assigned to part-time positions than employees in the remaining job categories. Nearly $14 \%$ of the respondents report that they work more than 40 hours each week. This data does not differentiate between the number of hours worked for which compensation is received and those hours worked in addition to hours 
TABLE VII

EDUCATION COMPLETED: SUMMARY OF NUMBER AND PERCENT OF QUESTIONNAIRE RESPONDENTS

\begin{tabular}{l||r|r} 
Education Completed & Number & Percent \\
\hline 1. Master's degree & 8 & 1.6 \\
2. Bachelor's degree & 70 & 14.3 \\
3. Some college training & 278 & 56.9 \\
4. High school graduation & 112 & 22.9 \\
5. Partial High School & 16 & 3.3 \\
6. Junior High School & 4 & .8 \\
7. Less than seven years of school & 1 & .2 \\
& & \\
\hline Total Respondents & 489 & 100.0
\end{tabular}

TABLE VIII

HOURS WORKED EACH WEEK FOR SCHOOL DISTRICT SUMMARY OF NUMBER AND PERCENT OF QUESTIONNAIRE RESPONDENTS

\begin{tabular}{|c|c|c|}
\hline Hours per week & ||Number & Percent \\
\hline 1. $1-19$ & 31 & 6.3 \\
\hline 2. $20-29$ & 45 & 9.2 \\
\hline 3. $30-39$ & 154 & 31.5 \\
\hline 4. $\quad 40$ & 191 & 39.1 \\
\hline 5. $>40$ & 68 & 13.9 \\
\hline Total Respond & 489 & 100.0 \\
\hline
\end{tabular}


assigned and for which no additional compensation is awarded.

Approximately 148 of the respondents have worked for this school district for less than two years (Table IX). The same number have been with the district for more than 14 years.

While 68 of of the respondent group have labored for five years or more in this district, only 428 have held the same position for that period (Table $\mathrm{X}$ ). It appears that many employees are reassigned to new district positions during their tenure. One-quarter of all classified employees represented in this study have held their present positions for less than two years. The largest group (157 individuals), in the context of the given categorical breakdown, is employees who have labored in their present positions for from two to four years.

There were five categories from which respondents could indicate their primary work setting. The "other" response in Table XI includes workers who serve as itinerants throughout the school district (like maintenance crewmen) and those in locations other the central administrative office or a school building site. Almost 408 of the classified respondents are housed in one of the 26 district elementary schools. The employee group representing intermediate settings 
TABLE IX

YEARS WORKED FOR SCHOOL DISTRICT: SUMMARY OF NUMBER AND PERCENT OF QUESTIONNAIRE RESPONDENTS

\begin{tabular}{|c|c|c|}
\hline Years worked & Number & Percent \\
\hline$<2$ & 67 & 13.7 \\
\hline 2. $2-4$ & 90 & 18.4 \\
\hline 3. $5-8$ & 107 & 21.9 \\
\hline 4. $9-14$ & 157 & 32.1 \\
\hline 5. $>14$ & 68 & 13.9 \\
\hline Total Respondents & 489 & 100.0 \\
\hline
\end{tabular}

TABLE X

YEARS IN PRESENT POSITION: SUMMARY OF NUMBER AND PERCENT OF QUESTIONNAIRE RESPONDENTS

\begin{tabular}{|c|c|c|}
\hline Years worked & Number & Percent \\
\hline 1. $<2$ & 125 & 25.6 \\
\hline 2. $2-4$ & 157 & 32.1 \\
\hline 3. $5-8$ & 100 & 20.4 \\
\hline 4. $9-14$ & 92 & 18.8 \\
\hline 5. $>14$ & 15 & 3.1 \\
\hline Total Respondents & 489 & 100.0 \\
\hline
\end{tabular}


TABLE XI

PRIMARY WORK SETTING: SUMMARY OF NUMBER AND PERCENT OF QUESTIONNAIRE RESPONDENTS

\begin{tabular}{l||r|r} 
Primary work setting & Number & Percent \\
\hline Elementary School & 189 & 38.8 \\
Intermediate School & 59 & 12.1 \\
High School & 68 & 14.0 \\
Administration Center & 62 & 12.7 \\
Other & 109 & 22.4 \\
& & \\
\hline Total Respondents & 489 & 100.0
\end{tabular}

TABLE XII

GENDER: SUMMARY OF NUMBER AND PERCENT OF QUESTIONNAIRE RESPONDENTS

\begin{tabular}{l|r|r} 
Gender & Number & Percent \\
\hline \hline 1. Female & 371 & 75.9 \\
2. Male & 118 & 24.1 \\
& & \\
\hline Total respondents & 489 & 100.0
\end{tabular}


(59 workers) is almost equal to those referent by the Administration Center (62) or high schools (68).

School employees, at the three designated levels (elementary, intermediate, and high school) combined, outnumber non-school-based employees by approximately 308 in this sample. Compared with the total classified employee population, of which 698 are school-based and 318 are non-school-based, the sample, proportionately, is slightly overrepresented by non-school employees (358).

A little more than three-fourths of the respondent group is female (Table XII). Male employees, based on a perusal of classified personnel listings, represent the majority of custodians and maintenance workers. Male workers are also dispersed, albeit to a much lesser degree, throughout most of the remaining job categories.

Eighty percent (392 respondents) report their personal status as married (Table XIII). A total of approximately 138 are widowed, divorced, or separated.

Nine out of ten questionnaire participants do not hold a second salaried position outside of the school district (Table XIV). Fifty percent report they are the primary wage earner in their household (Table XV).

The question of benefit use was tainted by the absence of a response selection for those employees who 
TABLE XIII

PERSONAL STATUS: SUMMARY OF NUMBER AND PERCENT OF QUESTIONNAIRE RESPONDENTS

\begin{tabular}{l||r|r} 
Status & Number & Percent \\
\hline \hline 1. Single & 32 & 6.5 \\
2. Married & 392 & 80.2 \\
3. Widowed & 14 & 2.9 \\
4. Divorced/Separated & 51 & 10.4 \\
\hline Total respondents & & \\
\hline
\end{tabular}

،

TABLE XIV

PAID POSITION OUTSIDE OF SCHOOL DISTRICT: SUMMARY OF NUMBER AND PERCENT OF QUESTIONNAIRE RESPONDENTS

\begin{tabular}{l||r|r} 
Other paid position & Number & Percent \\
\hline \hline 1. Yes & 47 & 9.6 \\
2. No & 443 & 90.4 \\
& & \\
\hline Total respondents & 490 & 100.0
\end{tabular}


TABLE XV

PRIMARY WAGE EARNER: SUMMARY OF NUMBER AND PERCENT OF QUESTIONNAIRE RESPONDENTS

\begin{tabular}{l|r|r} 
Primary wage earner & Number & Percent \\
\hline \hline 1. Yes & 197 & 40.3 \\
2. No & 292 & 59.7 \\
& & \\
\hline Total respondents & 489 & 100.0
\end{tabular}

TABLE XVI

BENEFIT USE: SUMMARY OF NUMBER AND PERCENT OF QUESTIONNAIRE RESPONDENTS

\begin{tabular}{l||r|r} 
Benefit user & Number & Percent \\
\hline \hline 1. Only myself & & \\
2. My spouse and I & 97 & 20.4 \\
3. Only my children & 122 & 25.7 \\
4. My family, including children & 7 & 1.5 \\
& 249 & 52.4 \\
\hline Total respondents & & \\
\hline
\end{tabular}


receive no benefits. This may explain the 15 missing or out of range cases. The $20 \%$ who selected "only myself" as a benefit user corresponds to those employees who identified themselves as single, widowed, divorced, or separated in Table XIII (Table XVI). Two-thirds of the respondents have an employed spouse (Table XVII). These figures, combined with data in Table XIII, show that, of the married classified employees in this study, 828 have employed spouses. In other terms, four out of five questionnaire participants represent two-income households.

\section{Analysis of Quantitative Data}

This study poses two research questions. The data analysis and results will be reported separately within the context of each question. Analysis is preceded by a section of descriptive data which defines job satisfiers and dissatisfiers for classified employees as a group.

Descriptive Data for the 100 Items. Frequency of responses and distribution of respondents were tabulated. The means for the dependent variables (questionnaire items 1-100) are presented in Table XVIII. Since responses were recoded in a common positive direction prior to analysis, a mean of less than 2.5 indicates agreement with the statement, or 


\section{TABLE XVII}

SPOUSE EMPLOYED: SUMMARY OF NUMBER AND PERCENT OF QUESTIONNAIRE RESPONDENTS

\begin{tabular}{l||r|r} 
Employed spouse & Number & Percent \\
\hline \hline 1. Yes & 321 & 65.6 \\
2. No & 80 & 16.4 \\
3. Not applicable & 88 & 18.0 \\
& & \\
\hline Total respondents & 489 & 100.0
\end{tabular}


TABLE XVIII

RESPONSE *MEANS FOR QUESTIONNAIRE ITEMS

\begin{tabular}{|c|c|c|c|c|c|c|c|c|c|}
\hline Item & Mean & Item & Mean & Item & Mean & Item & Mean & Item & Mear \\
\hline 1 & 2.60 & $\overline{211}$ & 2.63 & 41 & $\overline{1.90}$ & 61 & 2.82 & 81 & $\overline{1.5}$ \\
\hline 2 & 2.32 & 22 & 1.89 & 42 & 2.41 & 62 & 2.02 & 82 & 26 \\
\hline 3 & 1.86 & 23 & 2.06 & 43 & 2.05 & 63 & $2.71 \|$ & 83 & \\
\hline 4 & 1.81 & 24 & 2.72 & 44 & 3.26 & 64 & 2.19 & 84 & \\
\hline 5 & 2.27 & 25 & 2.74 & 45 & 2.12 & 65 & 2.25 & 85 & \\
\hline 6 & 2.84 & 26 & 2.65 & 46 & 2.18 & 66 & 2.16 & 86 & 3 \\
\hline 7 & 1.70 & 27 & $2.80 \|$ & 47 & 1.84 & 67| & 1.80 & 87| & \\
\hline 8 & 1.89 & 28 & $1.80 \|$ & 48 & 2.11 & 68 & 2.10 & 88 & \\
\hline 9 & 2.75 & 29 & $2.39 \mid$ & 49 & 2.20 & 69 & 2.25 & 89 & \\
\hline 10 & 2.08 & 30 & $1.85 \|$ & 50 & 2.67 & 70 & 1.87 & 90 & \\
\hline 11 & 2.59 & 31 & 2.10 & 51 & 2.79 & 71 & 2.22 & 91 & \\
\hline 12 & 3.01 & 32 & 2.64 & 52 & 2.06 & 72 & $2.51 \|$ & 92 & \\
\hline 13 & 1.83 & 33 & $1.81 \|$ & 53 & 2.12 & 73 & 1.78 & 93 & \\
\hline 14 & 2.21 & 34 & 2.14 & 54 & 2.36 & 74 & 2.14 & 94 & \\
\hline 15 & 2.40 & 35 & 1.89 & 55 & 2.07 & 75 & 2.89 & 95 & \\
\hline 16 & 1.58 & 36 & $1.81 \mid$ & 56 & 2.24 & 76 & 2.29 & 96 & \\
\hline 17 & 2.14 & 37 & 2.13 & 57 & 2.56 & 77 & $1.97 \|$ & 97| & \\
\hline 18 & 2.23 & 38 & 1.94 & 58 & 2.40 & 78 & 2.20 & 98 & \\
\hline 19 & 2.31 & 39 & 2.02 & 59 & 2.39 & 79 & 2.97 & 99 & \\
\hline 20 & 2.47 & 40 & $2.21 \|$ & 60 & 1.95 & 80 & 2.52 & 100 & \\
\hline
\end{tabular}

*after recoding in a common positive direction

( 1 = strongly agree; 4 = strongly disagree) 
satisfaction with job aspect. Conversely, a mean of greater than, or equal to, 2.5 conveys disagreement with the statement, or dissatisfaction with job aspect. The lower the mean, the stronger the agreement; the higher the mean, the stronger the disagreement. Single items eliciting the strongest agreement are presented in Table XIX. The single item evoking the highest satisfaction rating (mean $=1.58$ ) was "I am proud to work for the Beaverton School District." If these items are clustered by job aspect, it appears that job satisfiers for classified employees include supervisor, co-workers, and the work itself. Eighty-seven percent of the respondents deemed the work itself to be worthwhile. To the single item of overall job satisfaction (question 100), 828 of the sample population indicated that they are "satisfied" or "very satisfied" with their jobs.

Table XX presents individual items which constitute the major dissatisfiers for classified employees in this study. The only item eliciting disagreement or strong disagreement from well over three-quarters of the respondents was "I am highly paid." The issue of compensation reappears, in various forms, as a dissatisfier throughout the listing. The other category which emerges repeatedly is district 
TABLE XIX

QUESTIONNAIRE ITEMS OF HIGHEST SATISFACTION

\begin{tabular}{c||l|r|c}
\begin{tabular}{l|l} 
Item \\
Number
\end{tabular} & Item & $\begin{array}{c}\text { \% agree or } \\
\text { strongly } \\
\text { agree }\end{array}$ \\
\hline \hline 16 & I am proud to work for the school district. & 1.58 & 95 \\
7 & My supervisor is honest. & 1.70 & 89 \\
73 & My supervisor is friendly. & 1.78 & 89 \\
92 & I am satisfied with work itself. & 1.78 & 92 \\
67 & My co-workers are competent. & 1.80 & 94 \\
28 & My supervisor is kind. & 1.80 & 89 \\
36 & My worksite is not dark. & 1.81 & 92 \\
33 & I am allowed to work independently. & 1.81 & 91 \\
4 & My co-workers are responsible. & 1.81 & 92 \\
13 & My co-workers are cooperative. & 1.83 & 91 \\
30 & My work is worthwhile. & 1.85 & 87 \\
96 & I am satisfied with my co-workers. & 1.86 & 91 \\
77 & My work schedule is good. & 1.97 & 88
\end{tabular}

${ }^{*} 1$ = strongly agree; 4 = strongly disagree 
TABLE XX

\section{QUESTIONNAIRE ITEMS OF LOWEST SATISFACTION}

\begin{tabular}{|c|c|c|c|}
\hline $\begin{array}{l}\text { Item } \\
\text { Number }\end{array}$ & Item & ${ }^{*}$ Mean & $\begin{array}{c}\% \text { disagree } \\
\text { or strongly } \\
\text { disagree }\end{array}$ \\
\hline$\overline{44}$ & I am highly paid. & 3.26 & 87 \\
\hline 12 & There is no waste of time, money, or materials. & 3.01 & 74 \\
\hline 79 & Compensation is given for added responsibility. & 2.97 & 75 \\
\hline 75 & My salary is not less than I deserve. & 2.89 & 67 \\
\hline 27 & There is equal access to vacancies. & 2.80 & 59 \\
\hline 6 & Salary credit is given for experience. & 2.84 & 61 \\
\hline 61 & Work is not stressful. & 2.82 & 63 \\
\hline 89 & There is a good chance of promotion. & 2.81 & 64 \\
\hline 51 & I am secure about job future. & 2.79 & 59 \\
\hline 87 & Promotion is based on ability. & 2.76 & 59 \\
\hline 9 & Policies are standardized across district. & 2.75 & 56 \\
\hline 25 & I receive frequent recognition. & 2.74 & 64 \\
\hline
\end{tabular}

${ }^{*} 1$ = strongly agree; 4 = strongly disagree 
policies relative to salary, vacancies, promotion, and standard application throughout the school district. It is also worth noting that 598 of the classified population question their job security.

Factor Analysis of the 100 Items. Factor analysis resulted in a consolidated set of variables which then served as operational representatives of the original 100 variables. A summary of factor loadings is presented in Table XXI. Three individual questionnaire items were omitted because they did not load strongly with any one factor. These items (numbers 47,49 , and 52) relate to pace of work, temperature of work area, and supervisor expectations. Items 47 and 49 had already been found to be unreliable. Item 86 lovertime compensation) was a third unreliable question. Although number 100 loaded strongly with work Itself, it was removed from the factor because it was to serve as the variable for overall job satisfaction.

The resultant eight factors were designated: Supervisor, Schedule, Facilities and Equipment, Co-workers, District Policies, Benefits and Salary, Work Itself, and Work Quantity. Recognition, an additional job aspect, was addressed separately in focus group discussions. However, the seven individual questionnaire items, which could have factored as "recognition," loaded strongly with Supervisor and 
TABLE XXI

\section{ROTATED FACTOR LOADINGS AND QUESTIONNAIRE ITEMS \\ BY FACTOR}

\begin{tabular}{|c|c|c|c|c|c|}
\hline Factor & \begin{tabular}{|l} 
Item \\
Number
\end{tabular} & Loading & Factor & \begin{tabular}{|l} 
Item \\
Number
\end{tabular} & Loading \\
\hline \multirow[t]{31}{*}{ Supervisor } & $\overline{29}$ & .655 & & $\overline{2}$ & $\bar{~} .148$ \\
\hline & 65 & .638 & Policies & 90 & .714 \\
\hline & 66 & .624 & & 87 & .714 \\
\hline & 80 & .612 & & 89 & .714 \\
\hline & 30 & .576 & & 9 & .671 \\
\hline & 85 & .574 & & 27 & .601 \\
\hline & 71 & .572 & & 94 & .598 \\
\hline & 58 & .572 & & 50 & .577 \\
\hline & 72 & .572 & & 26 & .561 \\
\hline & 21 & .572 & & 12 & .495 \\
\hline & 98 & .566 & ||Benefits/Salary & 83 & .662 \\
\hline & 1 & .566 & & 86 & .662 \\
\hline & 43 & .566 & & 60 & .555 \\
\hline & 55 & .566 & & 51 & .523 \\
\hline & 41 & .566 & & 95 & .454 \\
\hline & 37 & .566 & & 99 & .454 \\
\hline & 3 & .566 & & 75 & .454 \\
\hline & 34 & .566 & & 44 & .454 \\
\hline & 7 & .566 & & 6 & .454 \\
\hline & 10 & .566 & & 63 & .454 \\
\hline & 28 & .566 & & 79 & .454 \\
\hline & 46 & .566 & ||Facilities/ & 97 & .633 \\
\hline & 73 & .566 & Equipment & 91 & .633 \\
\hline & 23 & .566 & & 14 & .633 \\
\hline & 64 & .566 & & 78 & .633 \\
\hline & 25 & .566 & & 18 & .633 \\
\hline & 32 & .566 & & 8 & .633 \\
\hline & 69 & .566 & & 76 & .633 \\
\hline & 93 & .566 & & 24 & .605 \\
\hline & 57 & .485 & & 53 & .535 \\
\hline & 11 & .463 & & 36 & .510 \\
\hline
\end{tabular}


TABLE XXI

\section{ROTATED FACTOR LOADINGS AND QUESTIONNAIRE ITEMS \\ BY FACTOR \\ (continued)}

\begin{tabular}{|c|c|c|c|c|c|}
\hline Factor & $\begin{array}{l}\text { Item } \\
\text { Number }\end{array}$ & Loading & Factor & $\begin{array}{l}\text { Item } \\
\text { Number }\end{array}$ & Loading \\
\hline Facilities/ & $\overline{15}$ & $\overline{.442}$ & Work Quantity & $\overline{\overline{54}}$ & .611 \\
\hline Equipment (cont) & 31 & .437 & (cont) & 5 & .572 \\
\hline \multirow[t]{14}{*}{ Co-workers } & 81 & .752 & Work Itself & 84 & .766 \\
\hline & 96 & .464 & & 74 & .529 \\
\hline & 13 & .464 & & 82 & .475 \\
\hline & 22 & .464 & & 88 & .475 \\
\hline & 35 & .464 & & 92 & .475 \\
\hline & 4 & .464 & & 19 & .475 \\
\hline & 62 & .464 & & 38 & .475 \\
\hline & 17 & .464 & & 40 & .475 \\
\hline & 59 & .464 & & 68 & .475 \\
\hline & 39 & .464 & & 70 & .475 \\
\hline & 48 & .464 & & 45 & .463 \\
\hline & 67 & .464 & & 16 & .459 \\
\hline & 56 & .382 & Schedule & 77 & .660 \\
\hline & 20 & .340 & & 33 & .548 \\
\hline \multirow[t]{2}{*}{ Work Quantity } & 42 & .695 & & & \\
\hline & 61 & .665 & & & \\
\hline
\end{tabular}


remained within that factor grouping during further data analysis. Figures 5, 6, and 7 are presented as samples of the distributions. Graphs of the distribution of responses for each of the eight factors reflected the full range of possible responses and relatively normal distribution curves. The distributions were not skewed; the sample population in this study can be viewed as representative of a normal distribution.

The means and standard deviations for the eight factors are exhibited in Table XXII. The highest level of satisfaction was elicited for items reflective of Work Schedule followed by Work Itself and Co-workers. The 2.71 mean assigned to District Policies indicates dissatisfaction with that job factor on the four-point scale.

Analysis of Job Satisfaction by Factors: Multiple Regression. Multiple regression was performed to determine the predictors of job satisfaction for the entire sample. Question 100 was used as an overall satisfaction score. The eight factor means were regressed with question 100 to identify the percent of variance in job satisfaction due to the named factors. Using stepwise regression, the factors of Work Itself, Supervisor, and Work Quantity together 


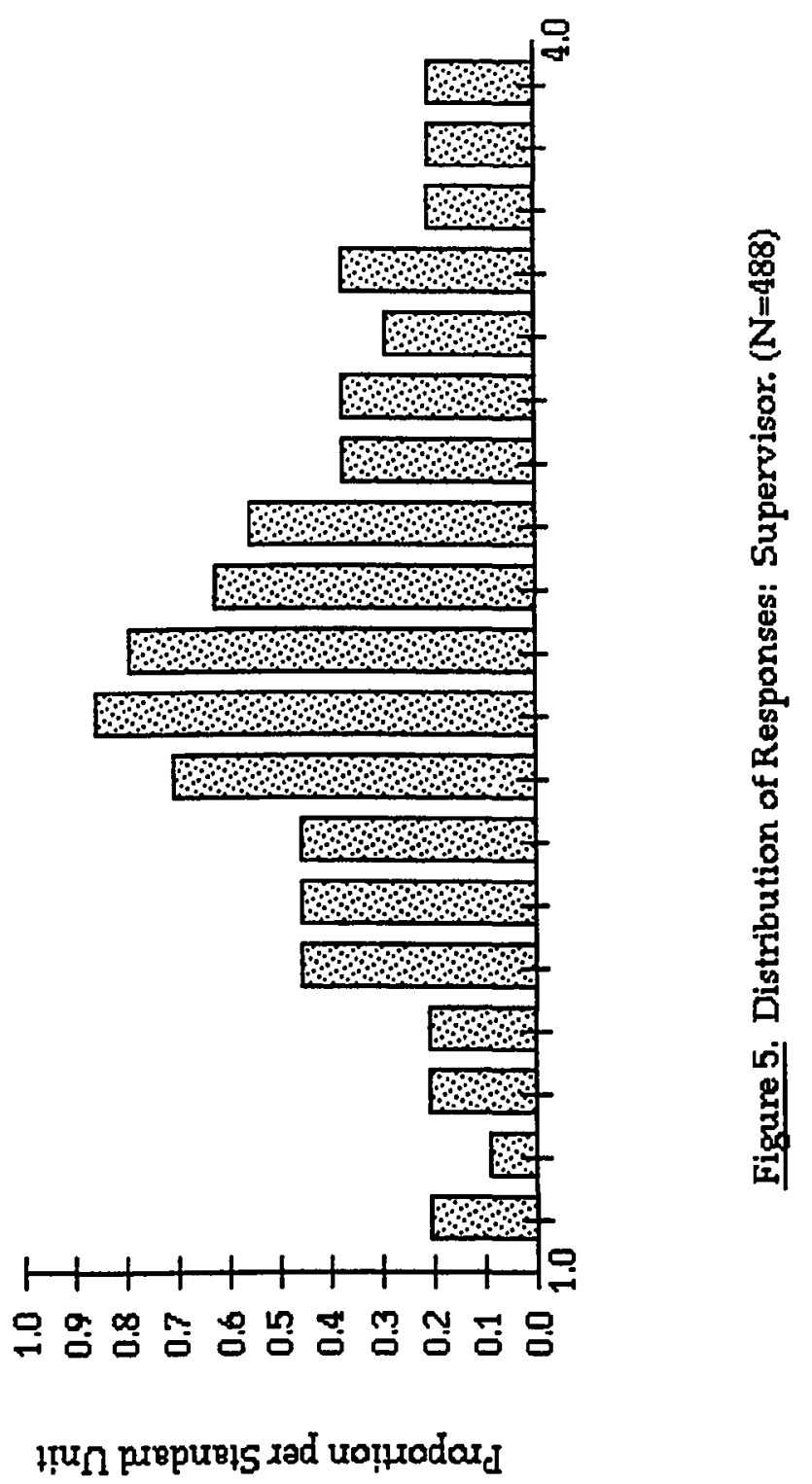




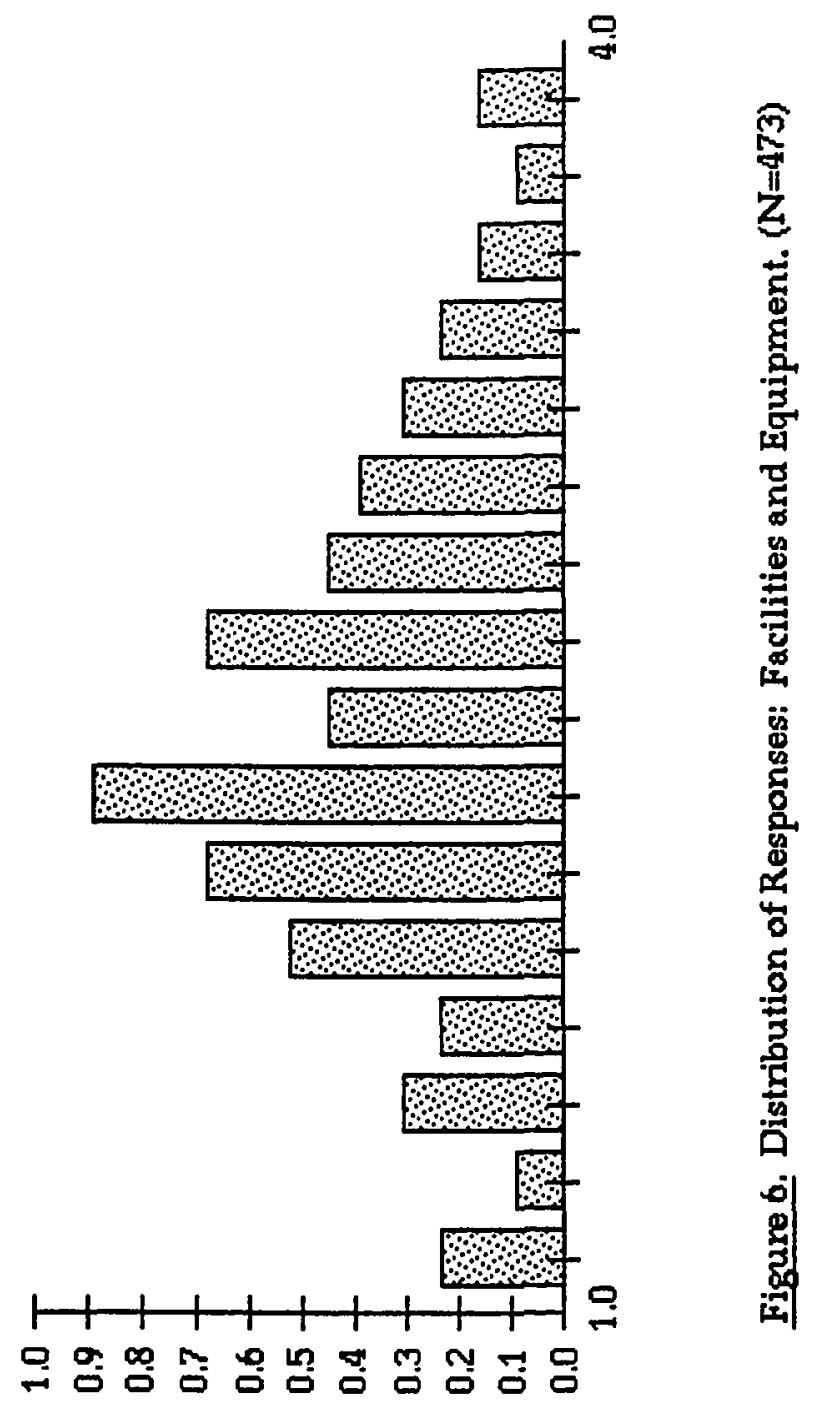

țu $\cap$ prepureis dad uotpradra d 


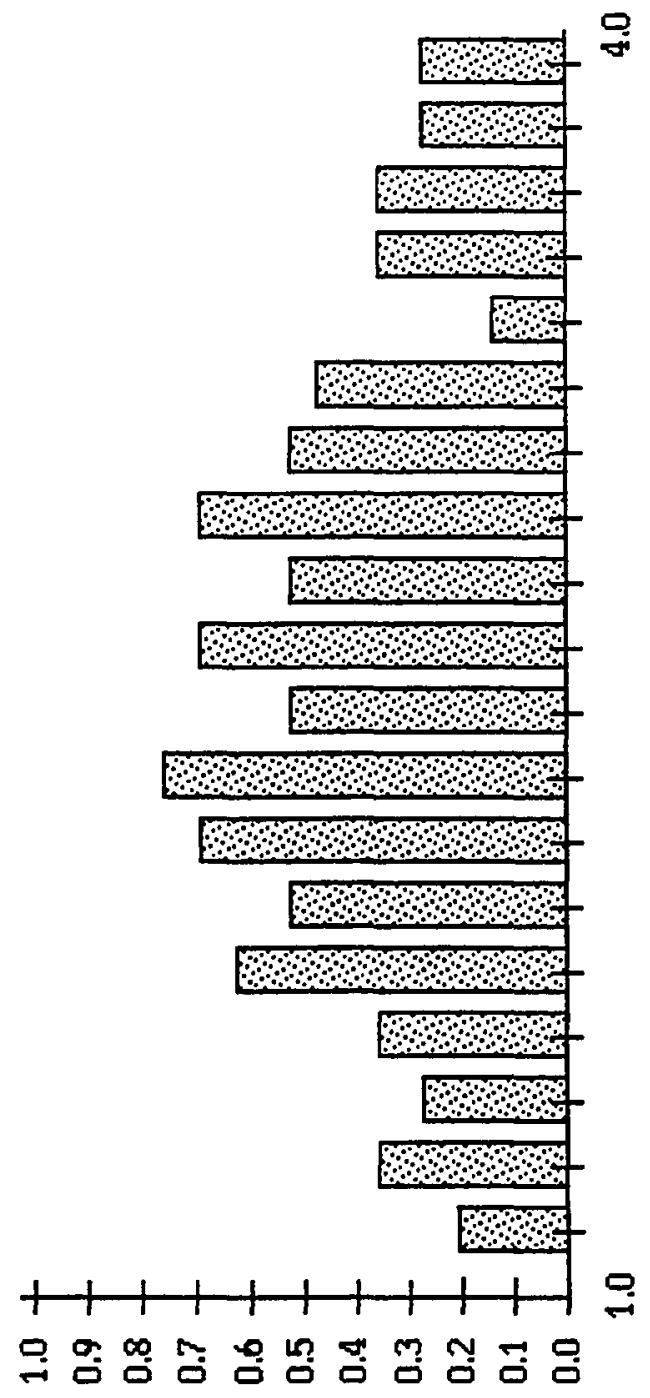

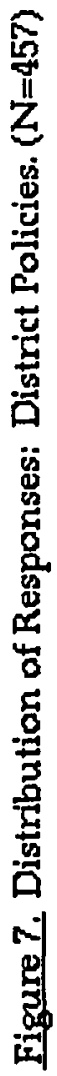
Inu prepure15 rad uoprodard 
TABLE XXII

MEANS AND STANDARD DEVIATIONS FOR

FACTORS

\begin{tabular}{l||c|c|c} 
Factor & $\mathrm{N}$ & *Mean & $\begin{array}{c}\text { Standard } \\
\text { Deviation }\end{array}$ \\
\hline \hline Schedule & 488 & 1.89 & 0.50 \\
Work Itself & 475 & 2.06 & 0.46 \\
Co-workers & 473 & 2.13 & 0.48 \\
Facilities and & & & \\
$\quad$ Equipment & 473 & 2.21 & 0.40 \\
Supervisor & 442 & 2.32 & 0.47 \\
Benefits and & & & \\
$\quad$ Salary & 458 & 2.40 & 0.47 \\
Work Quantity & 485 & 2.46 & 0.58 \\
District Policies & 457 & 2.71 & 0.52
\end{tabular}

${ }^{*} 1$ = high level of satisfaction; $4=$ high level of dissatisfaction 


\section{TABLE XXIII}

\section{MEANS AND STANDARD DEVIATIONS FOR \\ JOB ASPECTS, QUESTIONNAIRE \\ ITEMS 92 - 99}

\begin{tabular}{l||c|c|c|c} 
Job Aspect & $\begin{array}{c}\text { Questionnaire } \\
\text { Item }\end{array}$ & $\mathrm{N}$ & *Mean & $\begin{array}{c}\text { Standard } \\
\text { Deviation }\end{array}$ \\
\hline Work Itself & 92 & 488 & 1.78 & .63 \\
Co-workers & 96 & 490 & 1.86 & .62 \\
Supervisor & 93 & 490 & 1.9 & .87 \\
Facilities and & & & & \\
$\quad$ Equipment & 97 & 489 & 2.06 & .69 \\
District Policies & 94 & 489 & 2.32 & .68 \\
Job Status & 99 & 490 & 2.32 & .73 \\
Benefits and & & & & \\
$\quad$ Salary & 95 & 489 & 2.35 & .80 \\
Recognition & 98 & 490 & 2.36 & .72
\end{tabular}

*1 = "Very Satisfied"; 4 = "Very Dissatisfied" 
accounted for 508 of the variance in overall job satisfaction (Table XXIV).

Summary of Primary Sources of Job Satisfaction and Dissatisfaction for All Classified Employees. Eight job factors were identified in the factor analysis of the 100 questionnaire items. In a multiple regression analysis, the factor of Work Itself was found to account for a sizeable variance--from 19.98 for custodians to 66.58 for other support services personnel--in overall job satisfaction. Other contributing factors across job categories included Schedule, Co-workers, Supervisor, Benefits and Salary, and Work Quantity.

Using the results from both the questionnaire item level and the factor level, the primary sources of job satisfaction for this population of classified employees are co-workers, the work itself, the work schedule, and supervisor. The primary job dissatisfiers are salary and district policies, especially policies related to salary, promotion, vacancies, and standardized practice throughout the school district.

Research Question 1. Is there a significant difference in job satisfaction among the specific categories of classified employees? 


\section{TABLE XXIV}

\section{CONTRIBUTION OF FACTORS TO OVERALL JOB SATISFACTION FOR ALL CLASSIFIED EMPLOYEES}

\begin{tabular}{l||c|c} 
Factor & $\mathrm{R}$ & Cumulative R2 \\
\hline \hline Work Itself & .665 & .429 \\
Supervisor & .701 & .491 \\
Work Quantity & .707 & .500 \\
\hline Total Variance & & \\
Explained & & $50 \%$
\end{tabular}




\begin{abstract}
Description of Job Satisfaction by Factors for Each Job Category: Multiple regression was employed to
\end{abstract} compute the relative contribution of factors for each employee group. The eight factors were regressed with overall job satisfaction, quesionnaire item 100, for each of the nine job categories. Results are displayed in Table XXV. The total contribution of factors named ranged from 36.98 for custodians to 77.58 for technical workers. The factor of Work Itself accounted for a relatively sizable proportion of job satisfaction for all employee groups. Supervisor ranked into all groups with the exception of food service employees, bus drivers, and maintenance workers. The two latter job categories were the only ones in which Co-workers was found to account for some variance in overall satisfaction. Benefits and Salary and Work Quantity were each contributors to three employee groupings. Factor means were computed by job category (Table XXVI). The analysis of variance was employed to determine whether the difference in factor means across job categories was attributable to chance or sampling error or whether there was a significant difference among employee groups relative to job factor. The independent variable in every calculation was job category; the dependent variable was job factor. An additional analysis of variance was executed for the 
TABLE XXV

\section{RELATIVE PERCENTAGE CONTRIBUTION OF FACTORS TO OVERALL JOB SATISFACTION BY \\ JOB CATEGORY}

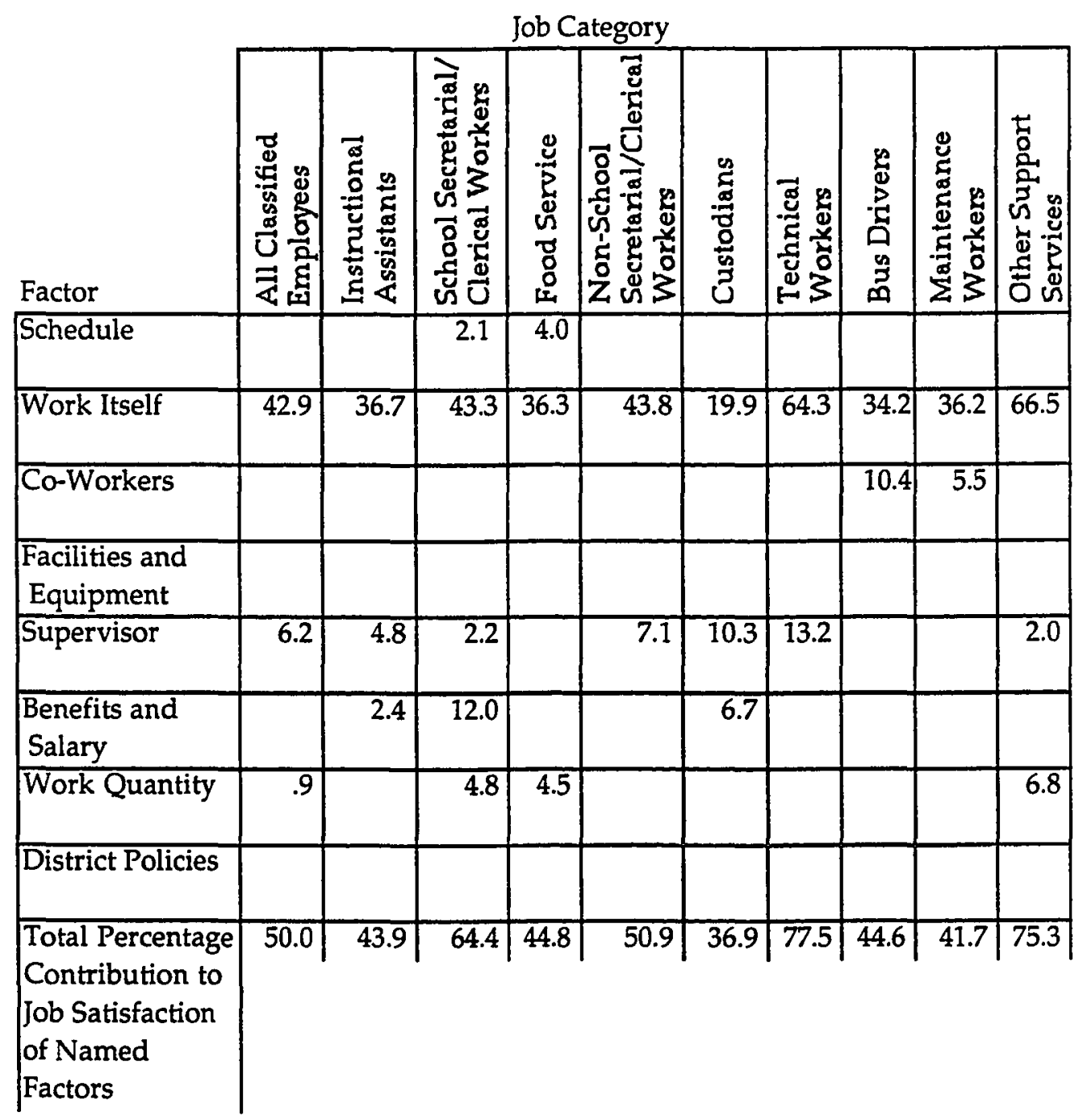

Note: Factors were loaded using step-wise regression by job category. Table is designed to be read in columns. Totals will not equal $100 \%$. 
TABLE XXVI

FACTOR *MEANS BY JOB CATEGORY

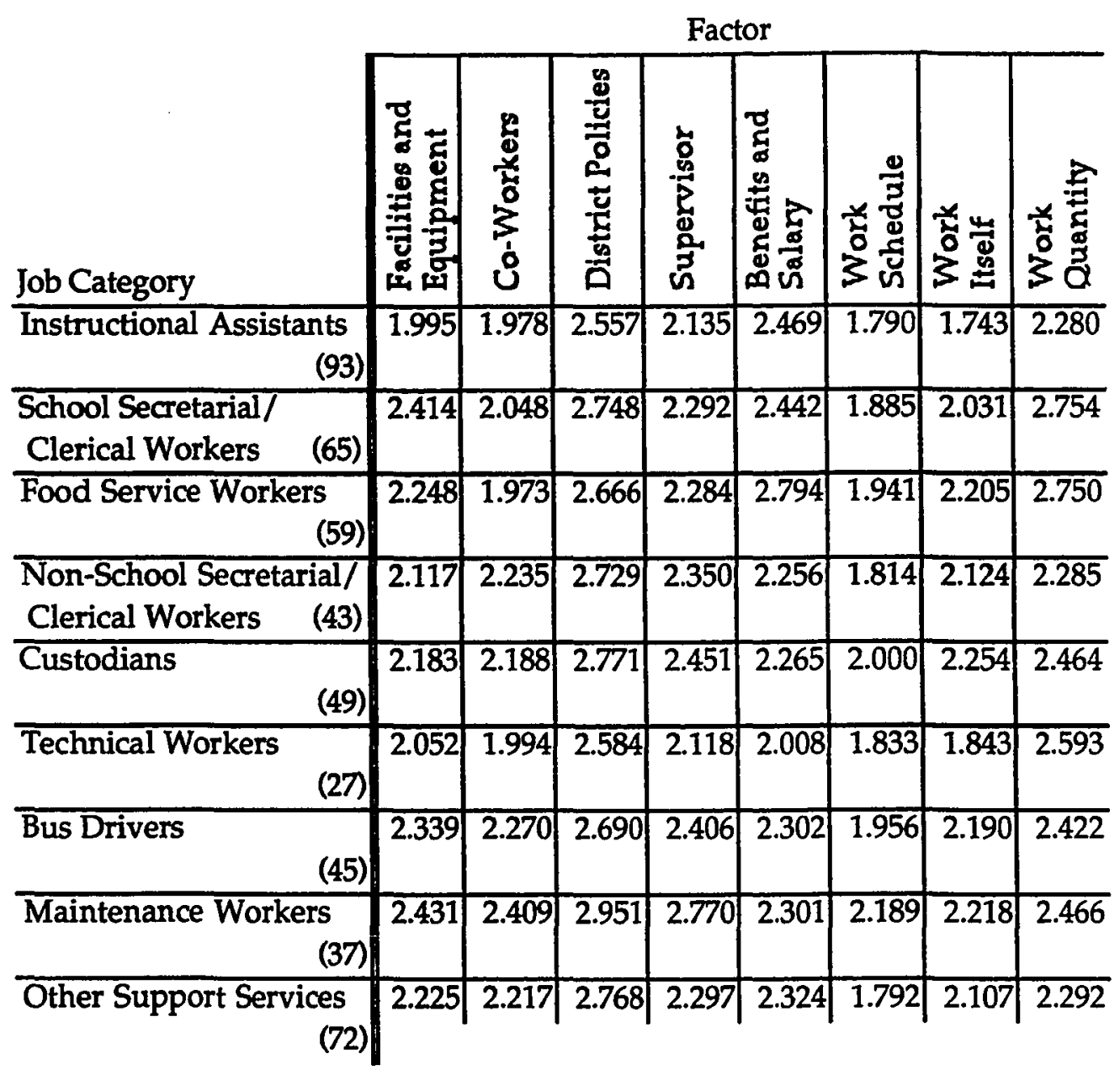

*1 = high satisfaction; 4 = high dissatisfaction

Note: The number in parenthesis indicates the total $\mathrm{N}$ for each job category. 
dependent variable of overall job satisfaction, questionnaire item 100. For every job factor, there is a significant difference ( $p<.001$, except for District Policies, where $p<.05)$ among employee groups. Visual representations of these significant differences are presented in Figures 8 through 15. There is also a significant difference $(p<.001)$ in overall satisfaction by job category (Figure 16).

Planned comparisons were conducted to determine which specific job categories were significantly different from other specific job categories. To attain the strongest comparison, without employing excessive comparisons, the means were combined into two groups for each factor. (If excessive comparisons are conducted and a significant difference is found, that difference may be due to chance since five out of any 100 occurrences may be due to chance.)

The criteria for combining job categories was to identify the lowest mean (highest satisfaction) for a factor, to add one standard deviation to the identified mean, and to combine all categories with means within that range. The resultant means were then compared with those that exceeded the specified range. Where the range of means did not fit the criteria for grouping, the job category with the lowest factor mean 


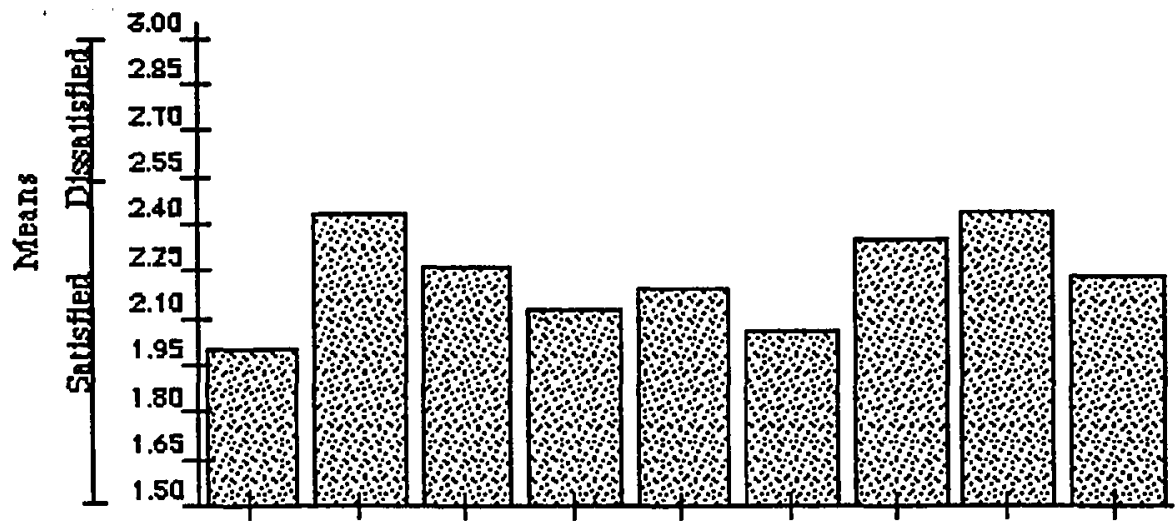

Figure 8. Job Satisfaction Means by Job Category: Facilities and Equipment. $(\mathrm{N}=473)$

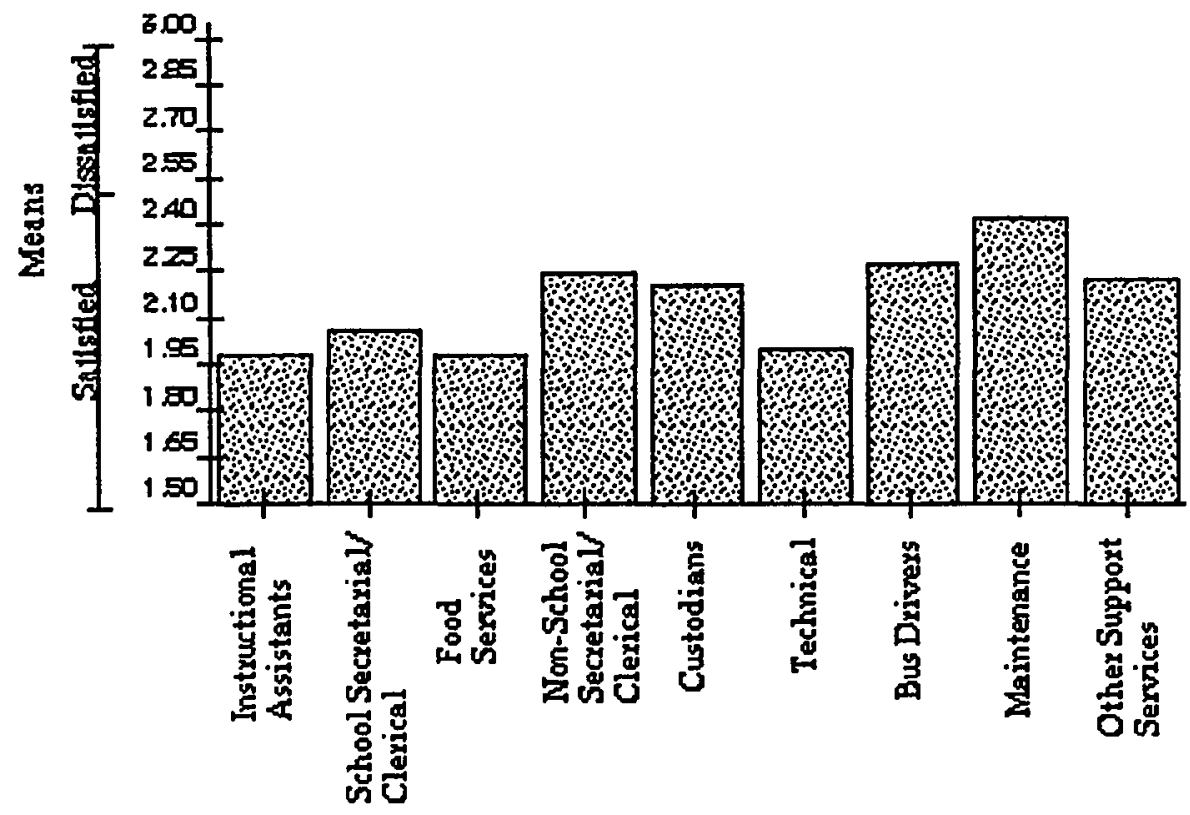

Figure 9. Job Satisfaction Means by Job Category: Co-workers. $(\mathrm{N}=473)$ 


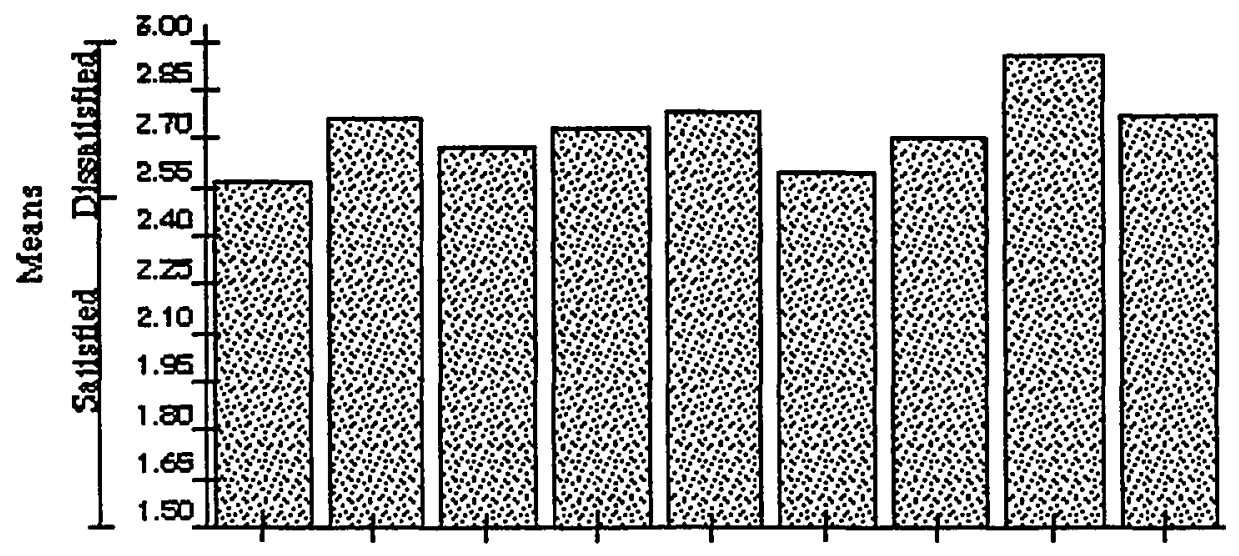

Fiqure 10. Job Satisfaction Means by Job Category: District Policies. (N=457)

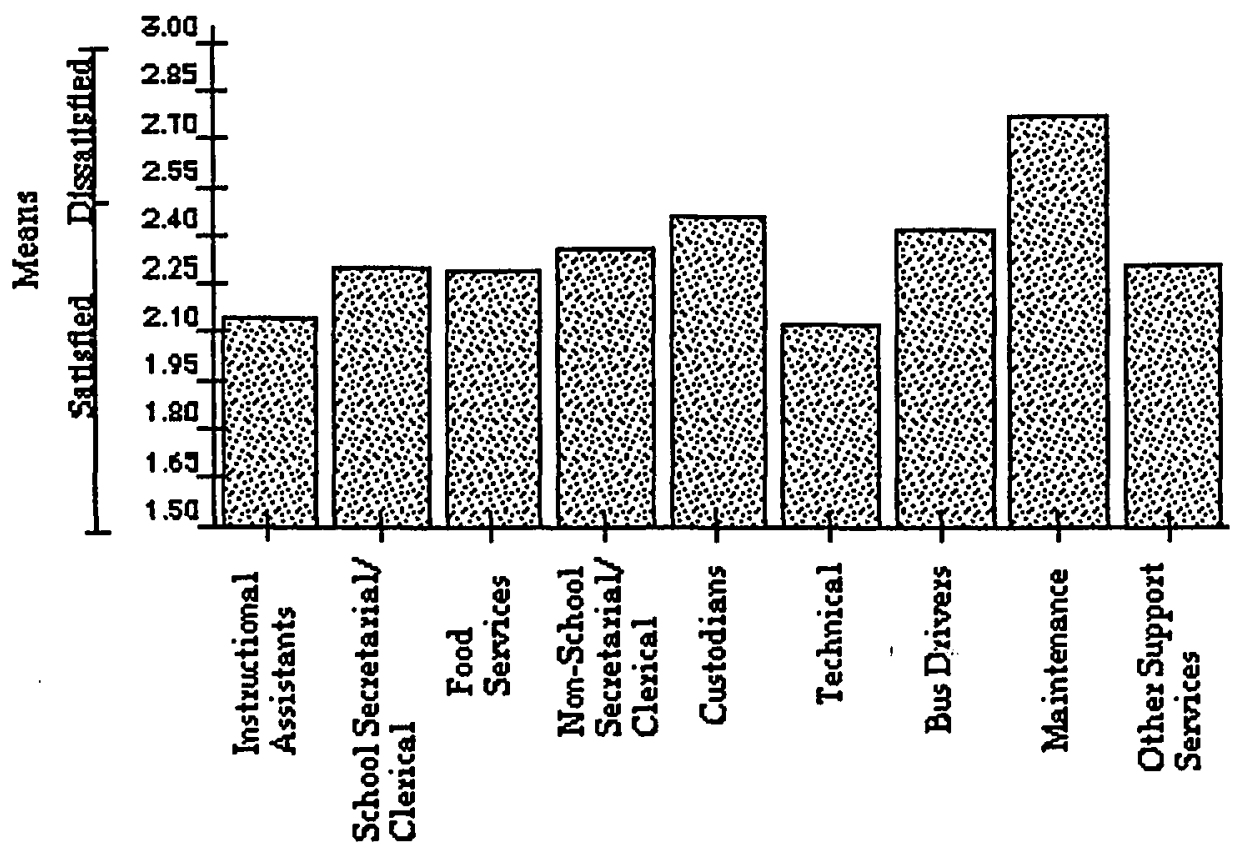

Figure 11. Job Satisfaction Means by Job Category: Supervisor. (N=442) 

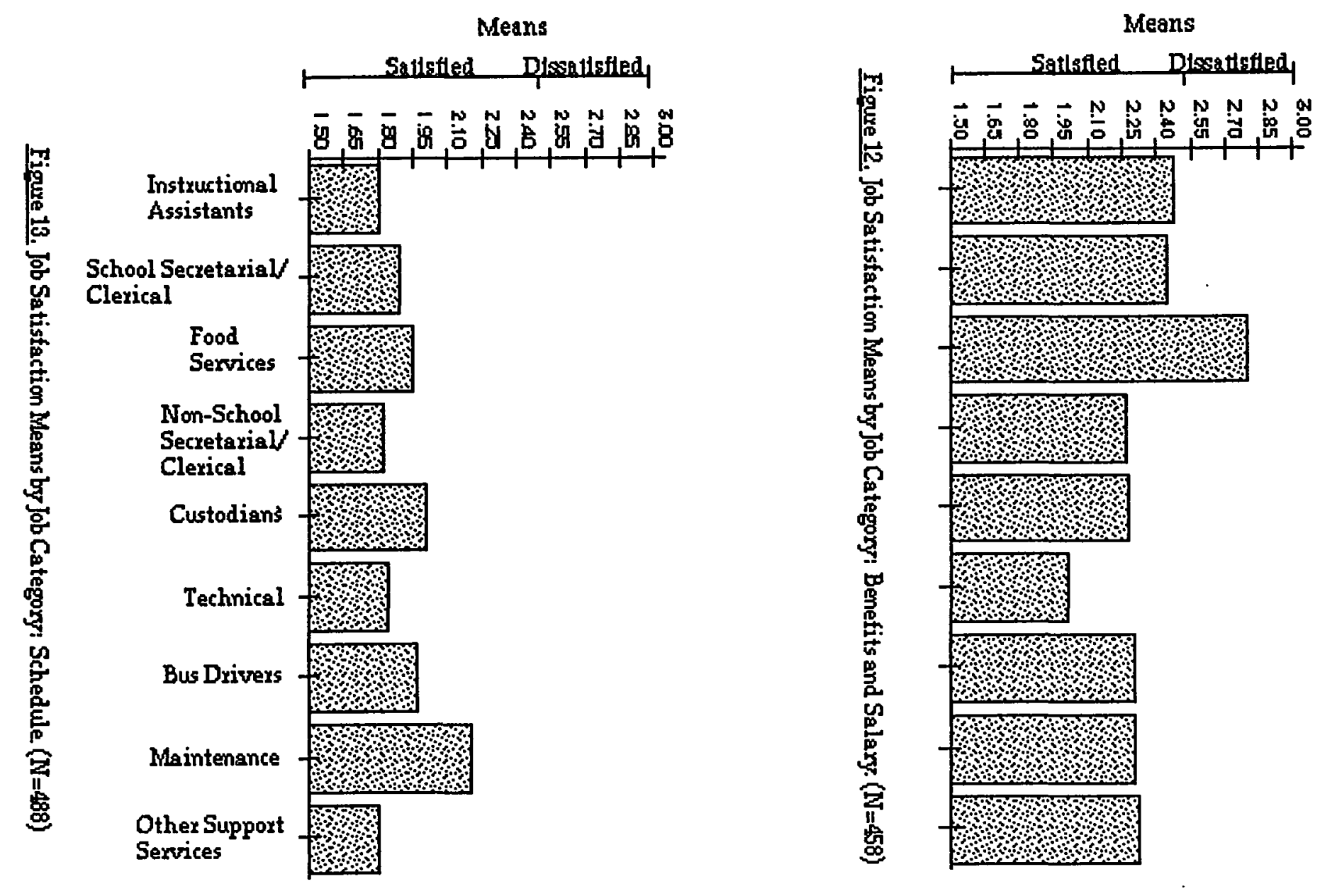


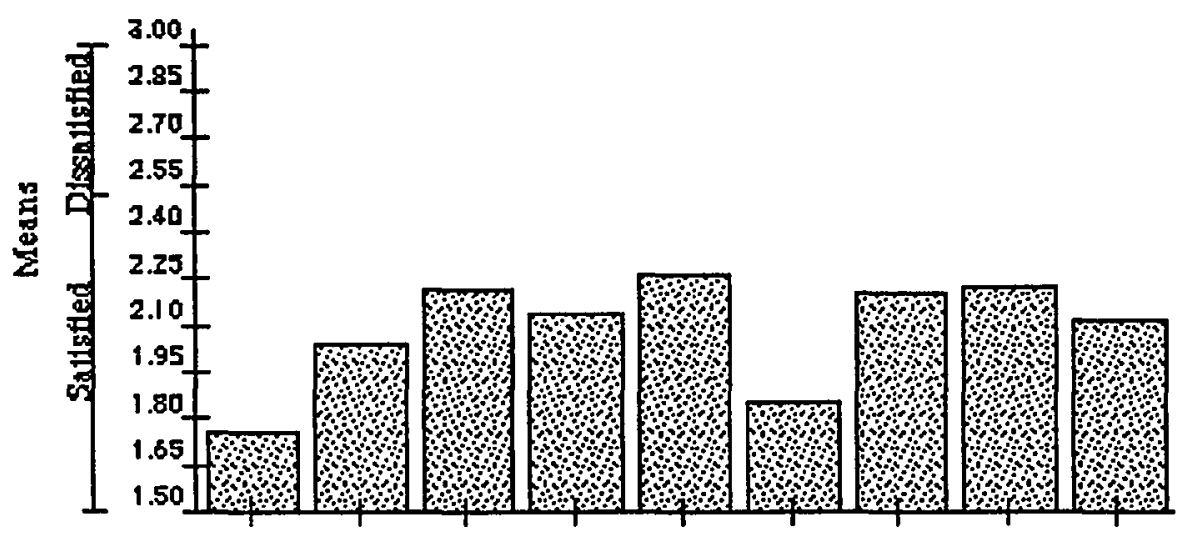

Fiqure 14, Job Satisfaction Means by Job Categary: Work Itself. (N $=475)$

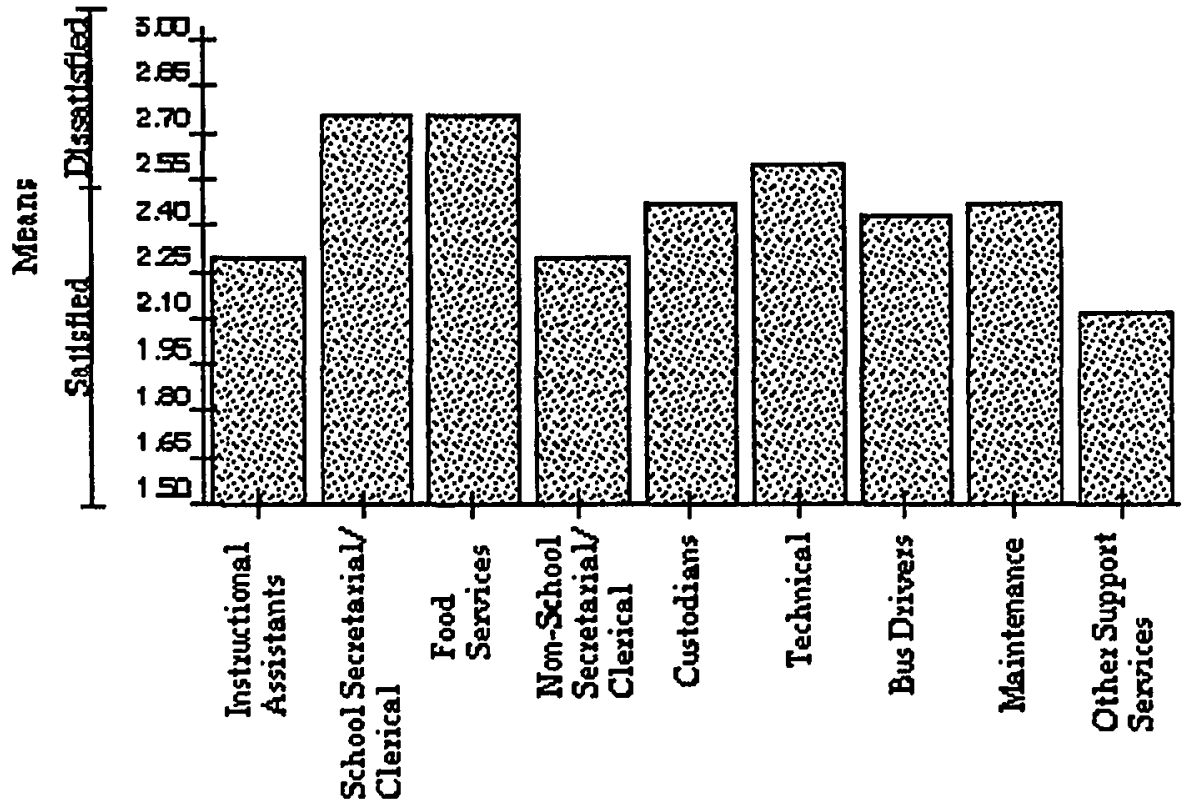

Figure 15. Job Satisfaction Means by Job Category: Wouk Quantity.(N=485) 


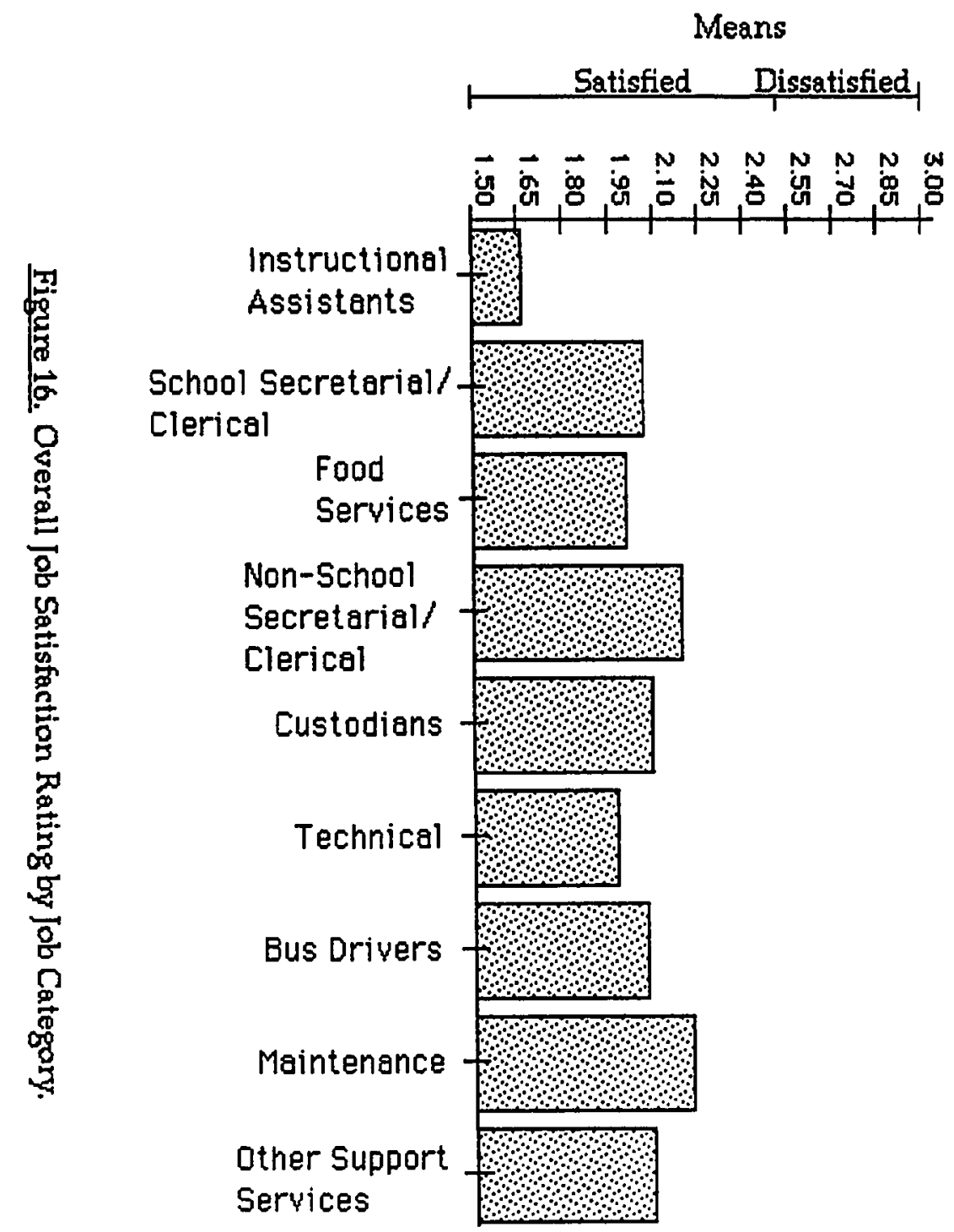


was compared solely with the job category with the highest factor mean.

Planned comparisons were also run to discern the specific differences among job categories on the variable of job satisfaction.

Planned Comparisons Data: Table XXVII shows the comparison groupings of job categories for each job factor and the results of planned comparisons. There are significant differences among employee categories relative to all job factors. On the factor of Facilities and Equipment, instructional assistants, food service workers, non-school secretarial and clerical employees, custodians, technical workers, and other support service personnel, as a group, are significantly more satisfied than school secretaries, bus drivers, and maintenance workers. Classified employees in all job roles are significantly more satisfied with their co-workers and their supervisors than are maintenance employees.

on the job factors of District Policies and Work Schedule, instructional assistants are significantly more satisfied than maintenance workers. Instructional assistants and food service workers are significantly less satisfied on the factor of Benefits and Salary than their remaining classified colleagues. 
TABLE XXVII

PLANNED COMPARISONS OF JOB CATEGORIES

BY JOB FACTOR

\begin{tabular}{|c|c|c|c|c|c|c|c|c|c|c|}
\hline & & & & & $\mathrm{bcc}$ & egory & & & & \\
\hline Factor & 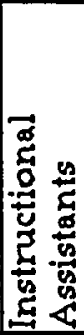 & 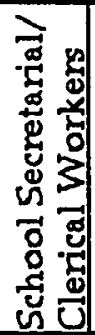 & 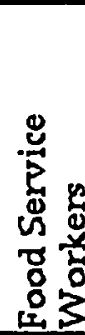 & 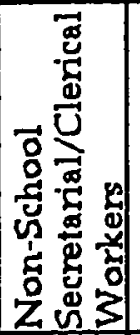 & 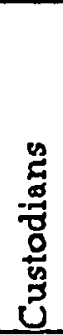 & 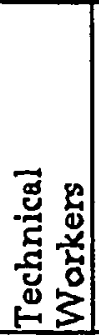 & 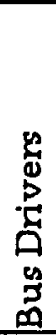 & 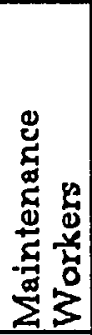 & 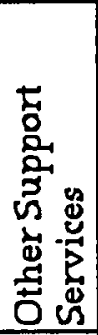 & 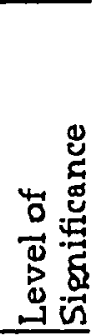 \\
\hline $\begin{array}{c}\text { Facilities and } \\
\text { Equipment }\end{array}$ & $\overline{\overline{1}}$ & 2 & $\overline{\overline{1}}$ & 1 & 1 & $\overline{11}$ & 2 & 2 & 1 & $\overline{<.001}$ \\
\hline Co-Workers & $\overline{1}$ & 1 & $\overline{1}$ & 1 & 1 & $\overline{1}$ & $\overline{1}$ & 2 & $\overline{1}$ & $\overline{<.001}$ \\
\hline District Policies & 1 & $\overline{0}$ & $\overline{0}$ & 0 & $\overline{0}$ & 0 & 0 & 2 & $\overline{0}$ & $\overline{<.001}$ \\
\hline Supervisor & 1 & 1 & 1 & 1 & 1 & 1 & 1 & $\overline{2}$ & 1 & $<.001$ \\
\hline $\begin{array}{l}\text { Benefits and } \\
\text { Salaries }\end{array}$ & 2 & 1 & $\overline{2}$ & $\overline{1}$ & 1 & $\overline{1}$ & 1 & 1 & $\overline{1}$ & $<.001$ \\
\hline Work Schedule & 1 & $\overline{0}$ & $\overline{0}$ & $\overline{0}$ & $\overline{0}$ & 0 & 0 & 2 & 0 & $\overline{<.001}$ \\
\hline Work Itself & 1 & 1 & 2 & 2 & 2 & 1 & 2 & 2 & 2 & $\overline{<.001}$ \\
\hline Work Quantity & 1 & 2 & 0 & $\overline{0}$ & 0 & $\overline{0}$ & 0 & 0 & $\overline{0}$ & $<.001$ \\
\hline
\end{tabular}

Note: The job categories which were grouped for comparison are designated by 1 or 2 for each Factor. One (1) indicates more satisfied; two (2) indicates iess satisfied. Zero designates not compared. Table is read horizontally. 
On the factor titled work Itself, instructional assistants, school secretarial and clerical employees, and technical workers are significantly more satisfied than food service workers, non-school secretaries, custodians, bus drivers, maintenance workers, and other support service personnel.

With regard to Work Quantity, instructional assistants are significantly more satisfied than school-based secretarial and clerical employees. The level of significance for all of the above group comparisons was .001 .

There is a significant difference $(p<.001)$ in overall job satisfaction among the categories of classified employees. Instructional assistants are significantly more satisfied $(p<.001)$ with their jobs than all other classified groups. When other job categories were individually compared with instructional assistants on the variable of overall job satisfaction, instructional assistants were found to be significantly more satisfied $(p<.001)$ than both maintenance workers and non-school secretarial and clerical employees. However, differences with other individual job categories were not significant ( $p$ > $.05)$

Maintenance workers, the job group with the lowest satisfaction mean, was compared with all other 
categories. The difference in job satisfaction between maintenance workers and the grouping of all other workers was not significant $(p>.05)$. Research Question 2. Are demographic/personal variables of classified employees related to overall job satisfaction?

Analysis: The Chi-square test was employed to assess the difference in job satisfaction among job categories on the variables of educational level, hours worked per week, years with the school district, years in present position, work setting, and gender. Results indicate that there is a significant relationship between job satisfaction and each of the demographic/personal variables $(p<.01)$.

To eliminate, or partial out, the influence of job role in the above relationships, the analysis of covariance (ANCOVA) was used with job category as the covariate. Results are displayed in Table XXVIII. Even after the variable of job category is removed, there is a significant difference in job satisfaction for three demographic/personal variables--hours worked per week, gender, and work setting. Figures 17, 18, and 19 illustrate the differences in job satisfaction within each of these variables. To assess these differences within each of the significant variables, planned comparisons were employed. 
TABLE XXVIII

\section{ANALYSIS OF COVARIANCE FOR JOB SATISFACTION AND DEMOGRAPHIC/PERSONAL VARIABLES WITH JOB CATEGORY AS COVARIATE}

\begin{tabular}{l||l} 
Variable & $\begin{array}{c}\text { Level of } \\
\text { Significance (p) }\end{array}$ \\
\hline Educational Level & .965 \\
Hours Worked per Week & $.045^{*}$ \\
Years Worked for School District & .754 \\
Years Worked in Present Position & .154 \\
Gender & $.046^{*}$ \\
Work Setting & $.048^{*}$
\end{tabular}

*Significant difference at $\mathrm{p}<.05$

TABLE XXIX

ANALYSIS OF COVARIANCE FOR JOB SATISFACTION AND JOB CATEGORY WITH DEMOGRAPHIC/PERSONAL VARIABLE AS COVARIATE

\begin{tabular}{l||l} 
Covariate & $\begin{array}{c}\text { Level of } \\
\text { Significance (p) }\end{array}$ \\
\hline Hours Worked per Week & $.001^{*}$ \\
Gender & $.001^{*}$ \\
Work Setting & $.013^{* *}$
\end{tabular}

*Significant difference at $p \leq .001$

**Significant difference at $p<.05$ 


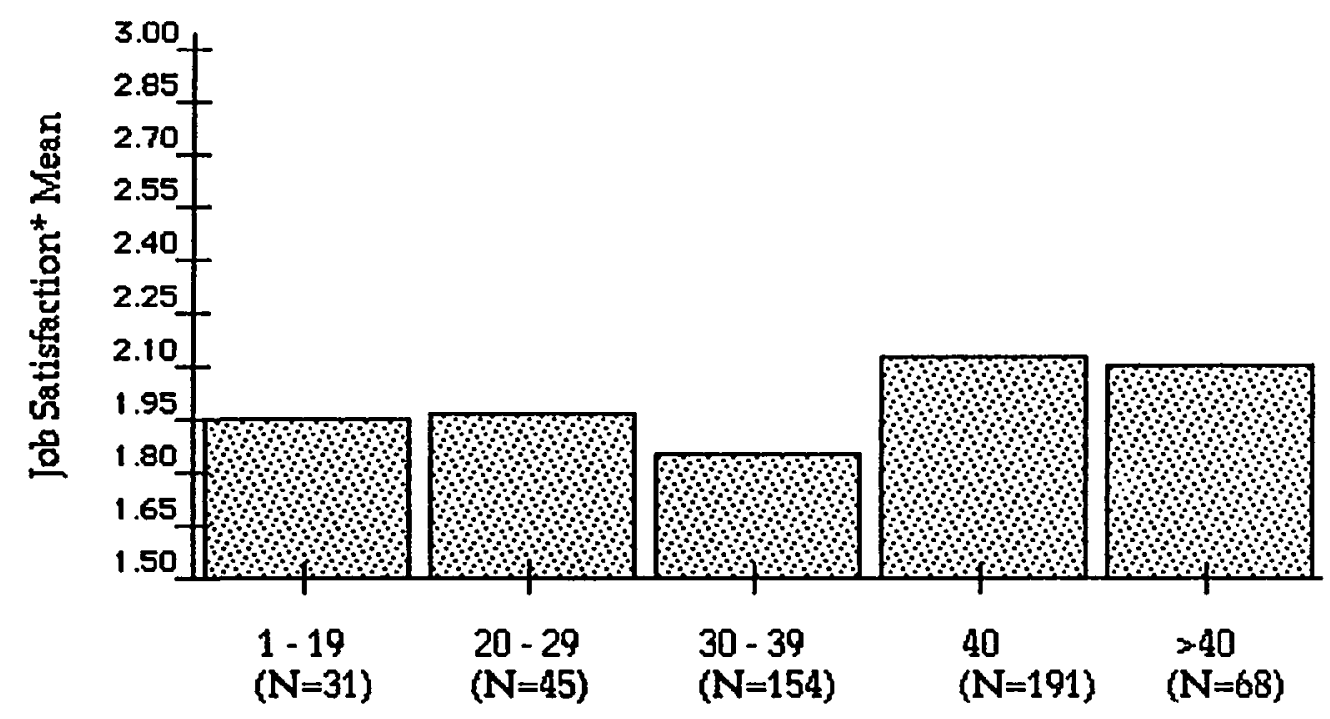

Hours Worked per Week

Figure 17. Job Satisfaction of Classified Employees by Hours Worked per Week.(after variable of job category is removed)

$* 1$ = very satisfied; $4=$ very dissatisfied 


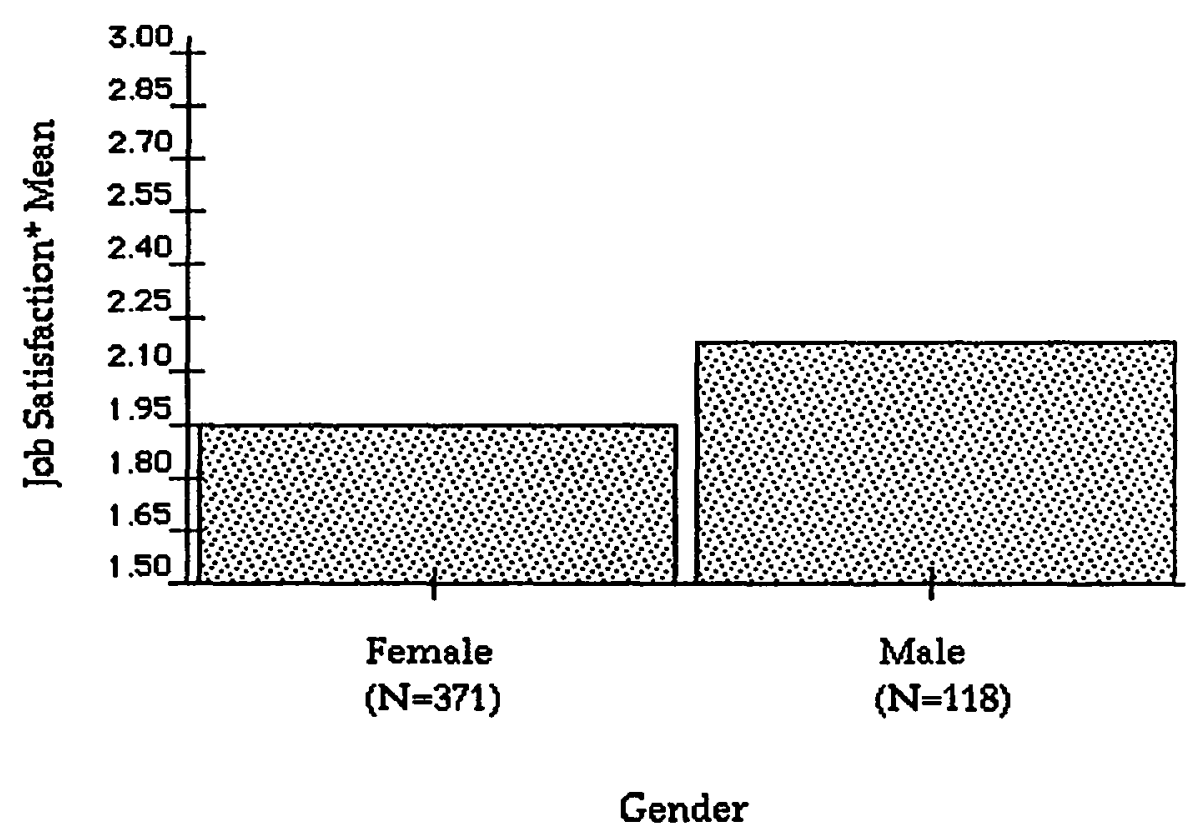

Figure 18. Job Satisfaction of Classified Employees by Gender. (after variable of job category is removed)

*1 = very satisfied; 4 = very dissatisfied 


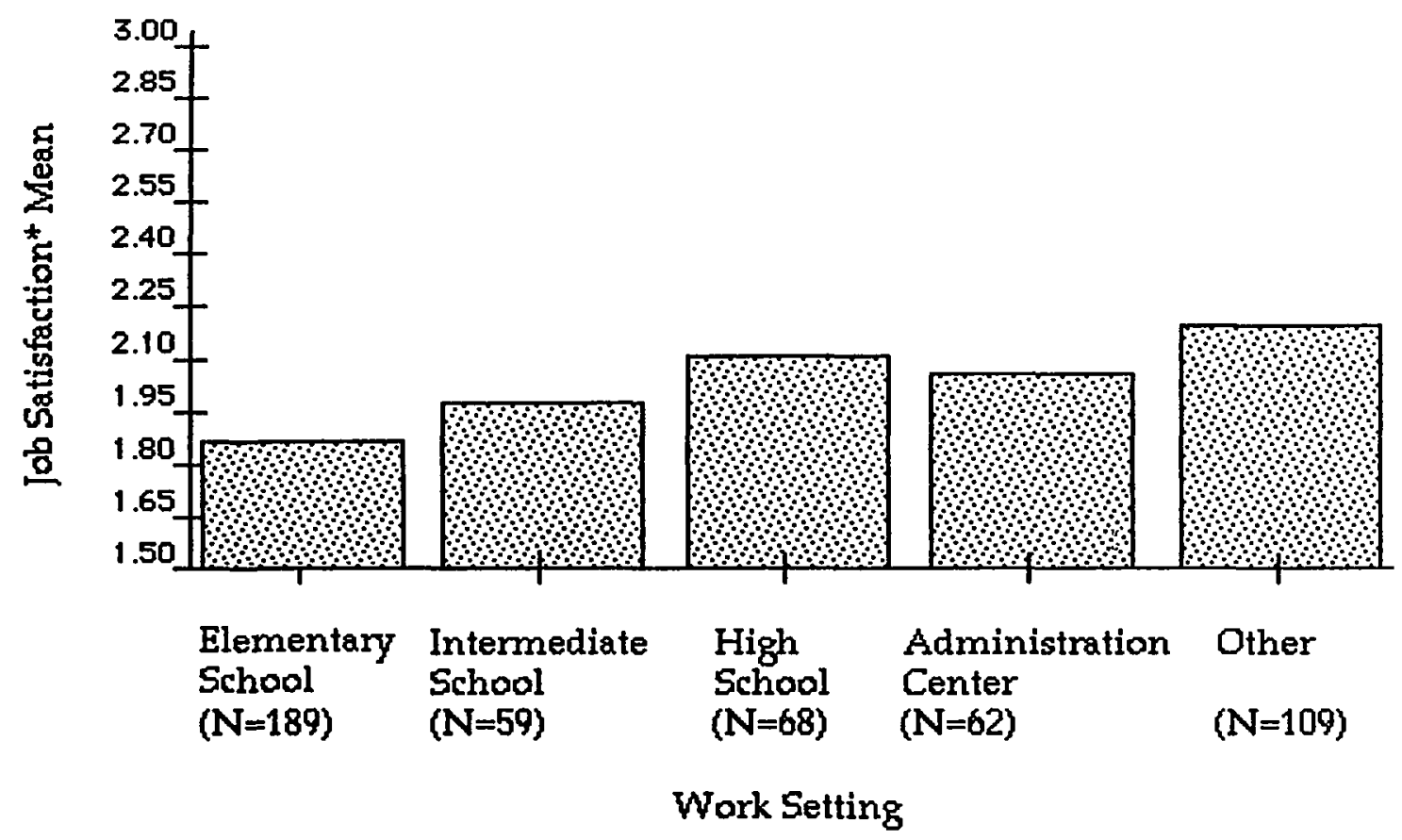

Figure 19. Job Satisfaction of Classified Employees by Work Setting. (after variable of job category is removed)

$* 1$ = very satisfied; $4=$ very dissatisfied 
Using planned comparisons, classified employees in elementary school settings were found to be significant ly more satisfied $(p<.001)$ than their colleagues in "other" settings. "Other" includes itinerant workers and those in offices, as differentiated from school-based and administration center workers.

With regard to gender, female workers are significantly $(p<.001)$ more satisfied than male workers. On the variable of hours worked per week, the category with the lowest satisfaction mean, 40 hours per week, was compared with the response group of highest satisfaction, 30-39 hours per week. There is no significant difference $(p>.05)$ between these groups. The significant difference found in overall job satisfaction on the variable of hours worked per week must be explained by other job variables. A second analysis of covariance was computed using the significant variables of hours worked per week, gender, and work setting, respectively, as covariates. After the variable of hours worked per week was removed, there remains a significant difference $(p=.001)$ in job satisfaction by job category. After the variable of gender was removed, there remains a significant difference $(p=.001)$ in job satisfaction by job category. After the variable of work setting is 
removed, there remains a significant difference $(\mathrm{p}<$ $.05)$ in job satisfaction by job category. Summary: There is a significant difference $(p \leq$ .001 ) in job satisfaction among classified employees relative to each of the following demographic/personal variables: educational level, hours worked per week, years with the school district, years in present position, work setting, and gender. When the influence of job role, as an extraneous variable in discerning the relationship between demographic/personal variables and job satisfaction, is eliminated, a significant difference $(p<.05)$ in job satisfaction remains for three variables. Those are hours worked per week, gender, and work setting. When the influence of hours worked per week, gender, and work setting are each partialed out separately, there remains a significant difference $(p<.05)$ in job satisfaction among employee groups.

\section{Results of Open-Ended Questions}

Overview. Each computer scan sheet was preprinted with two open-ended questions: (a) "What do you like most about your job?" and (b) "What do you dislike most about your job?" Responses to this section were compiled by job category as themes of job satisfaction and job dissatisfaction for classified employees. 
The compilation of job satisfiers is presented in Table XXX. The most frequently mentioned "like" was co-workers, followed closely by work variety and students. Five of the nine job categories cited aspects of the work itself as a job satisfier. Independence and work schedule were listed by individuals representative of almost half of the categories.

Job dissatisfiers for classified employees were more widely dispersed than satisfiers, according to write-in responses (Table XXXI). In fact, the only responses which emerged across more than three of the categories was "none" or no response at all, which appeared in six groups, and salary, mentioned by four job groups. Individuals representing one-third of the job categories mentioned lack of advancement oppportunities, overwork, and salary as sources of dissatisfaction. Other dislikes appear to be more specific to job category than representative of the general role of a classified employee. Specific job likes and dislikes are discussed below by work role. Issues by Job Category. Instructional Assistants: The overwhelming satisfier for this group, according to questionnaire write-ins, is students. One employee wrote, "I like working with the kids.... They are very challenging and because of that I find out more things 
TABLE XXX

JOB SATISFIERS OF CLASSIFIED EMPLOYEES

COMPILED FROM WRITE-IN RESPONSES

ON QUESTIONNAIRES

\begin{tabular}{|c|c|c|c|c|c|c|c|c|c|c|}
\hline Satisfier & 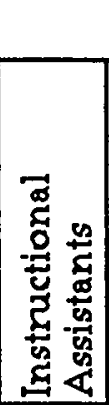 & 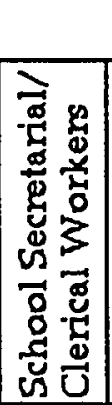 & 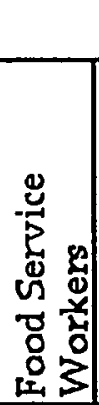 & 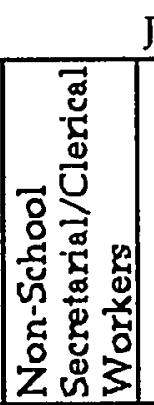 & 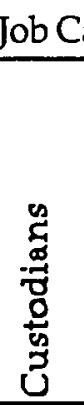 & 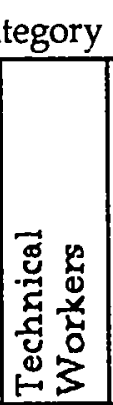 & 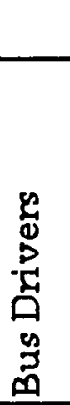 & 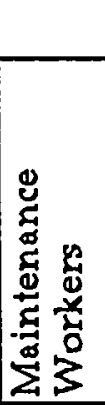 & 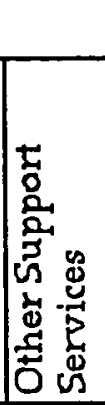 & 离 \\
\hline Co-workers & $\bar{X}$ & $\overline{\mathrm{X}}$ & $\bar{x}$ & $\bar{X}$ & $\bar{x}$ & $\overline{\bar{X}}$ & & $\overline{\mathrm{X}}$ & $\bar{x}$ & $\overline{8}$ \\
\hline $\begin{array}{l}\text { Variety of } \\
\text { Work }\end{array}$ & $\bar{x}$ & $\bar{x}$ & & $\bar{x}$ & $\bar{x}$ & $\bar{x}$ & & $\bar{X}$ & $\bar{X}$ & 7 \\
\hline Students & $\bar{x}$ & $\bar{X}$ & $\bar{x}$ & & $\bar{x}$ & & $\bar{X}$ & & $\bar{X}$ & 6 \\
\hline Work Itself & & & $\bar{x}$ & & $\bar{x}$ & $\bar{x}$ & $\bar{x}$ & & $\bar{x}$ & 5 \\
\hline Independence & & $\bar{X}$ & & $\bar{X}$ & & & $\bar{x}$ & & $\bar{X}$ & 4 \\
\hline Schedule & & & $\bar{x}$ & & & & $\bar{x}$ & $\bar{x}$ & $\bar{x}$ & 4 \\
\hline Benefits & & & & & $\bar{X}$ & & & & $\bar{X}$ & 2 \\
\hline $\begin{array}{l}\text { Interaction } \\
\text { with Public }\end{array}$ & & $\bar{x}$ & & $\bar{X}$ & & & & & & 2 \\
\hline $\begin{array}{l}\text { Pride of } \\
\text { Service }\end{array}$ & & & & & & & & $\bar{x}$ & & 1 \\
\hline
\end{tabular}


TABLE XXXI

\section{JOB DISSATISFIERS OF CLASSIFIED EMPLOYEES COMPILED FROM WRITE-IN RESPONSES ON QUESTIONNAIRES}

\begin{tabular}{|c|c|c|c|c|c|c|c|c|c|c|}
\hline & & & & Job $\mathrm{C}_{\mathrm{a}}$ & tego & & & & & \\
\hline Dissatisfier & 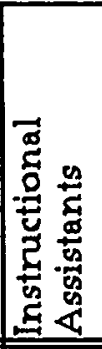 & 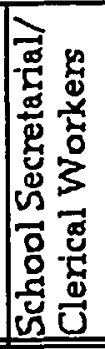 & 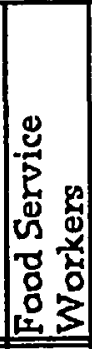 & 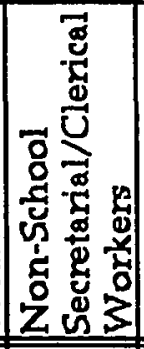 & 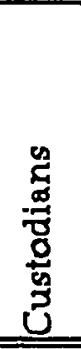 & 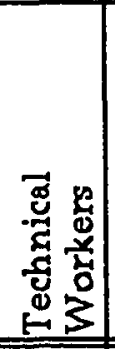 & 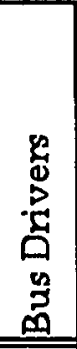 & 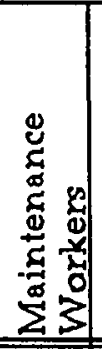 & 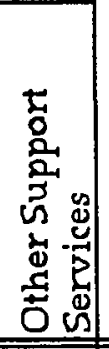 & 离 \\
\hline $\begin{array}{l}\text { "None" } \\
\text { or No Response }\end{array}$ & $x$ & $\mathrm{X}$ & $\bar{x}$ & & $\bar{X}$ & $x$ & & & $\overline{\bar{X}}$ & $\overline{6}$ \\
\hline Salary & $\bar{X}$ & $\bar{X}$ & & $\bar{X}$ & & & & & $\bar{X}$ & $\overline{4}$ \\
\hline $\begin{array}{l}\text { No Opportunities } \\
\text { for Advancement }\end{array}$ & $\bar{x}$ & & & & $\bar{X}$ & & & & $\bar{X}$ & $\overline{3}$ \\
\hline Overwork & & $\bar{X}$ & $\bar{x}$ & & & $\bar{X}$ & & & & $\overline{3}$ \\
\hline Job Insecurity & $\bar{X}$ & & $\bar{X}$ & & & & & & & 2 \\
\hline Lack of Variety & & & & & $\bar{x}$ & & & & $\bar{X}$ & $\overline{2}$ \\
\hline Unfair Policies & & & & & & & $\bar{x}$ & & $\bar{X}$ & 2 \\
\hline Rushed Deadlines & & $\bar{X}$ & & & & & & & & $\overline{1}$ \\
\hline Facilities & & $\bar{x}$ & & & & & & & & $\overline{1}$ \\
\hline Co-Workers & & & & $\bar{X}$ & & & & & & 1 \\
\hline Student Discipline & & & & & & & $\bar{X}$ & & & $\overline{1}$ \\
\hline $\begin{array}{l}\text { Lack of } \\
\text { Communication }\end{array}$ & & & & & & & & $\bar{x}$ & & $\overline{1}$ \\
\hline Supervisor & & & & & & & & $\bar{x}$ & & 1 \\
\hline
\end{tabular}


about myself. I grow." Instructional assistants like working with individuals, small groups, and entire classrooms.

These workers also appreciate their colleagues. Specific responses praised both other instructional assistants as "wonderful people" and entire school staffs for "closeness and loyalty." Instructional assistants like the variety of the tasks assigned to them. Several employees referred to the stimulation and challenge of varied responsibilities and a pace that is never boring.

Other specific satisfiers less frequently raised were autonomy, supervisor, and schedule, including both daily hours and annual calendar.

Dislikes were specifically stated, making categorization more difficult to discern. For example, while 77 of the 93 participating instructional assistants listed students as a job satisfier, the largest identifiable category of dissatisfaction, job insecurity, pooled only 12 respondents. One employee complained of a "chilling cold work area." Another stated, "I abhor the clerical aspects of my work." Such was the diversity of identified job dissatisfiers. School Secretarial and Clerical Workers: These employees appear to relish the contact with people, including students, parents, and teachers, that their 
jobs afford them. Wrote one secretary, "I like the feeling of accomplishment through helping." Their primary job satisfiers were both more numerous and more homogeneous than those of other job categories.

The dislikes of secretarial and clerical employees based in schools, on the other hand, were widely scattered from "fumes of the copy machine" to "sitting all day." Where definable issues emerged, as identified in Table XXXI, the responses represent subgroups of less than 10 individuals each. In this group, issues were often merged. For example, one respondent wrote, "At times the workload is very stressful and the salary is not commensurate with the responsibilities." Another listed "the workload and unrealized deadlines for its completion."

Food Service Employees: To approximately one-half of these questionnaire respondents, children constitute a job satisfier. Stated one, "Working with them keeps me young." Co-workers, "the people I work with," was the second most frequent response to "What do you like most about your job?"

For food workers, job dissatisfiers fall under the umbrella theme of job insecurity. Employees named increased responsibility and "add-ons to job," as hours and personnel are cut back: "They have taken people and hours away from our staff but we are still expected 
to do the same job with less people and less hours." The staff reductions and accompanying overwork are attributed to the district's effort to create a self-suppporting food service program.

Non-school Secretarial and Clerical Workers: Sources of job satisfaction for this group parallel those of their school-based counterparts, with the sole exception of students. Satisfiers include contact with people, co-workers, work variety, and autonomy.

Like school secretaries, office personnel are dissatisfied with their salaries. The only other emergent category was co-workers, namely those with a negative attitude or colleagues "who don't carry their share" of the workload. Other individual responses were scattered, including "my chair," "favoritism," "people intruding in my personal life," and "responsibility without money or recognition."

Custodians: Custodians, like instructional assistants, school secretarial and clerical staff, cooks, and bus drivers, derive job satisfaction from children or what one participant phrased "working with the little guys and girls." For all of these groups, students was the largest categorical response. One custodian asserted, "I love these kids and they love me. Together we make a heck of a good team." Custodial workers also cited aspects of their work, 
their co-workers, and job benefits, as differentiated from salary.

Dissatisfiers were specific, with only two distinguishable themes, no advancement opportunites and repetitive labor. In one custodian's words, "I don't like promotional procedures for advancement. They are unfair." Regarding the work itself, another employee complained of "manual repetitious work." These topics, however, represent the agreement of less than 10 individual respondents each. Of equal note is the issue named "'None' or no response" in Table XXXI. In addition to lack of response, several individuals stated that they have no dislikes. This did not occur in any other job category.

Technical Workers: Classified employees in the technical field derive job satisfaction primarily from their work--its variety and the challenge of learning --and from their co-workers.

The only cluster of agreement on job dissatisfiers centered on overwork. Precisely, technical workers named "too many projects," "short deadlines," and

"excessive overtime." One respondent wrote:

The workload is too great and the pace difficult to maintain. There isn't a week that goes by where I don't have to work overtime and then still bring work home. This makes it impossible to schedule my weeknight activities. 
Bus Drivers: Bus drivers, according to questionnaire write-ins, appreciate various aspects of their work, including the daily schedule, the school year calendar, mobility, autonomy, and the act of driving. Like school-based classified employees, drivers identified students as their chief source of job satisfaction. When asked, "What do you like most about your job?" one bus driver responded, "I like being asked! Thanks."

The areas of job dissatisfaction meriting the greatest response were unfair practices and lack of support and/or authority in the arena of student discipline. The unfairness theme covered issues of seniority, equal application of policies, and evaluation practices. Further, drivers want either some leverage in "having to deal with the children with behavioral problems" or greater support from school administrators in rule enforcement.

Maintenance Workers: In addition to the satisfiers of co-workers, job variety, and work schedule, named by other classified employees, maintenance representatives' responses also clustered in a philosophical grouping labeled "pride of service." Here, voiced job satisfiers included "being of service to the next generation of leaders," "making schools 
something to be proud of" and "contributing to the education of children."

On the question of dissatisfaction, maintenance employees raised two issues untouched by other job categories. The issues, lack of communication and supervisor, were closely allied in their comments, but were separated here of clarity. These workers question the lack of leadership, competence, and earned respect of their supervisor(s). One cites a pervasive "lower than thou management attitude." Others attribute intradepartmental communication problems to "people who are afraid to make decisions and speak out." One employee blames "backstabbers" for co-workers' decision to contain their complaints.

Other Support Services Workers: This category subsumes classified employees who work in a variety of settings and exercise diverse roles throughout the school district and whose positions do not fit within prior categories. It includes, but is not limited to, mail clerks, crossing guards, physical management aides, computer operațors, bookkeepers, and graphic designers. As a heterogeneous grouping, their responses to the inqueries of both job satisfaction and dissatisfaction reflected issues expressed across the other eight categories. 


\section{OVERVIEW OF RESULTS}

\section{Summary of Research Questions and Hypotheses}

The results of this study are summarized below relative to the two primary research questions, the six research hypotheses introduced in Chapter II, and their corresponding null hypotheses.

Research Question 1. Is there a significant difference in job satisfaction among the specific categories of classifiea employees?

Research Hypothesis 1: There is a significant difference in job satisfaction among classified employees relative to job category.

Null Hypothesis 1: There is no significant difference in job satisfaction among classified employees relative to job category. According to the results of this study, there is a significant difference $(p<.001)$ in overall job satisfaction by job category. Even after the significant variables of hours worked per week, gender, and work setting are individually eliminated, the difference in job satisfaction by job category remains significant $(p<.05)$. There is also a significant difference between job categories in job satisfaction for each of the eight identified job factors $(p<.001$, except for District Policies, where $p<.05)$. 
The null hypothesis was rejected; Research Hypothesis 1 was accepted.

Research Question 2. Are the demographic/personal variables of classified employees related to overall job satisfaction?

Research Hypothesis 2a: There is a significant difference in overall job satisfaction among classified employees relative to gender.

Nul1 Hypothesis 2a: There is no significant difference in overall job satisfaction among classified employees relative to gender.

Results of this study indicate that there is a significant difference $(p<.001)$ in overall job satisfaction relative to gender. When the variable of job role is partialed out, the difference in job satisfaction relative to gender remains significant ( $p$ <.05). Female employees were found to be significantly more satisfied than male employees.

Null Hypothesis 2a was rejected; Research Hypothesis 2 a was accepted.

Research Hypothesis 2b: There is a significant difference in overall job satisfaction among classified employees relative to educational level.

Null Hypothesis $2 \mathrm{~b}$ : There is no significant difference in overall job satisfaction among classified employees relative to educational level. 
A significant difference $(p<.001)$ was found in overall job satisfaction of classified employees relative to educational level. However, when the variable of job category is eliminated, the difference is no longer significant $(p>.05)$.

The null hypothesis was accepted; Research Hypothesis $2 \mathrm{~b}$ was rejected.

Research Hypothesis 2c: There is a significant difference in overall job satisfaction among classified employees relative to length of employment.

Null Hypothesis 2c: There is no significant difference in overall job satisfaction among classified employees relative to length of employment.

A significant difference $(p \leq .001)$ was found in overall job satisfaction relative to both variables which assessed length of employment--years worked for the school district and years worked in present position. The elimination of the variable of job category negated the difference.

Null Hypothesis 2c was accepted; Research Hypothesis $2 \mathrm{c}$ was rejected.

Research Hypothesis 2d: There is a significant difference in overall job satisfaction among classified employees relative to number of hours employed. 
Null Hypothesis 2d: There is no significant difference in overall job satisfaction among classified employees relative to number of hours employed.

The variable of hours worked each week was found to be significant at the .001 level. Even after the variable of job category was partialed out, a signficant difference $(p=.001)$ remained. The specific nature of that difference was not explained using planned comparisons.

Null Hypothesis 2d was rejected; Research Hypothesis $2 \mathrm{~d}$ was accepted.

Research Hypothesis 2e: There is a significant difference in overall job satisfaction among classified employees relative to work setting.

Null Hypothesis 2e: There is no significant difference in overall job satisfaction among classified employees relative to work setting.

Based on the results of this study, there is a significant difference in job satisfaction $(p<.001)$ among classified employees relative to work setting. Even after the job category variable is eliminated, there remains a significant difference $(p<.05)$.

According to this study, elementary school-based employees are significantly more satisfied than workers who are based neither in intermediate or high schools nor in the administration center. The less satisfied 
category would include other office- or shop-based workers and those with itinerant positions.

Null Hypothesis 2 e was rejected; Research Question $2 e$ was accepted.

Chapter IV has presented the detailed results of this study on job satisfaction of classified employees. These results will be discussed in Chapter $V$, along with the implications, conclusions, and recommendations of this study. 
CHAPTER V

\section{DISCUSSION AND RECOMMENDATIONS}

Chapter $\mathrm{V}$ includes an overview of the study, a comparison of qualitative and quantitative results, discussion and recommendations.

OVERVIEW

This study was designed to assess the sources of job satisfaction for the classified employees of one suburban public school district. This group of employees was selected because classified workers comprise approximately 408 of the school district staff, both in this district and as a state-wide average (B.Jones, personal communication, December 23, 1988). As individuals responsible for maintaining clean safe schools, transporting students, preparing nutritious meals, and providing instruction--directly, or through provision of materials--classified employees support the educational process and contribute to school climate, or learning environment. They are also visible purveyors of services to adults entering school buildings and valuable links to the surrounding community. 
In education, as in the business sector, the strength of an organization may be predicated on the strength and vitality of its foundation. In the case of school districts, that foundation--or support system--is composed largely of classified employees. To nurture their needs, their needs must be known. The targeted population included instructional assistants, school and non-school secretarial and clerical employees, food service workers, custodians, maintenance personnel, bus drivers, technical workers, and other support services personnel.

The questions to be answered by this study were: (a) What are the primary sources of job satisfaction and dissatisfaction for classified employees? (b) Is there a significant difference in job satisfaction among the specific categories of classified employees? (c) Are demographic/personal factors of classified employees related to overall job satisfaction? Job satisfaction has long been under study in the industrial arena and business community, and, more recently, in social services, the health field, and education. However, as detailed in Chapter II, studies in education have addressed, almost exclusively, the administrative and certified teaching staffs. Exceptions exist, but those few studies of job satisfaction of classified employees have generally 
isolated one job category for examination. Prior to this research, there was no existing study which investigated job satisfaction across the spectrum of classified workers, comparatively among workers, and within each job category.

Theories for studying job satisfaction and existing instruments were presented and discussed in Chapter II and Chapter III, respectively. The research model selected for this study incorporated both qualitative and quantitative methodology. The first phase of the research entailed convening focus groups, one for each job category. A questionnaire was developed, based upon the job satisfiers and dissatisfiers ennumerated and the issues raised in focus group discussions. The instrument contained 100 items measured on a four-point modified Likert scale. Ninety-one of the items were descriptive of work; eight items were general job aspects. The final item elicited a satisfaction rating for overall job satisfaction. (This was decided in lieu of a longitudinal study with length of employment as a variable.) The 100 items were followed by eleven demographic/personal variables and two open-ended questions. The questions were: "What do you like most about your job?" and "What do you dislike most about your job?" 
The school district studied may be considered typical for a fast-growing suburban community. The student population is not typical on a state-wide level, however, in that the average student age is younger and the population is growing more rapidly than in other districts. In terms of growth, neighboring urban-based Portland Public School District grew by 400 students during the 1988-89 academic year; this district's student population increased by 1,136 for the same period (J. Pahl, personal communication, March $16,1990)$.

COMPARISON OF FOCUS GROUP RESULTS, QUESTIONNAIRE RESULTS AND OPEN-ENDED QUESTION RESPONSES

\section{Job Satisfaction}

In general, the analysis of questionnaire responses--including both quantitative data and open-ended, write-in responses--appears to support the information gathered in focus group discussions. The primary job satisfiers are co-workers, students, work variety, work itself, autonomy, and work schedule. Where means are stated below, they refer to a 4-point satisfaction scale of 1 through 4 , where 1 indicates high satisfaction and 4 denotes high dissatisfaction. The neutral point on the scale, 
though not stated on the questionnaire (see Appendix E), is considered to be 2.5 .

Co-workers. "Co-workers" was identified as a satisfier by eight focus groups and by eight job groupings, as reflected in write-in responses. At the questionnaire item level, one-third of the twelve items listed as representing the highest satisfaction scores related to coworkers. In fact, more than 908 of the respondents "agree" or "strongly agree" that their co-workers are "responsible," "cooperative," and "competent." The mean for Co-workers on the factor leve1, 2.13, corresponds to "satisfied."

Students. School-based employees value students as a job satisfier, according to both focus groups and write-in responses. There were no questionnaire items addressing students because $35 \%$ of the sample employee population included non-school-based workers.

Work Variety. The satisfaction of variety in work was expressed by four focus groups and by representatives of seven out of nine job categories on write-in responses. Questionnaire item 70, "There is variety in my work," drew a high satisfaction mean of 1.87 . 
Work Itself. Five employee categories identified work itself as a satisfier in both focus groups and write-in responses, although the respective groupings differed slightly. In the multiple regression analysis, the factor of Work Itself was shown to constitute the best predictor of job satisfaction for all employee categories in this study. As a factor, its mean rating was 2.06 .

Autonomy. The satisfaction of independence on the job was expressed in six focus groups and by four job categories in write-in responses. Questionnaire item 33, "I am allowed to work independently," earned a mean of 1.81 and ranked among the items of highest satisfaction.

Work schedule. Five focus groups and four job categories, as reflected in write-in responses, value their present work schedules. On the factor level, Work Schedule had the lowest overall mean (1.89) which translates to the highest level of satisfaction, relative to other factors. Questionnaire item 77, "I have a good work schedule," merited a mean of 1.97. Other Satisfiers. Other job aspects were discussed in Chapter IV. They include supervisor, facilities, recognition, salary and benefits, and educational opportunities. In each case, these aspects 
were discussed by focus groups as constituting job satisfiers. Of these, only the factors of supervisor and Facilities and Equipment were supported as job satisfiers when questionnaire data were analyzed. The aspect of recognition and corresponding questionnaire items were subsumed under the factor of supervisor in the factor analysis. However, according to analysis of write-in responses, none of these five aspects constitutes a job satisfier across job categories. In fact, only one, benefits, was listed and, even then, only by two groups.

\section{Job Dissatisfaction}

Three major job dissatisfiers emerge in a comparison of results from focus groups and the questionnaire. They are work overload, district policies, and insecurity about job future.

Work Overload. Eight of nine focus groups identified work quantity as a primary source of job dissatisfaction. On write-in responses, three groups-school-based secretarial workers, food service employees, and technical personnel--echoed their discontent with work overload. On the factor level of questionnaire analysis, Work Quantity had a mean rating of 2.46, second only to District Policies in dissatisfaction (Table XXII). For school secretarial 
and clerical workers, the mean was 2.75 ; for cooks, Work Quantity merited a 2.75 mean. Questionnaire item 61, "My work is not stressful," which loaded with this factor, had a mean rating of 2.80 (disagree).

District Policies. Classified employees expressed dissatisfaction with policies in group discussions and on questionnaires. In focus groups, the related concern of outdated or inaccurate job descriptions, was listed as a dislike by three job groups--school and non-school secretarial employees and technical workers. On questionnaire write-in responses, bus drivers and other support services employees voiced concern over specific "unfair" policies. If opportunity for job advancement is viewed as a district policy issue, three additional job categories addressed policy as a concern in response to the open-ended questionnaire items. District policies, on a factor level, earned the highest dissatisfaction mean (2.71). On the listing of questionnaire items of lowest satisfaction (Table XX) are the policy-related concerns of access to vacancies, salary credits, promotional opportunities, and standardization of policies across the district. On questionnaire item 94,338 of the respondents are "dissatisfied" or "very dissatisfied" with policies. 
Job (In) Security. Employees are also consistently concerned about job security. Five focus groups voiced insecurity about their job future. Respondents from two of these same job categories wrote related comments on their questionnaires. On the single item, "I feel certain about the future of my job," the mean response of 2.79 indicates considerable disagreement. Fifty-nine percent of respondents "disagree" or "strongly disagree" with the statement.

Other Dissatisfiers. The issues of salary and supervisor also merit discussion as sources of dissatisfaction. Although salary was listed by only one focus group as a dislike, four job categories listed low pay as a write-in response to "What do you dislike most about your job?" Further, questionnaire item 44, "I am highly paid," elicited the strongest single-item disagreement on the questionnaire with a mean of 3.26. "My salary is not less than I deserve" (item 75) also merited a low satisfaction mean of 2.89 . on the factor level, the data are deceptive since salary and benefits are paired and employees are generally satisfied with their benefits.

"Supervisor" was cited by five focus groups as a dislike. On the factor level, supervisor had a mean of 2.32. However, the single item eliciting a 
satisfaction rating for supervisor (item 93) had a mean of 1.90--"satisfied." Only one job group, maintenance workers, voiced dissatisfaction with supervisor on write-in responses. Correspondingly, the factor mean for Supervisor for maintenance employees was a dissatisfied 2.77 .

Dissatisfiers voiced strongly across a majority of focus groups, but not strongly supported by questionnaire data include job status, co-workers, and communication.

\section{SUMMARY AND DISCUSSION}

Participation in the Study

The questionnaire was sent to 630 workers. In return, 490 usable forms were received for a response rate of $78 \%$. This high return rate may be attributed to a number of factors. In focus group discussions, employees expressed gratitude for being given a voice, having an opportunity to respond. This sentiment was evidenced on several questionnaire comments, as well. Approximately 30 respondents returned letters and/or explanatory notes with their questionnaires. One employee wrote, "The nicest thing about this survey is: being asked." Another stated, "I only have two hopes. 
1. That you will truly listen and care. 2. That some action is taken fast."

Some workers believed that change may come from voicing their opinions. One who did not hold this belief returned a blank form with the notation:

Due to the rampant nepotism, favoritism and 'old boy' networking so prevalent in the district this survey will be meaningless. Nothing is going to change.

Sponsorship of this study by the school district may have added credibility to or may have limited the return rate. The simplicity of the questionnaire format, in spite of its length, seems to have facilitated return.

Some survey recipients had specific questions involving content. One issue of confusion may also constitute a limitation of the study. The term "supervisor" was not defined in the questionnaire. For some employees, this involved making a decision between immediate supervisor and school, or department, administrator as a reference point. For maintenance workers, it meant differentiating leadman from foreman from department supervisor.

In other cases, the confusion surrounding "supervisor" centered more on lack of information. One intermediate school-based employee wrote, "I'm not sure who my immediate supervisor is and I don't feel 
comfortable asking." It appears, however, from focus group discussions and written comments, that most employees interpreted the term to mean the individual responsible for their evaluation.

\section{Predictors of Job Satisfaction}

According to statistical analysis, three factors accounted for $50 \%$ of the variance in reported job satisfaction. Those factors were Work Itself, Work Quantity, and Supervisor. Across all job categories, one factor--Work Itself--accounted for at least 19.98 of the variance (for custodians) and up to 66.68 of the variance (for other support service workers) in job satisfaction. That is, the items which loaded as the factor Work Itself contribute significantly to a classified employee's overall job satisfaction. Those specific items included:

My work contributes to the education of students.

My work is respected.

My work is not repetitive.

My work is fun.

My work is creative.

My work gives me a sense of accomplishment. My work is stimulating.

My work is challenging. 
In the factor analysis, the single item of overall job satisfaction (item 100) also loaded strongly with the factor of Work Itself.

The aspects of work listed above as Work Itself correspond to what Herzberg (1968) identified as job "content" and labeled "motivators" and to what Maslow (1943) referred to as needs of "self-actualization." They constitute the intrinsic rewards of work.

It is interesting to note that for bus drivers and maintenance workers, the factor of co-workers contributed 10.48 and $5.5 \%$, respectively, to overall job satisfaction (Table XXX). Co-workers did not appear as a predictor of job satisfaction for any other job category. Since these two groups serve in an itinerant capacity, they may rely more on departmental colleagues for support than do other workers.

Results Compared with other studies

Sources of Job Satisfaction and Dissatisfaction. In a comparison of results across studies, it should be noted that assessment instruments varied and specific populations differed. Since the present study is the first comprehensive research project to address the spectrum of public school district classified employees, a closely comparable investigation does not 
exist. However, a comparison of results with studies of other specific job categories is possible.

According to the present study, primary job satisfiers for all classified employees include: co-workers, students, work variety, work itself, autonomy, and work schedule. Simon (1972) in a study of school secretaries, Perko (1985), assessing teachers, and Borquist (1986) in a study of school administrators all supported co-workers and work itself as major sources of job satisfaction. The two latter studies used the term "interpersonal relations" for what the present study calls relations with co-workers. Simon's research also identified achievement and recognition as satisfiers. In the present study, the aspect of recognition was included in the factor of Supervisor and did not constitute a source of satisfaction. According to Collins and Masley (1980), the primary satisfiers for school employees, across job boundaries, are decision-making and communication.

In Borquist's research, autonomy was found to satisfy elementary and district-level administrators. Autonomy was highlighted in Work in America (U.S. Department of Health, Education, and Welfare, 1973) as "what the workers want most." The latter study, sampling over 1,500 workers on job satisfaction across 
occupations, concludes that employees want "to become masters of their immediate environments and to feel that their work and they themselves are important" (p.13). Peters and Waterman (1982), in observing excellent companies, found that "these companies give people control over their destinies" (p.239). Classified school district employees also appear to value autonomy.

A 1988 opinion survey by the Oregon Classified Employees Council (OCEC) found that over $80 \%$ of the classfied school employees surveyed were "satisfied" or "very satisfied" with their jobs (G. Downey, personal communication, December 16,1988$)$. The present study, with a corresponding figure of over 828 , confirms those results.

Although four out of five classified workers report overall job satisfaction, their dissatisfaction with some aspects of work cannot be negated. The present study identified work quantity, district policies, and job insecurity as primary dissatisfiers. The Perko (1985) and Borquist (1986) studies also cited dissatisfaction among teachers and administrators with amount of work and district policies. The OCEC survey pointed to lack of time to complete assigned tasks and insecurity, as well as lack of opportunity for 
promotion and lack of feedback. Job insecurity had been labeled a äissatifier by Harrison (1979) and Collins and Masley (1980), in studies of school employees and the national female labor force, respectively. As discussed earlier, 598 of the respondents in the present study agreed or strongly agreed that they feel "uncertain" about job future. In job satisfaction research of school secretaries by Simon (1972) and of school custodians by Young (1982), sources of job satisfaction and dissatisfaction were the same. Their outcomes contradict Herzberg's theory that satisfaction and dissatisfaction are rooted in different spheres--namely the job itself and the job surroundings.

The results of the present study support Herzberg in the area of dissatisfiers. Several of the identified satisfiers, however, can be subsumed under the categories of working conditions and relationships which Herzberg listed as hygiene factors, or potential job dissatisfiers.

\section{Personal/Demographic Variables and Job}

Satisfaction. Results of this study indicate that there is a significant difference in job satisfaction relative to the variables of gender, hours worked per week, and work setting, even after the influence of job 
category is removed. Female classified employees were found to be significantly more satisfied than males. The Perko (1985) study found the same to be true among teachers. Studies by McNeely (1988) of human service workers and by Lynch and Verdin (1983) of library employees uncovered no significant relationship between job satisfaction and gender.

Why are female employees in this study more satisfied with their jobs than males? One reason may relate to women's traditional role in the workplace. That is, in two-income households, women typically earn the second, or lesser, salary. Men are culturaliy educated to view themselves as the "breadwinners." It may follow that, if women have lower expectations, they are consequently more complacent and less apt to assert their needs. This would assumably apply most in cases of older employees; women of prior generations may have been taught that their rightful role was to serve men and to enjoy it.

On the job factor of Benefits and Salary, the most dissatisfied category was food service workers, followed by instructional assistants (Figure 12). And, yet, these same groups reported relatively high levels of overall job satisfaction (Figure 16). 
It appears that employees in characteristically female positions are not asserting their dissatisfaction with salary and, therefore, earning less than employees with comparable positions in characteristically male roles. For example, a receptionist at the district's administration center-who answers questions and directs visitors and telephone calls to the appropriate people within the administrative offices and across the school district-has a lower starting salary than a beginning night custodian at an intermediate or high school (Beaverton School District's Classified Employee Handbook 1988-91). One might question whether the level of responsibility for the custodial position is, in fact, comparably greater and merits the higher salary. other reasons why female employees were found to be more satisfied with their jobs are beyond speculation, based on the scope of this study, and may merit further investigation.

Prior studies analyzing the demographic/personal characteristics of selected workers failed to address the number of hours employed. The present study did not unveil the specific nature of the difference in job satisfaction relative to hours worked. Based on job satisfaction means, however, employees who work 30-39 
hours per week are the most satisfied; those employed 40 hours per week are the least satisfied. The difference may be explained in reference to this school district's group insurance benefit policy. Classified employees who work 30 or more hours per week receive the full district health insurance contribution; those working 20-29 hours receive one-half of that contribution while workers employed less than 20 hours are ineligible for any benefits. That is, personnel in the most satisfied category are granted full insurance coverage without full-time labor. Other postulates may equally explain the difference.

The present study also found that elementary school-based, classified employees are the most satisfied subset. They are significantly more satisfied than itinerant workers or those in non-school-based shops and offices in the targeted school district. Personal experience indicates that an elementary school, relative to other settings, provides an environment most closely aligned with an extended family atmosphere--a nurturing climate. In addition, a primary source of satisfaction, according to seven of the nine focus groups, is students. It might follow that a school site provides a potentially more 
satisfying work environment because of the proximity of children.

Knowing that the factor of students appears as a job satisfier for classified workers, school administrators can act to further enhance satisfaction. First, administrators and teaching staff could be encouraged to model their appreciation for custodians, secretaries, cooks, instructional assistants, and other classified employees. Young children and adolescents, alike, often emulate the behavior they observe. Teachers could also directly teach individual appreciation of classified employees as part of the human relations curriculum which already exists. In this way, all employees may benefit from tapping into an already strong source of job satisfaction. This study found no significant difference in job satisfaction relative to educational level or length of employment, after the influence of job category was eliminated. Prior studies were inconclusive on the former variable. Several studies found no relationship between education and job satisfaction (Leslie, 1986; McNeely, 1988; Pyles, 1983). Only one study (Schmidt, Anderson \& Clarke, 1983) concluded that level of education inversely correlates with level of job satisfaction. 
Research results are mixed on the relationship between length of employment and job satisfaction. Lynch and Verdin (1983) and Pyles (1983) found that employees with longer tenure are more satisfied workers. Schmidt, Anderson, and Clarke (1983) concluded that the reverse is true. Other studies have determined that no relationship exists between the two variables (Leslie, 1986; McNeely, 1988).

\section{A Process for Evaluating Worker Satisfaction}

As this study neared completion, administrators in the targeted school district solicited the results and researcher recommendations. Consequently, in-service trainings are already being implemented to address the requests of this population of classified employees. For example, as workshops are planned, many will be accessible to all employees, regardless of job classification. It is evident that management is willing, even eager, to listen and to modify existing policies and practices.

other concerned school district administrators might ask, based upon this researcher's experience, what methodology to employ in a study of job satisfaction. The answer is necessarily dependent on the extent of the proposed effort--in time, personnel, and financial resources. 
Ideally, this researcher would recommend the process employed in the present study. The utilization of focus groups plus a written questionnaire provides the most comprehensive qualitative and quantitative data. Development of a research tool specific to a population provides the most enlightening and relevant information for that employee group. While certain themes predictably emerge across studies, such as co-workers, supervisor, and work itself, the precise descriptors reflecting the corresponding issues may vary significantly between populations. One might contend, that since questionnaire results generally substantiated or reaffirmed focus group results in this study, small group discussions with randomly selected employees could suffice. Certainly, discussions provide an opportunity to more deeply probe into response rationale and to diverge from the prepared script. Further, individuals can raise related issues or pose questions where the forum permits an interchange of ideas.

If asked to choose between the focus group or questionnaire format, this researcher would select the written questionnaire alternative. The decision is predicated on the inherent differences between qualitative and quantitative methodology. The former, 
as stated, facilitates clarification of opinion and permits flexibility in a discussion format. It is a more personal process for information gathering which allows the researcher to observe the nuances in vocal tone or body language indicative of a certain opinion. Issues can be raised which were not foreseen by the researcher, but which add new dimension and breadth to a study.

However, in a focus group of six to ten participants, the individual personalities and group dynamics can influence, if not decide, the outcome. The facilitator must exercise strong leadership skills to prevent certain personalities from monopolizing discussion or imposing personal opinions on the group. Such qualitative methodology is also labor-intensive and relies on relatively soft data. Further, observer bias can threaten the validity of qualitative studies where the researcher is essentially the research tool. Questionnaire research, on the other hand, reaps measurable, statistically analyzable hard data. A larger sample population can be surveyed without increasing research personnel or time. The reliability of data can be assessed scientifically. In this study, questionnaire methodology enhanced the researcher's ability to compare data referent to specific 
demographic and personal variables. With the use of computer analysis techniques, an immense pool of data can be quickly sorted and studied.

For those who may wish to replicate this study, the two-phase process is outlined here. No attempt has been made to affix time, personnel, or cost requirements since those may vary considerably with related variables including: personnel availability and efficiency, specific methodology, the objectives of the study and salaries.

Focus Group Phase:

1. Development of core questions

2. Selection and organization of participants

3. Assemblage of sessions

4. Transcription of sessions

5. Analysis of discussion results Questionnaire Phase:

6. Development of questionnaire based on focus group results

7. Selection of sample population

8. Administration of questionnaire

9. Compilation of data

10. Statistical analysis

11. Comparison of results 
If time and resources are available, the above

process is recommended. Variations, or the selection of one phase only, can reduce bottomline costs. If only a minimal investment is feasible, this researcher suggests utilization or modification of the questionnaire developed in this study.

\section{RECOMMENDATIONS}

Training Needs by Job Category

Certain inservice training needs were suggested by classified employees in focus group discussions, as write-in questionnaire responses, and/or in personal communication with the researcher. In-service training models have been monitored extensively in business and industry. According to Wright (1981), "It has been found that they are most effective when performed by an in-house team that can treat specific personnel needs" (p.10). Those specific needs are outlined below by job category .

Instructional Assistants. These employees want training in conflict management and the use of equipment (audio-visual, computers, etc.). They wish to be included in district-level workshops offered to teachers covering instructional theories and practices and new textbook adoptions. 
School Secretarial/Clerical Workers. School-based clerical workers ask for on-going training in secretarial skills, including word processing, which would enhance their job performance and determine, in part, advancement opportunities within the school district. They also emphasize the need for thorough first-aid training--practical nursing to treat everyday medical emergencies. Nurses, in this district, serve multiple sites; office secretaries are called upon to dispense daily medical treatment. The district may wish to assess the prevalence of this practice and be advised of the legal implications.

Food Service Employees. Kitchen staff, like instructional assistants, desire training in conflict resolution, or "dealing with difficult staff." They would also like a workshop on merchandising foods to better please students and, thereby, increase lunch sales.

Bus Drivers. Many drivers aspire to training positions and request an in-service class which would help them acquire the requisite skills. They suggest that managers within the transportation department enhance their own communication and organizational skills to improve the intradepartmental flow of information and the routing and scheduling process. 
Non-School Secretarial/Clerical Personnel. Classified employees in this category want an interpersonal communication workshop.

Custodians. This group of workers offered the most suggestions for in-service trainings. They would appreciate an opportunity to meet with custodians from other settings within the district to share knowledge and "ideas that work in my building." Custodians believe that their colleagues should teach workshops on hazardous materials and other specific issues. Presently, trainings are too general to satisfy their needs and too large to serve as a discussion forum. Iike instructional assistants and food service workers, custodians request training in problem-solving. Night custodians also ask for training to prepare them to compete for day positions. This training would involve specific knowledge related to the day-shift job role, as differentiated from night-shift work.

Technical Workers. Because of the diversity of the roles these employees occupy, in-service needs should be further assessed individually. Generally, the workers want more specialized training for their particular jobs. -

Maintenance Employees. These workers ask that maintenance managers--leadmen and foremen--receive 
training in interpersonal relations to better manage their respective crews.

Recommendations for All Classified Employees

The quantitative and qualitative results of this study indicate that adherence to the following recommendations may increase the job satisfaction of classified employees in this school district. It should be noted that many of the recommendations require little or no expense on the part of the school district. The district under study should consider:

1. eliminating or reducing the impact of the "caste system" which presently exists. Categorizing employees as "administrators," "certified" or "classified" has inadvertently served to magnify an underlying status hierarchy. A review of national personnel practices may illuminate alternatives. One suggestion is to designate teachers and classified workers, together, as "support staff." District administrators may wish to first assess the reaction of teachers to this proposal. Perhaps general categories used in human resource departments could be disposed of in favor of a single specific job role title. 
2. establishing an informal, risk-free avenue for employees' suggestions and complaints. A committee of individuals could serve as a sounding board, to provide feedback to employees and to communicate repeated issues of concern to department or personnel administrators.

3. providing training for all school district staff in interpersonal relations, including appreciation, teamwork, and participatory decision-making.

4. reviewing the employee evaluation procedure to guarantee its relevance and consistent application across job categories and work settings.

5. including all district staff in in-service opportunities. If the district considers segregating employees for training, needs of classified staff should be considered of equal importance to those of teachers and administrators.

6. implementing changes which address the specific requests of employees by job category, as itemized in this study, such as departmental displays of employees' photos and 
names to increase inter- and intradepartmental recognition and a newsletter for custodial workers.

7. assessing staffing needs earlier in order to hire individuals and confirm placements of tenured, classified employees prior to the opening of each academic calendar year.

8. updating job descriptions to more accurately reflect existing roles. Classified employees should be involved in this process of reviewing and rewriting existing descriptions.

9. re-evaluating district practice relative to filling job vacancies. The policy of equal access is in place; employees question the equality of present district practices.

10. studying lines of communication within the district to discover where information channels exist and where they are lacking. 11. encouraging ongoing recognition of employees, at all levels. This can supplement or supplant Classified Employees' Week. A cross-district and cross-categorical committee could be appointed to explore avenues of recognition and to serve as core facilitators for implementation of a process. 
12. comparing the results of this study with the results of recent studies of administrator satisfaction (Borquist, 1986) and teacher satisfaction (Leslie, 1986) in the same district to discern similarities and differences among the job categories.

13. disseminating these research results to all employees in the studied school district.

14. researching the comparable worth of job roles, with particular attention to those which are characteristically male- or female-dominated.

These recommendations are considered by the researcher to be realistic suggestions based upon the results of this study. The first suggestion of eliminating the "caste system," is likely to be viewed by practitioners as unrealistic. A hierarchy of personnel assignments admittedly underlies most bureaucratic organizations. Some may argue that the structure serves the useful purpose of motivating employees to attain a higher rung on the proverbial ladder. Others might assert that removal or alteration of a categorical job title is merely a superficial change. This researcher asserts, based on the opinions expressed by participants in this study, that even a superficial change in the direction of employee 
equalization would serve to illustrate the administration's recognition of the issue and the intention of remediating it. Additionally, those recommendations, or training ideas, which appear to be less realistic, may be the most critical to address. Deeply ingrained practices are sometimes considered immovable; those same practices may serve to perpetuate antiquated theories of personnel management.

It appears that the above recommendations would constitute good human resource management practices in a multitude of work settings. The attraction of new, wel1-qualified employees and retention of those presently employed may depend on this district's prompt implementation of these actions and programs.

\section{Future Research}

Studies of this magnitude generally conclude with recommendations for related research projects. Bogden and Biklen (1982) advise, "There is nothing that does not need further research; it is this belief that makes a researcher's life meaningful" (p.181). With the acknowledgment that a call for research may constitute a cliché, this researcher chooses to confirm the import of a meaningful life. 
Specific foci for future research endeavors may include (a) the development of a theory of job satisfaction for classified workers based upon the outcomes of this research, (b) an examination of the significant variables of gender and number of hours worked, as they relate to job satisfaction, (c) the replication of this study in other work settings, such as business and the social services arena, and (d) a follow-up study in this district to assess the effects of implemented changes.

The present study presents a process and instrument for evaluating the job satisfaction of classified employees in a public school district. Replication of this study is advised in other school districts and across job classifications to assess the validity of generalizing the results.

Research addressing classified employees has been sorely lacking in the educational field. Hopefully, by redressing this trend, researchers will recognize and respond to the needs of this deserving and oft-overlooked population. 
REFERENCES CONSULTED

Adams, J.S. (1963). Toward an understanding of inequity. Journal of Abnormal Social Psychology, $\underline{67}, 422-436$.

Adams, J.S. (1975). Inequity in social exchange. In R.M. Steers \& L.W. Porter (Eds.), Motivation and work behavior (p.138-154). New York: McGraw-Hill.

Babbie, E.R. (1973). Survey research methods. Belmont, CA: Wadsworth.

Bacharach, S.B. (1983). Old wine in new bottles: The quality of work life in schools and school districts (Report No. NIE-G-78-0080). Ithaca: State University of New York, School of Industrial and Labor Relations at Cornell University. (ERIC Document Reproduction Service No. ED 243178)

Bailey, S. (1976). The purposes of education. Bloomington, IN: Phi Delta Kappa Foundation.

Beaverton School District. (1985). Classified employee handbook 1985-88 (available from Director of Classified Personnel, Beaverton, OR)

Bennis, W.G. (1959). Leadership theory and administrative behavior: The problem of authority. Administrative Science Quarterly, $\underline{4}$, 259-301.

Best, J.W. \& Kahn, J.V. (1986). Research in education (5th ed.). Englewood Cliff, NJ: Prentice-Hall.

Bogdan, R.C. \& Biklen, S.K. (1982). Qualitative research for education: An introduction to theory and methods (pp. 145-170). Boston: Allyn and Bacon.

Borquist, L.C. (1986). Job satisfaction of administrators in a public suburban school district (Doctoral dissertation, Portland State University) . American Doctoral Dissertations, ADD87-11931. 
Brayfield, A.H. \& Crockett, W.H. (1955). Employee attitudes and employee performance. Psychological Bulletin, 52, 396-424.

Calder, B.J. (1977). Focus groups and the nature of qualitative marketing research, Journal of Marketing Research, 14, 353-364.

Campbell, D.T. \& Fiske, D.W. (1959). Convergent and discriminant validation by the multitraitmultimethod matrix. Psychological Bulletin, 56, 81-105.

Casanova, U. (1986, April). The woman in the principal's office. Paper presented at the Annual Meeting of the American Educational Research Association. San Francisco, CA.

Casletter, W.B. (1971). The personnel function of educational administration. New York: Macmillan.

Cofer, C.N. \& Appley, M.H. (1964). Motivation: Theory and research. New York: Wiley.

Collins, J.J. \& Masley, B.A. (1980). Stress/Burnout report. Share \& Exchange, $\underline{8}(4), 28$ p.

Cronbach, I.J. (1950). Further evidence on response sets and test design. Educational and Psychological Measurement, $11,3-31$.

Crowne, D.P. \& Marlowe, D. (1964). The approval motive: Studies in evaluative dependence. New York: John Wiley \& Sons.

Cummings, L.L. \& Berger, C.J. (1976). Organizational structure: How does it influence attitudes and performance? Organizational Dynamics, $\underline{5}(2)$, 34-49.

Davids, M. (1988). Labor shortage woes. Public Relations Journal, $\underline{44}(11), 24-29,59$.

Dickson, P. (1975). The future of the workplace: The coming revolution in jobs. New York: Weyoright and Talley.

Fantini, M.D. (1986). Regaining excellence in education. Columbus, OH: Merrill. 
Festinger, L. (1957). A theory of cognitive dissonance. Evanston, ILL: Row, Peterson.

French, J.R.P. \& Caplan, R.D. (1970) . Psycho-social factors in coronary heart disease. Industrial Medicine, 39, 333-397.

Fruchter, B. (iy54). Introduction to factor analysis. Princeton: D.Van Nostrand Company.

Gorsuch, R.L. (1974) - Factor analysis. Philadelphia: W.B. Saunders.

Greene, C.N. (1973). Causal connections among managers' merit pay, job satisfaction, and performance. Journal of Applied Psychology, 58, 95-100.

Hackman, J.R. \& Lawler, E.E., III. (1971). Employee reactions to job characteristics. Journal of Applied Psychology Monograph, 55 (3), 259-286.

Hackman, J.R. \& Oldham, G.R. (1975). Development of the job diagnostic survey. Journal of Applied Psychology, 60 (2), 159-170.

Harrison, C. (1979). Working women speak: Education, training, counseling. Washington, D.C.: National Commission on Working Women. (ERIC Document Reproduction Service No. ED 179 718)

Herzberg, F. (1968). One more time: How do you motivate employees? Harvard Business Review, $\underline{46}(1), 53-62$.

Herzberg, F., Mausner, B. \& Snyderman, B. (1959). The motivation to work. New York: Wiley.

Herzberg, F., Mausner, B., Peterson, R.O., \& Capwell, D.F. (1957). Job attitudes: Review of research and opinion. pittsburgh: Psychological service.

Hinrichs, J.R. (1974). The motivation crisis: Winding down and turning off. New York: AMACOM.

Holdaway, E.A. (1978). Facet and overall satisfaction of teachers. Educational Administration Quarterly, 14, 30-47. 
Homans, G.C. (1961). Social behavior: Its elementary forms. New York: Harcourt, Brace.

Hoppock, R. (1935). Job satisfaction. New York: Harper.

Howe, H., II. (1985). Giving equity a chance in the excellence game. In G. Gross \& R. Gross (Eds.), The great school debate (pp. 281-297). New York: Simon \& Schuster.

Hoy, W.K. \& Miskel, C.G. (1982). Educational administration: Theory, research, and practice (2nd ed.). New York: Random House.

Jacques, E. (1961). Equitable payment. New York: Wiley.

Jenkins, D.C. (1971). Psychological \& social precursors of coronary disease (II). New England Journal of Medicine, 307-317.

Jick, T.D. (1983). Mixing qualitative and quantitative methods: Triangulation in action. In J. Van Maanen (Ed.), Qualitative methodology (pp. 135-148). Beverly Hills, CA: Sage.

Johnson, J.J. (1980). Fred Taylor '83: Giant of non-repute. Stevens Indicator, 97(2), 4-8.

Kahn, R.L. (1974). The work module: A proposal for the humanization of work. In J. O'Toole (Ed.), Work and the quality of life (p. 199-226). Cambridge: MIT Press.

Kahn, R.I., Wolfe, D.M., Quinn, R.P. \& Snoek, J.D. (1964). Organizational stress: Studies in role conflict and ambiguity. New York: John Wiley \& Sons.

King, N. (1970). Clarification and evaluation of the two-factor theory of job satisfaction. Psychological Bulletin, 74, 18-31.

Kohn, M.L. \& Schooler, C. (1973). Occupational experience and psychological functioning: An assessment of reciprocal effects. American Sociological Review, 38, 97-118. 
Kornhauser, A.W. (1965). Mental health of the industrial worker: A Detroit study. New York: John Wiley \& Sons.

Krueger, R.A. (1988). Focus groups: A practical guide for applied research. Beverly Hills, CA: Sage.

Kuiper, S. \& Van Huss, S.G. (1981). Role ambiguity and job satisfaction of clerical and secretarial employees in a consolidated county school district. Delta Pi Epsilon Journal, 23(4), 1-11.

Lawler, E.E., III. (1971). Pay and organizational effectiveness: A psychological view. New York: McGraw-Hill.

Lawler, E.E., III. (1975). Expectancy theory. In R.M. Steers \& I.W. Porter (Eds.), Motivation and work behavior (p.190-200). New York: McGraw-Hill. (Abridged from Motivation in work organizations, $1973,44-47$ )

Lawler, E.E., III \& Porter, L.W. (1987). The effect of performace on job satisfaction. In D.W. Organ (Ed.), The applied psychology of work behavior (p.88-99) . Plano, TX: Business Publications. (Reprinted from Industrial Relations, 1967, ?(1), 20-28)

Leavitt, H.J. (1962). Unhuman organizations. Harvard Business Review, 40, 90-98.

Leslie, K. (1986) Sources of job satisfaction and dissatisfaction among teachers in the Beaverton School District. Unpublished manuscript.

Lewin, K.A. (1935) . A dynamic theory of personality. New York: McGraw-Hill.

Iinda, G. (1982). Focus groups: A new look at an old friend. Marketing \& Media Decisions, 17(1), 96-98.

Locke, E.A. (1:59). What is job satisfaction? Organizational behavior and human performance, 4 , 309-336. 
Locke, E.A. (1976). The nature and causes of job satisfaction. In M. Dunnette (Ed.), Handbook of industrial and organizational psychology (pp. 1297-1349). Chicago: Rand McNally.

Locke, E.A. (1982). The ideas of Frederick W. Taylor: An evaluation. The Academy of Management Review, ?(1), 14-24.

Lynch, B.P. \& Verdin, J.A. (1983). Job satisfaction in libraries: Relationships of the work itself, age, sex, occupational group, tenure, supervisory level, career commitment, and library department. Library Quarterly, $\underline{5}$ (4), 434-447.

Masciocchi, J. \& Leslie, K. (1988, Nov.). Superintendent's report to the school board: Focus group interviews with classified staff. (Available from the Office of Educational Public Relations, Beaverton School District, Beaverton, OR)

Maslow, A.H. (1943). A theory of human motivation. Psychological Review, 50 (4), 370-396.

Maslow, A.H. (1968). Toward a psychology of being (2nd ed.). New York: Van Nostrana.

Matteson, M.T. \& Ivancevich, J.M. (1987). Controlling work stress: Effective human resource and management strategies. San Francisco: Jossey-Bass.

Mayo, E. (1933). The human problems of an industrial civilization. New York: Macmillan.

McGregor, D. (1960). The human side of enterprise. New York: MCGraw-Hill.

McGregor, D.M. (1972). The human side of enterprise. In V.H. Vroom and E.L. Deci (Eds.). Management and motivation. Baltimore: Penguin Books.

McNeeley, R.I. (1988). Age and job satisfaction in human service employment. Gerontologist, 28(2), 163-168.

Myers, M.S. (1964). Who are your motivated workers? Harvard Business Review, $\underline{42}(1), 73-88$. 
Myers, M.S. (1981). Every employee a manager. New York: McGraw-Hill.

Oregon School Employees Association \& Oregon Association of School Executives. (1984, Aug.). Position description guide for classified school employees (Available from Oregon School Employees Association, Salem, OR)

Ouchi, W.G. (1981). Theory Z. New York: Avon.

Patchen, M. (1961) . The choice of wage comparisons. Englewood Cliffs, N.J.: Prentice-Hall.

Perko, L.L. (1985). Job satisfaction of teachers in the Portland Metropolitan Area: An examination of differing factors and their relationship to Herzberg and Lortie theories (Doctoral dissertation, Portland State University and University of Oregon). American Doctoral Dissertations, ADD85-17640.

Peters, T. \& Austin, N. (1985). A passion for excellence. New York: Random House.

Peters, T.J. \& Waterman, R.H., Jr. (1982). In search of excellence. New York: Warner Books.

Porter, L.W. \& Steers, R.M. (1974). The role of task-gaol attributes in employee performance. Psychological Bulletin, 81, 434-452.

Pyles, D.J. (1983). Factors related to job satisfaction of public school noncertified food service personnel. Dissertation Abstracts International, $44(10)$. (University Microfilms No. ADG84-02361)

Roethlisberger, F.J. \& Dickson, W.J. (1939). Management and the worker. Cambridge: Harvard University Press.

Rogers, C. (1951). Client-centered therapy. Boston: Houghton Mifflin.

Rooks, J. Wanted: Entry-level workers. Oregonian, Sunrise Edition, 30 Oct. 1988 , sec. D, P. 1,12. 
Rummel, R.J. (1970). Applied factor analysis. Evanston: Northwestern University Press.

Schmidt, W.V., Anderson, C., Clarke, T. (1983, February). Factors influencing federal employee worker satisfaction: A baseline study. Paper presented at the Annual Meeting of the Western Speech Communication Association, Albuquerque, NM.

Schofield, J.W. \& Anderson, K.M. (1984, January). Integrating quantitative components into qualitative studies: Problems and possibilities for research on intergroup relations in educational settings. Paper presented at the meeting of the Society for Research on Child Development Study Group on Ethnic Socialization, Los Angeles, CA.

Schwab, D.P. \& Cummings, L.L. (1975). Theories of performance and satisfaction: A review. In R.M. Steers \& L.W. Porter (Eds.), Motivation and work behavior (p.223-241). New York: McGraw-Hill. (Reprinted from Industrial Relations, 1970, 7, $408-430$ )

Selltiz, C., Wrightsman, I.S. \& Cook, S.W. (1976). Research methods in social relations ( $3 \mathrm{rd}$ ). New York: Holt, Rinehart and winston.

Sergiovanni, T.J. \& Carver, F.D. (1975). The new school executive: A theory of administration. New York: Dodd, Mead, and Company.

Sergiovanni, T.J. \& Starratt, R.J. (1971) . Emerging patterns of supervison: Human perspectives. New York: McGraw-Hill.

Shepard, J.M. (1973). Specialization, autonomy, and job satisfaction. Industrial Relations, 12, $274-281$.

Simon, T.I. (1972). A study of the motivation of school secretaries (Doctoral dissertation, University of Southern California, 1972). Dissertation Abstracts International, 72, 5516-A.

Slezak, J. (1984). Odyssey to excellence: How to build effective schools through leadership and management skills. San Francisco: Merritt. 
Smith, P.C., Kendall, L.M. \& Hulin, C.L. (1969). The measurement of satisfaction in work and retirement. Chicago: Rand McNally.

State of Oregon, Department of Human Resources (May, 1988) Portland Metropolitan Labor Trends. Salem, OR: State Department.

Steers, R.M. \& Porter, L.W. (1975). Motivation and work behavior. New York: McGraw-Hill.

Stellar, A.W. \& Pell, C. (1986). Clean up your school custodian program. Updating School Board Policies, $17(11), 1-\overline{3}$.

Stone, E.F. (1976). The moderating effect of work-related values on the job scope - job satisfaction relationship. Organizational Behavior and Human Performance, 15, 147-167.

Strauss, G. (1974). Is there a blue-collar revolt against work? In J. O'Toole (Ed.), Work and the quality of life (p. 40-69). Cambridge: MIT Press.

Taylor, F.W. (1916). The principles of scientific management. New York: Harper and Brother.

Tolman, E.C. (1932). Purposive behavior in animals and men. New York: Century.

Turner, A.N. \& Lawrence, P.R. (1965). Industrial jobs and the worker. Boston: Harvard University Graduate School of Business Administration.

U.S. Department of Health, Education, and Welfare. (1973). Work in America. Cambridge, MA: MIT Press.

Vroom, V. (1964). Work and motivation. New York: wiley.

Vroom, V.H. \& Deci, E.I. (Eds.) (1972) . Management and motivation. Baltimore: Penguin Books.

Weich, K.E. (1964). Reduction of cognitive dissonance through task enhancement and effort expenditure. Journal of Abnormal Social Psychology, 66, 533-539. 
Wheeless, V.E., Wheeless, I.R. \& Howard, R.D. (1982,

May). An analysis of the contribution of participative decision-making and communication with supervisor as predictors of job satisfaction. Paper presented at the Annual Forum of the Association for Institutional Research, Denver, CO.

White, R.W. (1959). Motivation reconsidered: The concept of competence. Psychological Review, 66, 297-333.

Whitman, D. (1989). The forgotten half. U.S. News \& World Report, $106(25), 44-53$.

William T. Grant Foundation Commission of Work, Family and Citizenship. (1988). The forgotten half: Non-college-bound youth in American. Phi Delta Kappan, 69 (6), 409-414.

Wright, G.R. (1981). Generalizing personnel training models used in business and industry to school settings. Proceedings of the Annual Meeting of the National Association of Stîte Directors of Teacher Education and Certification, Williamsburg, VA.

Young, I.P. (1982). A multivariate study of administrator leadership behavior and custodian satisfaction. Planning and Changing, 13(2), 110-123. 
APPENDIX A

LETTER TO DEPARTMENT COORDINATORS 
October 17,1988

TO:

FROM: Kathy Leslie and Jeri Masciocchi

RE : Job Satisfaction Study

As was mentioned at the August retreat, one of the priorities of the Beaverton School District is to identify the job satisfiers of staff so that employee needs can be met. As you may know, studies of job satisfaction have been completed for administrators and teachers. It is time to address classified personnel.

Jeri Masciocchi, serving as a researcher for this office, will coordinate this third phase of the job satisfaction study. The first step involves the organization of focus groups. The purpose is to identify sources of satisfaction and dissatisfaction for employee groups. Eight occupational classifications have been identified within the classified category. Each group will meet for approximately two hours one day in November, outside of regular working hours. All information will remain confidential and participants will not be personally identified in any data analysis reports.

We are asking for your assistance in identifying a representative group. Please list 25 including those who have been with the District less than three years and those with more than 10 years experience; those who are supportive of the District and those who are not; and, employees who are strong union members and those who are not. The purpose is to garner a broad spectrum of opinions. The information gathered from focus group discussions will be used to develop a written questionnaire.

Would you please indicate in some way what group each person on your list represents. Please mail your list to Jeri Masciocchi, McKinley School, by Friday, October 21 , so that participants receive adequate notice. You can reach Jeri at $\times 4530$ with questions. 
APPENDIX B

LETTER TO EMPLOYEES 
October 25,1989

TO:

FROM: Kathy Leslie, Director, Educational Public Relations

RE: Job Satisfaction Study

One of the priorities of the Beaverton School District is to identify the job satisfiers of staff so that employee needs can be met. The focus for the 1988-89 school year is classified personnel.

The first step involves convening a series of focus groups to identify issues of importance. Based upon group discussions, a written survey will be developed and administered later in the year.

There will be eight focus groups, each representing a major occupational classification. You have been selected to serve on the focus group which will be held on , November _ at the Administration Center, conference room - p.m. Nine of your colleagues have been invited to serve with you. We hope that you will be able to participate in this important session.

All information will remain confidential, and you will not be personally identified in any data analysis reports. If you cannot attend, please call the public relations office, ext. 4360 , by Wednesday, October 26 , so that an alternate can be notified. If you have questions, please call Jeri at McKinley School, ext. 4530 . 
APPENDIX C

FOCUS GROUP QUESTIONS 
1. What comes to mind when you hear the words: Beaverton School District?

2. When you talk with your friends about your job, what do you tell them with pride?

3. Can you describe in detail when you feel exceptionally good about your job?

4. When you go home in the evening, what do you complain about?

5. Could you describe in detail when you feel exceptionally bad about your job?

6. On a piece of paper, list three things that you like about your job and three things that you dislike. (Share and list on blackboard.)

7. Why did you become a ?

8. What could be changed to make this the perfect job for you?

9. How do you feel about your salary?

10. Have you thought about leaving your profession? Why? Have you thought about leaving the school district? Why?

11.: Do you feel secure about your job?

12. If you could have this conversation with someone else in the district, who would you choose? Why?

13. (Night shift) why are you working night shift? What are the effects on you? What price do you pay?

14. (Technical services) Considering your education and/or specialized training, how do you feel being termed a "classified employee?"

15. Do you think there are adequate opportunities for advancement?

16. Are you receiving recognition for your work? From whom? How?

17. What forms of recognition do you like best? 
18. Do you have enough information to do your job wel1?

19. Do you wish you were receiving more information?

20. Who would you like to receive the information from?

21. What do you think management is doing that is right?

22. How important is it for you to socialize with your colleagues?

23. What are your colleagues doing that is right?

24. On a scale of 1 to 5 (one being low), how would you rank the prestige of your job?

25. Considering everything that we have talked about today, what one action could be taken to improve district operations the most?

26. What other issues/questions had you hoped to address today? 
APPENDIX D

FOCUS GROUP SURVEY 
Group \#

For each item please circle the letter which best applies to you:

1. Sex
A. Female
B. Male

2. Age (at last birthday)
A. $18-27$
B. $28-37$
C. $38-47$
D. $48-57$
E. 58 and over

3. Marital status
A. Married
C. Separated
B. Divorced
D. Never married

4. Highest academic degree earned
A. High School Diploma
B. Associate's
C. Bachelor's
D. Master's
E. Doctoral
F. Other

5. How many years have you worked for Beaverton District?
A. 1-5
B. $6-10$
E. $\quad 21-25$
C. $11-15$
F. $26-30$
G. More than 30
D. $16-20$

6. How many years have you worked in your present position?
A. 1-5
B. $6-10$
E. $21-25$
C. $11-15$
D. $16-20$
F. $26-30$
G. More than 30

7. Do you hold any other paid position(s) outside of your job for Beaverton District?
A. Yes
B. No

8. Are you the primary wage earner in your household?

A. Yes

B. No

9. Does your spouse hold a salaried position?
A. Yes
B. No
C. Does not apply 
10. Please rank your overall level of job satisfaction in your present position. Circle one number:
$\begin{array}{lllll}1 & 2 & 3 & 4 & 5\end{array}$
$\because \overline{\text { low high }}$ 
APPENDIX E

JOB SATISFACTION QUESTIONNAIRE 
The purpose of this questionnaire is to identify those areas of your job that promote a feeling of

satisfaction for you as an employee of Beaverton School District. Your participation in this project is voluntary. This survey is CONFIDENTIAL. Because there is so little research in this area, your cooperation and honest input are greatly appreciated. The results will be available to you by fall, 1989, through the office of Educational Public Relations.

Your mailing envelope is coded so that you will not receive a reminder notice. The envelope will be discarded; you will never be identified with your responses.

The mark under "SPECIAL CODES" tells the researcher your general job category (e.g.: Secretary, Bus Driver, Technical Services worker).

Your questionnaire includes the following sections:

Items 1-91 ask you to rate specific factors in your work experiences.

Items 92-100 ask you to rate general aspects of your job.

Items 101-113 ask for demographic information or short answer responses.

DIRECTIONS

Please:

* use a \#2 pencil

* carefully fill in circles

* make no other marks
* complete all items

* do not bend or fold answer sheet

* keep your place with care

Return your completed answer sheet by INTERSCHOOL MAIL in the SAME ENVELOPE addressed to:

JERI MASCIOCCHI, MCKINLEY SCHOOL by Wednesday, March 15 . 
The following statements represent opinions about jobs. Your agreement or disagreement will depend on your personal experience in Beaverton school District.

Please mark the letter which best matches your first response for each statement.

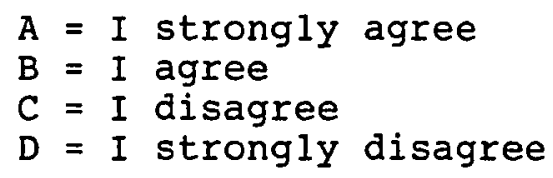

1. Only a few employees receive recognition.

2. I am taken for granted.

3. My supervisor is supportive.

4. My co-workers are responsible.

5. My work is frustrating.

6. Salary credit is not given for experience.

7. My supervisor is honest.

8. My worksite is safe.

9. Policies are standardized across the district.

10. My supervisor is available when needed.

11. I am not involved in decision-making.

12. There is waste of time, money, and/or materials in the district.

13. My co-workers are cooperative.

14. I lack equipment that I need.

15. My work is healthful.

16. I am proud to work for Beaverton School District.

17. My co-workers are negative.

18. My work facilities are inefficient.

19. My work is creative.

20. There is low morale among my co-workers.

21. The recognition I receive is a token gesture.

22. My co-workers are supportive

23. I am uncomfortable talking with my supervisor.

24. My worksite is noisy.

25. I receive frequent recognition.

26. The district uses poor evaluation procedures.

27. There is equal access to job vacancies.

28. My supervisor is kind.

29. I receive less recognition than I deserve.

30. My work feels worthless.

31. My worksite is disorganized.

32. Recognition is consistent.

33. I am allowed to work independently.

34. My supervisor does not follow through.

35. My co-workers are considerate.

36. My worksite is dark.

37. My supervisor does not communicate with employees. 
38. My work gives me a sense of accomplishment.

39. My co-workers are wasteful.

40. My work is stimulating.

41. My supervisor is insensitive.

42. I am overloaded with work.

43. My supervisor is a poor manager.

44. I am highly paid.

45. I am respected.

46. I receive no feedback from my supervisor.

47. My work is fast-paced.

48. My co-workers are proud of their work.

49. My work area is cold.

50. job descriptions are inaccurate.

51. I feel uncertain about the future of my job.

52. My supervisor has high expectations.

53. My worksite is comfortable.

54. My co-workers are overworked.

55. My supervisor is a good listener.

56. I feel like a team member.

57. My work is fragmented.

58. I feel like the bottom of the ladder.

59. My co-workers resist change.

60. I receive great benefits.

61. My work is stressful.

62. My co-workers are smart.

63. My salary is adequate for normal expenses.

64. I am listened to.

65. I feel "dumped on."

66. It is risky to ask questions.

67. My co-workers are incompetent.

68. My work is challenging.

69. My supervisor evaluates my work.

70. There is variety in my work.

71. I feel like a second-class citizen.

72. I have a dead-end job.

73. My supervisor is unfriendly.

74. My work is respected.

75. My salary is less than I deserve.

76. My worksite is attractive.

77. I have a good work schedule.

78. I have up-to-date equipment at work.

79. Compensation is given for added responsibilities.

80. My supervisor gives short notice on tasks.

81. My co-workers were hard to meet.

82. My work is repetitive.

83. District policy provides for comp time.

84. My work contributes to the education of students.

85. I have too many bosses.

86. Overtime on my job is not compensated.

87. I think promotions are based on ability.

88. My work is fun. 
89. I have a fairly good chance for promotion.

90. Evaluation forms are adequate.

91. My work facilities are well maintained.

Please mark the letter which best describes your level

of satisfaction with each aspect of your job.

$\begin{array}{cccc}\text { Very } & & & \text { Very } \\ \text { Satisfied } & \text { Satisfied } & \text { Dissatisfied } & \text { Dissatisfied } \\ \text { A } & \text { B } & \text { C } & \text { D }\end{array}$

92. WORK ITSELF

93. SUPERVISOR

94. DISTRICT POLICIES

95. SALARY/BENEFITS

96. CO-WORKERS

97. FACILITIES/EQUIPMENT

98. RECOGNITION

99. MY JOB STATUS

100. OVERALL JOB SATISFACTION

Please mark the one letter that most closely identifies you.

101. Primary work setting

A. Elementary School

B. Intermediate School

C. High School

D. Administration Center

E. Other

102. Sex

A. female

B. male

103. Personal status

A. single

B. married

C. widowed

D. divorced/separated

104. Do you hold any other paid position(s) outside of your job for Beaverton District?

A. yes

B. no

105. Are you the primary wage earner in your household?

A. yes

B. no 
106. Who uses your benefits?

A. only myself

B. my spouse and I

C. only my children

D. my family, including children

107. Does your spouse hold a paid position?

A. yes

B. no

108. Education completed

A. Master's degree

B. Bachelor's degree

C. Some college training

D. High School graduation

E. Partial High School

F. Junior High School

G. less than seven years of school

109. How many hours do you work each week for Beaverton Schools?

110. How many years have you worked for Beaverton?

111. How many years have you worked in your present position?

112. What do you like most about your job?

113. What do you dislike most about your job? 


\section{APPENDIX F}

COVER LETTER FOR QUESTIONNAIRE 
March 6, 1989

TO: Classified Employees

FROM: Jeri Masciocchi

RE: Employee Questionnaire

This fall Kathy Leslie and I conducted a series of focus group interviews with classified employees to determine job satisfiers and dissatisfiers. Information gathered from these group interviews was used to develop the attached questionnaire.

Just as focus group participants were selected at random, you have been selected at random to participate in this questionnaire. Your answers will remain CONFIDENTIAL. The surveys are coded and only Jeri Masciocchi has the code list. This will provide a check-off system so that when your survey is returned you will not receive reminder notices. The code list will be destroyed before results are compiled. Under no circumstances, will anyone ever know how you filled out your questionnaire.

The study of job satisfiers among Beaverton School District employees is one of thirteen priorities established by the School Board. You can be assured that you and your fellow employees will benefit from your participation in this study. We need to know what is important to you -- what you want and what you don't want.

Please complete your survey today. Thank you. 
APPENDIX G

COVER LETTER FOR FOLLOW-UP QUESTIONNAIRE 
March 27, 1989

TO: Classified Employees

FROM: Jeri Masciocchi Researcher

RE: Job Satisfaction Questionnaire

Approximately three weeks ago you received a questionnaire addressing job satisfaction. If you returned your answer sheet, thank you. You may disregard this mailing. If you mislaid it, here is a second copy and an opportunity to state your views.

This questionnaire is CONFIDENTIAL. You will never be identified with your responses. Do not fill in the areas for "NAME" OR "ID NUMBER."

Your feelings about your job are important. I hope that you will take a few minutes to fill out the questionnaire and return it to me.

Thank you. 
APPENDIX H

QUESTIONNAIRE ITEM SPLIT-HALF RELIABILITY CORRELATION STATISTICS 


\begin{tabular}{|c|c|c|c|c|c|}
\hline Question & $\begin{array}{c}\text { Item Total } \\
(\mathrm{r})\end{array}$ & $\begin{array}{l}\text { Excluding } \\
\text { This Item } \\
\text { (r) }\end{array}$ & Question & $\begin{array}{c}\text { Item Total } \\
(\mathrm{r})\end{array}$ & $\begin{array}{c}\text { Excluding } \\
\text { This Item } \\
(\mathrm{r})\end{array}$ \\
\hline$\overline{1}$ & .442 & .422 & 31 & 7.342 & .322 \\
\hline 2 & .604 & .588 & 32 & .624 & .611 \\
\hline 3 & .659 & .644 & 33 & .348 & .331 \\
\hline 4 & .378 & .360 & 34 & .598 & .580 \\
\hline 5 & .473 & .452 & 35 & .418 & .403 \\
\hline 6 & .345 & .322 & 36 & .254 & .235 \\
\hline 7 & .544 & .527 & 37 & .576 & .558 \\
\hline 8 & .403 & .383 & 38 & .464 & .447 \\
\hline 9 & .388 & .364 & 39 & .397 & .379 \\
\hline 10 & .557 & .539 & 40 & .492 & .474 \\
\hline 11 & .498 & .478 & 41 & .597 & .580 \\
\hline 12 & .460 & .439 & 42 & .313 & .291 \\
\hline 13 & .401 & .385 & 43 & .590 & .572 \\
\hline 14 & .347 & .325 & 44 & .241 & .221 \\
\hline 15 & .375 & .354 & 45 & .551 & .538 \\
\hline 16 & .461 & .446 & 46 & .546 & .528 \\
\hline 17 & .458 & .439 & *47 & .070 & .048 \\
\hline 18 & .381 & .361 & 48 & .499 & .484 \\
\hline 19 & .439 & .419 & *49 & .069 & .047 \\
\hline 20 & .565 & .546 & 1 & .414 & .392 \\
\hline 21 & .655 & .641 & 2 & .301 & .276 \\
\hline 22 & .390 & .374 & 3 & .251 & .231 \\
\hline 23 & .453 & .430 & 4 & .335 & .319 \\
\hline 24 & .228 & .202 & 5 & .165 & .142 \\
\hline 25 & .578 & .561 & 6 & .639 & .623 \\
\hline 26 & .422 & .401 & 7 & .624 & .608 \\
\hline 27 & .348 & .324 & 8 & .327 & .308 \\
\hline 28 & .558 & .542 & 9 & .474 & .454 \\
\hline 29 & .548 & .532 & 10 & .251 & .230 \\
\hline 30 & .482 & .469 & 11 & .191 & .167 \\
\hline
\end{tabular}




\begin{tabular}{r|c|c|c|c|c} 
Question & $\begin{array}{c}\text { Item Total } \\
(\mathrm{r})\end{array}$ & $\begin{array}{c}\text { Excluding } \\
\text { This Item } \\
(\mathrm{r})\end{array}$ & $\begin{array}{c}\text { Question } \\
\text { Item Total } \\
(\mathrm{r})\end{array}$ & $\begin{array}{c}\text { Excluding } \\
\text { This Item } \\
(\mathrm{r})\end{array}$ \\
\hline \hline 61 & .320 & .297 & 81 & .194 & .174 \\
62 & .416 & .402 & 82 & .333 & .312 \\
63 & .314 & .292 & 83 & .156 & .133 \\
64 & .639 & .627 & 84 & .233 & .212 \\
65 & .622 & .609 & 85 & .505 & .486 \\
66 & .561 & .545 & $* 86$ & .096 & .069 \\
67 & .363 & .347 & 87 & .486 & .467 \\
68 & .433 & .414 & 88 & .586 & .571 \\
69 & .436 & .418 & 89 & .445 & .425 \\
70 & .312 & .292 & 90 & .345 & .325 \\
71 & .592 & .575 & 91 & .359 & .341 \\
72 & .526 & .506 & 92 & .463 & .448 \\
73 & .409 & .391 & 93 & .655 & .639 \\
74 & .482 & .466 & 94 & .438 & .422 \\
75 & .249 & .226 & 95 & .401 & .381 \\
76 & .430 & .413 & 96 & .478 & .463 \\
77 & .289 & .271 & 97 & .510 & .494 \\
78 & .380 & .359 & 98 & .671 & .659 \\
79 & .422 & .402 & 99 & .566 & .551 \\
80 & .484 & .465 & 100 & .613 & .600 \\
& & & & &
\end{tabular}

* Unreliable question 